Detecção de fronteira em sistemas de partículas 

SERVIÇO DE PÓS-GRADUAÇÃO DO ICMC-USP

Data de Depósito:

Assinatura:

\title{
Detecção de fronteira em sistemas de partículas
}

\author{
Marcos Henrique Alves Sandim
}

Orientador: Prof. Dr. Afonso Paiva Neto

Dissertação apresentada ao Instituto de Ciências Matemáticas e de Computação - ICMC-USP, como parte dos requisitos para obtenção do título de Mestre em Ciências - Ciências de Computação e Matemática Computacional. VERSÃO REVISADA 
Ficha catalográfica elaborada pela Biblioteca Prof. Achille Bassi e Seção Técnica de Informática, ICMC/USP, com os dados fornecidos pelo(a) autor(a)

\begin{tabular}{|c|c|}
\hline \multirow[t]{3}{*}{ S213d } & $\begin{array}{l}\text { Sandim, Marcos Henrique Alves } \\
\text { Deteç̧ão de fronteira em sistemas de partículas / } \\
\text { Marcos Henrique Alves Sandim; orientador Afonso } \\
\text { Paiva Neto. -- São Carlos, } 2015 . \\
\quad 73 \text { p. }\end{array}$ \\
\hline & $\begin{array}{l}\text { Dissertação (Mestrado - Programa de Pós-Graduação } \\
\text { em Ciências de Computação e Matemática } \\
\text { Computacional) -- Instituto de Ciências Matemáticas } \\
\text { e de Computação, Universidade de São Paulo, } 2015 .\end{array}$ \\
\hline & $\begin{array}{l}\text { 1. computação gráfica. 2. processamento } \\
\text { geométrico. 3. sistemas de partículas. 4. fronteira. } \\
\text { I. Neto, Afonso Paiva, orient. II. Título. }\end{array}$ \\
\hline
\end{tabular}


M simulações físicas baseadas em partículas, a informação sobre quais partículas pertencem à fronteira do sistema e quais são consideradas internas é, em geral, uma informação útil porém difícil de ser obtida eficientemente. Esta informação pode ser usada na geração da superfície livre de um fluido ou no cálculo da tensão superficial do mesmo, entre outras aplicações. Técnicas encontradas na literatura podem apresentar resultados satisfatórios, mas em geral são sensíveis à escala do problema, distribuição das partículas e envolvem operações computacionalmente caras como inversão de matrizes. O objetivo deste trabalho é estudar os métodos existentes e apresentar uma alternativa com custo computacional mais baixo e que seja capaz de lidar com problemas de diferentes escalas e naturezas de forma mais simples que os métodos existentes. 

${ }^{\mathrm{N}}$ particle-based physics simulations, the information about which particles belong to the boundary of the system and which are considered internal is, in general, an information that is useful but hard to obtain in an efficient way. This information can be applied to generate the free surface of the fluid or to compute the surface tension, among other applications. Techniques found in the literature may present satisfactory results, but in general they are sensible to the problem scale, particle distribution and involve computationally expensive operations such as matrix inversion. The goal of this study is to analyze the existing methods and present an alternative with lower computational cost and which is capable of handling problems with different scales and nature in a simpler way than the existing methods. 

Resumo

$\begin{array}{lll}\text { Abstract } & \text { iii }\end{array}$

Sumário $\quad$ vi

$\begin{array}{lcr}\text { Lista de Figuras } & \text { viii }\end{array}$

$\begin{array}{ll}\text { Lista de Tabelas } & \text { ix }\end{array}$

Lista de Siglas $\quad$ xi

1 Introdução $\quad 1$

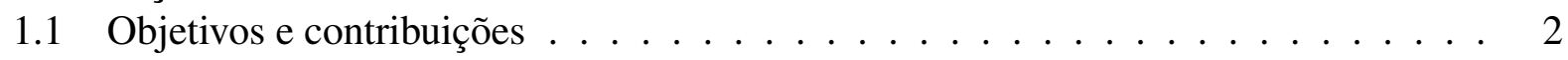

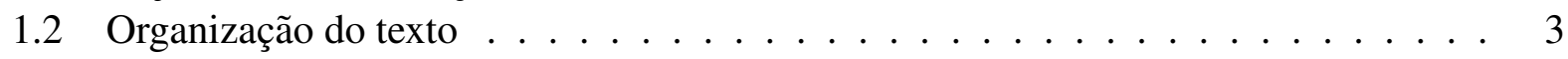

2 Trabalhos relacionados $\quad 5$

2.1 Computação gráfica . . . . . . . . . . . . . . . . . . . . 5

2.1.1 Aplicação de limiar na função característica . . . . . . . . . . . . . . 6

2.1.2 Aplicação de limiares no deslocamento da partícula ao centroide da sua vizinhança e densidade . . . . . . . . . . . . . . . . . . 7

2.2 Física computacional . . . . . . . . . . . . . . . . . . . 8

2.2.1 Análise da sobreposição de esferas de raio fixo . . . . . . . . . . . . . . 9

2.2.2 Análise espectral e região de sondagem . . . . . . . . . . . . . . . 12

3 Fundamentos $\quad 15$

3.1 Hidden Point Removal . . . . . . . . . . . . . . . . . . . . . . . . 15

3.1 .1 Inversão . . . . . . . . . . . . . . . . . . . 16

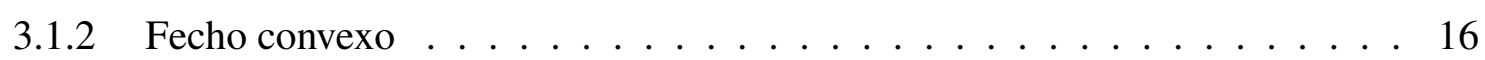

3.1.3 Aproximação do parâmetro $R \ldots \ldots \ldots$. . . . . . . . . . . . . . . . . 18

3.1.4 Extensões e trabalhos relacionados . . . . . . . . . . . . . . . 19

3.2 Grade virtual . . . . . . . . . . . . . . . . . . . . . 20

3.3 Cálculo de vetor normal usando PCA . . . . . . . . . . . . . 23 
4 HPR local para detecção de fronteira $\quad \mathbf{2 5}$

4.1 Escolha de observadores . . . . . . . . . . . . . . . . . . 25

4.1 .1 Grade de busca . . . . . . . . . . . . . . . . . 26

4.1.2 Deslocamento do centroide . . . . . . . . . . . . . . . 27

4.2 HPR local usando inversão exponencial . . . . . . . . . . . . . . . . . 28

4.2 .1 Curvatura local . . . . . . . . . . . . . . . . . . 32

5 Resultados $\quad 35$

5.1 Duas dimensões . . . . . . . . . . . . . . . . . . . . 35

5.1 .1 Marrone et al. . . . . . . . . . . . . . . 35

5.1 .2 Bell et al. . . . . . . . . . . . . . . . . 40

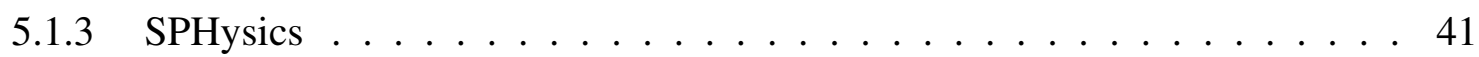

5.2 Três dimensões . . . . . . . . . . . . . . . . . . . . . . . . . 44

5.2 .1 Exemplos estáticos . . . . . . . . . . . . . . . . . . 44

5.2 .2 Exemplos dinâmicos . . . . . . . . . . . . . . 57

$\begin{array}{lll}6 & \text { Conclusão } & 67\end{array}$

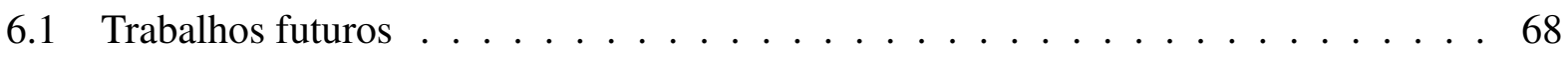

$\begin{array}{llr}\text { A Prova do Lema } 4.1 & 69\end{array}$

$\begin{array}{ll}\text { Referências } & 71\end{array}$ 


\section{Lista de Figuras}

2.1 Resultado da detecção de borda utilizando o metodo de He et al. . . . . . . . . . . 9

2.2 Resultado da detecção de borda utilizando o metodo de He et al. . . . . . . . . . . 9

2.3 Diferentes métodos para analisar a cobertura de uma circunferência $1 h$. . . . . . . 10

2.4 Problema causado pelo método backpoint. . . . . . . . . . . . . . . . 11

2.5 Segmentos representando arcos sobre a circunferência $1 h$ de uma partícula. . . . . 11

2.6 Análise de tempo para os métodos apresentados por Dilts. . . . . . . . . . . . . . 12

2.7 Região de sondagem. . . . . . . . . . . . . . . . . . . . . . 13

3.1 A oclude B a partir do observador O . . . . . . . . . . . . . . . 15

3.2 Exemplo de inversão utilizando o operador HPR . . . . . . . . . . . . . . . . . . 17

3.3 Geometria do problema tratado pelo operador HPR. . . . . . . . . . . . . . . 17

3.4 As formas da curva $L$ em função do ângulo $\beta \ldots \ldots \ldots \ldots$. . . . . . . . . 18

3.5 Regiões vazias de acordo com o operador HPR. . . . . . . . . . . . . . . . . . . . . . . . . . . . . . . . .

3.6 Grade regular num espaço bi-dimensional. . . . . . . . . . . . . . . . . . . . . . 21

3.7 Grade virtual num espaço bi-dimensional. . . . . . . . . . . . . . . . . . . 22

3.8 Aproximação da normal através de PCA . . . . . . . . . . . . . . . . . 23

4.1 Pipeline do método de escolha de observadores em duas dimensões usando a grade de busca. . . . . . . . . . . . . . . . . . . 27

4.2 Pipeline do método de escolha de observadores em duas dimensões usando deslocamento do centroide. . . . . . . . . . . . . . . . . . . . . . . . . . . . . . . .

4.3 Organização do teste de inversão. . . . . . . . . . . . . . . . . . . . . . . 29

4.4 Teste com HPR usando inversão esférica e aproximação do parâmetro $R$. . . . . . 30

4.5 Teste com HPR usando inversão esférica e parâmetro $R=2 \ldots$. . . . . . . . . . 30

4.6 Teste com HPR usando inversão exponencial e parâmetro $\gamma=2 . \ldots . . .31$

4.7 Gráfico da distância entre os pontos e o observador antes e depois da aplicação da função de inversão. . . . . . . . . . . . . . . . . . . . 32

5.1 Resultado do método de Müller et al. [MCG03] . . . . . . . . . . . . . . . . . 36

5.2 Resultado do método de He et al. $\left[\mathrm{HLW}^{+} 12\right]$. . . . . . . . . . . . . . . . . . . . 37

5.3 Resultado do método de Marrone et al. [MCLTG10]. . . . . . . . . . . . . . . . 38

5.4 Resultado do método de Dilts [Dil00]. . . . . . . . . . . . . . . . . . 38

5.5 Resultado do método proposto usando escolha de observadores através da grade de busca. . . . . . . . . . . . . . . . . . 39

5.6 Problema causado pelo mal alinhamento entre a grade de busca e os dados. . . . . 39 
5.7 Resultado do método proposto usando escolha de observadores através do deslocamento do centroide. . . . . . . . . . . . . . . . . . . . 40 40

5.8 Resultados obtidos no teste usando o vórtice proposto por Bell et al. [BCG89]. . . 41

5.9 Resultados obtidos para o conjunto de dados produzido com o SPHysics. . . . . . . 43

5.10 Conjunto de dados produzido a partir do modelo Stanford Bunny. . . . . . . . . . . 45

5.11 Conjunto de referência para o modelo Stanford Bunny. . . . . . . . . . . . . . . 46

5.12 Resultados obtidos aplicando a técnica baseada em grade ao modelo Stanford Bunny. 46

5.13 Resultados obtidos aplicando a técnica baseada deslocamento de centroide ao modelo Stanford Bunny. . . . . . . . . . . . . . . . . . . . . . 47

5.14 Resultados obtidos aplicando as técnicas de Marrone et al., Müller et al. e He et al. ao modelo Stanford Bunny. . . . . . . . . . . . . . . . . . . . . . . 48

5.15 Conjunto de dados produzido a partir do modelo Asian Dragon. . . . . . . . . . . . 49

5.16 Conjunto de referência para o modelo Asian Dragon. . . . . . . . . . . . . . . . . 49

5.17 Resultados obtidos aplicando a técnica baseada em grade ao modelo Asian Dragon. 50

5.18 Resultados obtidos aplicando a técnica baseada em deslocamento de centroide ao modelo Asian Dragon. . . . . . . . . . . . . . . . . . . . . . 50

5.19 Resultados obtidos aplicando as técnicas de Marrone et al., Müller et al. e He et al. ao modelo Asian Dragon. . . . . . . . . . . . . . . . . . . . . . . . . 51

5.20 Conjunto de dados produzido a partir do modelo Armadillo. . . . . . . . . . . . 52

5.21 Conjunto de referência para o modelo Armadillo. . . . . . . . . . . . . . . . 53

5.22 Resultados obtidos aplicando a técnica baseada em grade ao modelo Armadillo. . . 53

5.23 Resultados obtidos aplicando a técnica baseada em deslocamento de centroide ao modelo Armadillo.. . . . . . . . . . . . . . . . . . . . . . . . . . . . . . . . 54

5.24 Resultados obtidos aplicando as técnicas de Marrone et al., Müller et al. e He et al. ao modelo Armadillo. . . . . . . . . . . . . . . . . . . . . 55

5.25 Fronteira obtida no teste de deformação de uma esfera. . . . . . . . . . . . . . . 58

5.26 Fronteira obtida no teste de deformação de uma esfera (corte). . . . . . . . . . . . 59

5.27 Geometria inicial da cena da queda de esfera (gota) . . . . . . . . . . . . . . 60

5.28 Resultado do teste de queda de esfera. . . . . . . . . . . . . . . . . . . . 61

5.29 Resultado do teste de queda de esfera (corte). . . . . . . . . . . . . . . . . . 62

5.30 Geometria inicial da cena de colisão de blocos (quebra de barragens). . . . . . . . . 63

5.31 Resultados obtidos na cena de colisão de blocos. . . . . . . . . . . . . . . . . . 64

5.32 Resultados obtidos na cena de colisão de blocos (corte) . . . . . . . . . . . . . . 65

A.1 Esboço usado na prova do Lema 4.1. . . . . . . . . . . . . . . . . . . . . 69 


\section{Lista de Tabelas}

2.1 Comparação dos métodos existentes para detecção de fronteira . . . . . . . . . . . 6

5.1 Tempo de execução em milissegundos das técnicas desenvolvidas. . . . . . . . . . . 56

5.2 Tempo total de execução em milissegundos das técnicas estudadas. . . . . . . . . . . 56

5.3 Contagem de falsos positivos e falsos negativos para as técnicas estudadas. . . . . . 56 
CFD - Computational Fluid Dynamics

CUDA - Compute Unified Device Architecture

GPU - Graphics Processing Unit

HPR - Hidden Point Removal

MPS - Moving-Particle Semi-implicit

PIC - Particle In Cell

PCA - Principal Component Analysis

RAM - Random Access Memory

SPH - Smoothed Particle Hydrodynamics

TPO - Target Point Occlusion 
A dinâmica dos fluidos computacional (do inglês: Computational Fluid Dynamics - CFD) é uma área que há anos tem recebido atenção dos pesquisadores. Métodos sem malha, como o Smoothed Particle Hydrodynamics - SPH [GM77], Moving-Particle Semi-implicit - MPS [KO96] e o Particle In Cell - PIC [HE55], são um subconjunto de técnicas que abrem mão do uso de uma malha explícita para representar o fluido ou domínio de simulação para obter um grau maior de liberdade na simulação, permitindo o uso de domínios com menos restrições e facilitando o tratamento de deformações locais, uma vez que não são necessárias operações específicas para a manutenção da conectividade da malha quando ocorrem grandes deformações ou mudanças topológicas. Apesar de suas vantagens, esses métodos possuem problemas que requerem tratamento especial, como a detecção de vizinhança, controle de fronteira e definição de superfície livre. O foco desse trabalho está na definição de partículas de fronteira de um fluido, pois com essa informação é possível aproximar a superfície livre do fluido, calcular a sua tensão superficial, facilitar o tratamento de condições de fronteira entre o fluido e outros objetos e a imposição de condições de contorno.

A detecção de fronteira é um assunto pouco explorado na literatura sobre métodos baseados em partículas. Discussões sobre esse problema em geral se resumem a uma pequena parcela de diversos trabalhos maiores. Dentre trabalhos que citam a detecção de partículas de fronteira, alguns dedicam uma maior atenção a esse problema e podem ser resumidos a cinco trabalhos das áreas de computação gráfica e de física computacional: Müller et al. [MCG03], He et al. [HLW $\left.{ }^{+} 12\right]$, Marrone et al. [MCLTG10], Dilts [Dil00] e Haque et al. [HD07]. Esse é um conjunto bastante restrito de trabalhos, que em geral cobrem o problema a partir de algum ponto de vista específico, para solução de outro subproblema apresentado no trabalho e que possuem limitações que dificultam sua aplicação em um contexto diferente daquele para o qual o método foi desenvolvido. 
Os trabalhos de Müller et al. e He et al. pertencem à literatura do método SPH aplicado na área de computação gráfica, tais trabalhos apresentam soluções simples e com baixo custo mas com resultados bastante sensíveis à distribuição das partículas do sistema. Na literatura de física computacional, o trabalho de Dilts apresenta uma solução robusta que produz resultados com qualidade e que não é sensível a casos onde a distribuição é irregular ou caótica, mas é limitado a dados em duas dimensões. Para estender esse trabalho para três dimensões, Haque et al. propõe uma solução equivalente mas com um custo computacional bastante elevado e que é reconhecidamente complexa, nas palavras dos próprios autores e de outros. O trabalho de Marrone et al. cita a solução proposta por Haque et al. e que aponta sua alta complexidade computacional e de implementação, e apresenta uma solução derivada daquela proposta por Dilts e posteriormente por Haque et al. A solução proposta por Marrone et al. é consideravelmente mais simples que aquela proposta por Haque et al., mas possui uma forte dependência da qualidade dos vetores normais usados na aplicação do método. Vetores normais mal orientados ou com direções difusas podem comprometer gravemente os resultados obtidos.

Quanto à qualidade dos resultados, ela pode ser medida em termos de falsos negativos e falsos positivos. Baixas taxas de falsos positivos e negativos indicam resultados com boa qualidade. Mas a definição de falso positivo ou falso negativo pode ser subjetiva, uma vez que não existe uma definição exata ou métrica que defina o que é uma partícula de fronteira ou uma partícula interna em um sistema de partículas. Nesse trabalho são usados conjuntos de referência para esse tipo de análise quando disponíveis, nos demais casos é necessária uma análise manual para definição de quais partículas são ou deveriam ser consideradas como pertencentes à fronteira do sistema. Uma vez definidas qual seria a solução ideal, um falso positivo representa uma partícula que de acordo com a solução ideal não pertence à fronteira mas que é marcada como tal pelo método aplicado. Similarmente, um falso negativo representa uma partícula que idealmente deveria ser marcada como pertencente à fronteira do sistema mas que é marcada com um ponto interno pelo método aplicado. Logo, quanto menor o número de falsos positivos e negativos um método apresentar, mais próximo o seu resultado estará da solução ideal.

Sendo assim, as soluções conhecidas para o problema de detecção de fronteira possuem deficiências e limitações que dificultam o seu uso em contextos diferentes daqueles para o qual foram criadas. Uma solução mais genérica, livre das limitações conhecidas e com qualidade de resultados comparável ao obtido pelos métodos existente, pode ser aplicada de uma forma mais ampla, unificando a detecção de fronteira usada na solução de outros problemas relacionados ao método SPH.

\subsection{Objetivos e contribuições}

O objetivo deste trabalho é estudar a soluções existentes para o problema de detecção de partículas de fronteira e a partir disso propor uma alternativa simples e viável para tais soluções. 
Além de uma baixa complexidade computacional, o objetivo é desenvolver um método que o método seja relativamente simples de ser aplicado para facilitar seu uso em diferentes contextos e futuras melhorias e extensões. Outro ponto importante, em especial na área de física computacional, é a qualidade dos resultados obtidos que devem apresentar o menor número possível de erros. Sendo assim, as contribuições deste trabalho são: revisão da literatura sobre detecção de fronteira em sistemas de partículas, estudo do comportamento do operador HPR (Seção 3.1) em diferentes contextos e aplicação local do operador HPR para resolver o problema de detecção de fronteira.

\subsection{Organização do texto}

No Capítulo 2 é apresentado um estudo das principais técnicas existentes para detecção de partículas de fronteira, separado em dois grupos: computação gráfica e física computacional. No Capítulo 3 são apresentados e discutidos conceitos e ferramentas usados na solução proposta, apresentada no Capítulo 4. No Capítulo 5 são apresentados e discutidos os resultados obtidos para dados de duas e três dimensões, e no Capítulo 6 as conclusões que podem ser retiradas deste trabalho. 



\section{CAPÍTULO}

\section{2}

\section{Trabalhos relacionados}

O método SPH na ultima década recebeu muita atenção devido a diversos fatores como o aumento da capacidade computacional e o advento da computação de propósito geral em GPU, o que permitiu que simulações de maior escala fossem executadas em tempo hábil em computadores pessoais. Apesar disso, o problema da detecção de partículas de fronteira ainda foi pouco tratado. As soluções para esse problema encontradas na literatura até a finalização dessa dissertação são poucas, reduzindo-se a apenas quatro técnicas principais, divididas em cinco trabalhos em duas áreas: computação gráfica e física computacional. Na área de computação gráfica temos os trabalhos de Müller et al. [MCG03] e He et al. $\left[\mathrm{HLW}^{+} 12\right]$, e na área de física computacional os trabalhos de Marrone et al. [MCLTG10], Dilts [Dil00] e Haque et al. [HD07]. Os trabalhos de Dilts e Haque et al. estão altamente relacionados pois tratam da mesma solução, um para duas dimensões o outro para três, portanto são tratatados como uma única técnica. Outros trabalhos utilizam essas técnicas ou pequenas variações das mesmas. A Tabela 2.1 traz um comparativo com alguns pontos importantes sobre esses métodos, que serão discutidos com mais detalhes adiante, bem como a complexidade de pior caso para cada um deles. Na análise de complexidade $d$ é o número de dimensões do espaço onde o problema está contido, $n$ é o número médio de vizinhos por partícula, $M$ é o número total de partículas e $K$ é o número de observadores usados, sendo $M \gg K \gg n$.

\subsection{Computação gráfica}

Os métodos para detecção de fronteira usados em computação gráfica buscam ser mais simples e rápidos, mesmo que isso signifique uma perda de precisão nos resultados e exija a necessidade 
Tabela 2.1: Comparação dos métodos existentes para detecção de fronteira

\begin{tabular}{|c|c|c|c|c|c|}
\hline & \multicolumn{2}{|c|}{ Computação gráfica } & \multirow{2}{*}{ Método proposto } & \multicolumn{2}{|c|}{ Física computacional } \\
\hline & [MCG03] & {$\left[\mathrm{HLW}^{+} 12\right]$} & & [MCLTG10] & [HD07] \\
\hline Independente de limiares & Não & Não & Sim & Não & Sim \\
\hline $\begin{array}{l}\text { Independente de normais } \\
\text { bem definidas }\end{array}$ & Sim & Sim & Sim & Não & Sim \\
\hline $\begin{array}{l}\text { Independente da função } \\
\text { núcleo escolhida }\end{array}$ & Não & Não & Sim & Não & Sim \\
\hline $\begin{array}{l}\text { Independente de uma } \\
\text { distribuição regular de } \\
\text { partículas }\end{array}$ & Não & Não & Sim & Não & Sim \\
\hline $\begin{array}{l}\text { Complexidade no pior } \\
\text { caso da solução em 3D }\end{array}$ & $O(M n)$ & $O(M n)$ & $O(K n \log n)$ & $O\left(M n d^{3}\right)$ & $O\left(M n^{2}\right)$ \\
\hline
\end{tabular}

de ajuste de parâmetros para cada caso em particular. Essas métodos em geral se resumem a um pequeno trecho do trabalho pois são apenas uma ferramenta usada para alcançar outros objetivos.

\subsubsection{Aplicação de limiar na função característica}

Um dos trabalhos mais conhecidos e citados sobre o método SPH na área de computação gráfica é o trabalho de Müller et al. de 2003 [MCG03]. Esse trabalho serviu de ponto de partida para diversos outros na área e aborda diversos aspectos do método SPH, dentre eles a detecção de partículas de fronteira para o cálculo da tensão superficial do fluido.

Naquele trabalho é proposta uma forma de aproximar uma função característica para as partículas do sistema. A função característica, ou função indicadora, por definição é uma função binária que assume valor 1 para elementos do conjunto de interesse e 0 para os demais. Nesse contexto, a função característica é usada para identificar regiões internas e externas do sistema de partículas. Em teoria, a função característica deve assumir valor 1 para todo vetor $\mathbf{r}$ correspondente à posição de uma partícula do sistema e 0 para todo o restante do espaço. A aproximação proposta é baseada na Janela de Parzen [Par62] e utiliza uma normalização pelo volume das partículas:

$$
c_{S}(\mathbf{r})=\sum_{j} m_{j} \frac{1}{\rho_{j}} W\left(\mathbf{r}-\mathbf{r}_{j}, h\right) .
$$

Na Equação (2.1), o vetor posição r é o ponto pertencente ao sistema $S$ para o qual está sendo computada a função característica $c_{S}, j$ corresponde aos índices das partículas na vizinhança de $\mathbf{r}$, $m_{j}$ é a massa da partícula de índice $j, \rho_{j}$ sua densidade e $\mathbf{r}_{j}$ sua posição. A função $W\left(\mathbf{r}-\mathbf{r}_{j}, h\right)$ corresponde a uma função núcleo centrada em $\mathbf{r}$ e com raio de suavização igual a $h$. O parâmetro $h$ é relacionado com o espaçamento médio $d_{0}$ das partículas no sistema. Alguns autores usam 
aproximações para esse valor baseadas na distribuição inicial das partículas, mas em geral são usados valores próximos de $h \approx \alpha d_{0} \operatorname{com} \alpha \in[1.3,1.6]$. A função núcleo mais usada para o cálculo da função característica é o núcleo gaussiano, onde $\alpha_{d}$ representa um fator de normalização dependente da dimensão $d$ da função núcleo:

$$
W(\mathbf{r}, h)=\alpha_{d} e^{-\frac{\|\mathbf{r}\|^{2}}{h}}
$$

Como essa aproximação é baseada na vizinhança do ponto definido por $\mathbf{r}$, pontos com menos vizinhos ou vizinhos mais afastados tendem a possuir um valor de $c_{S}$ menor e pontos que correspondem ao centro de partículas do sistema podem ter um valor diferente de 1. Logo, pontos com valores maiores de $c_{S}$ correspondem à regiões internas e pontos com valores menores correspondem à regiões mais externas. Pontos onde a variação da função característica é maior correspondem então a interfaces entre fluido e meio externo.

A partir da função característica, a normal no ponto $r$ é aproximada através do gradiente de $c_{S}: \mathbf{n}=\nabla c_{S}$. Finalmente, para separar as regiões de fronteira do fluido é aplicado um limiar $\theta$ no módulo da normal em $\mathbf{r}$. Pontos onde $\|\mathbf{n}\|>\theta$ pertencem a regiões cuja variação da função característica é maior que o limite desejado, logo estão próximos à interface entre o fluido e o meio externo. Então caso $\left\|\mathbf{n}_{i}\right\|>\theta$, a partícula de índice $i$ pertence à uma região de interface. Portanto é considerada uma partícula de fronteira.

Como esse método baseia-se em aproximar uma função característica utilizando uma técnica que utiliza amostragem, mudanças na escala, distribuição das partículas e escolha da função núcleo causam variações nos valores de $c_{S}$ o que obriga a escolha de diferentes valores de $\theta$ para cada caso a ser analisado. Outro problema causado por esses fatores é a instabilidade da solução: um mesmo valor de $\theta$ pode gerar resultados diferentes em regiões de um mesmo sistema, levando a uma taxa de erro relativamente alta em alguns casos, principalmente de falsos positivos. Os valores das taxas de erro são apresentados no Capítulo 5, juntamente com os demais métodos estudados.

\subsubsection{Aplicação de limiares no deslocamento da partícula ao cen- troide da sua vizinhança e densidade}

Em 2012, He et al. [HLW ${ }^{+}$12] publicou um artigo que trata da interação entre fluidos sem malha e objetos sólidos. Um dos passos envolve uma correção na pressão das partículas do sistema, correção essa feita através de uma equação de Poisson que depende da imposição de condições de contorno para possuir uma solução única. Então foi apresentado um método baseado em uma medida de assimetria das partículas e na variação da densidade para identificar partículas de fronteira e usar essa informação na equação de Poisson.

A medida de assimetria usada, chamada de $A s y_{i}^{f}$ (assimetria da partícula de fluido $i$ ), é baseada na deslocamento entre uma partícula e o centroide da sua vizinhança: quanto maior o valor de $A s y_{i}^{f}$, maior a probabilidade de $i$ ser uma partícula de fronteira. Para o cálculo do centroide da 
vizinhança de $i$ é feita uma suavização através de uma função núcleo normalizada $\tilde{W}$ que satisfaça $\sum_{j} \tilde{W}\left(\mathbf{x}_{i}-\mathbf{x}_{j}, h\right)=1$. O centroide $\hat{\mathbf{x}}_{i}^{f}$ da partícula de fluido $i$ então é calculado usando essa função núcleo através da Equação (2.3). Vale notar que a vizinhança de $\mathbf{x}_{i}^{f}$ inclui qualquer tipo de partícula, não apenas de fluido.

$$
\hat{\mathbf{x}}_{i}^{f}=\sum_{j} \mathbf{x}_{j} \tilde{W}\left(\mathbf{x}_{i}^{f}-\mathbf{x}_{j}, h\right)
$$

Então a medida de assimetria pode ser calculada como o deslocamento entre $\mathbf{x}_{i}^{f}$ e $\hat{\mathbf{x}}_{i}^{f}: A s y_{i}^{f}=$ $\left\|\mathbf{x}_{i}^{f}-\hat{\mathbf{x}}_{i}^{f}\right\|$, ou como é apresentada no trabalho de He et al.:

$$
A s y_{i}^{f}=\left\|\mathbf{x}_{i}^{f}-\sum_{j} \mathbf{x}_{j} \tilde{W}\left(\mathbf{x}_{i}^{f}-\mathbf{x}_{j}, h\right)\right\|
$$

Para separar as partículas de fronteira é aplicado um limiar no valor de $A s y_{i}^{f}$ : se $A s y_{i}^{f}>0.3 h$ então $i$ é considerada uma partícula de fronteira. O valor do limiar é associado ao valor de $h$ para reduzir o impacto de possíveis mudanças de escala na detecção da fronteira. Porém os próprios autores notam que caso $i$ esteja em uma região com deficiência de partículas, como gotas ou borrifos, o valor de $A s y_{i}^{f}$ pode não ser suficiente para definir se $i$ é ou não uma partícula de fronteira. Para esses casos foi imposta uma segunda condição para uma partícula $i$ ser considerada de fronteira baseada na densidade de $i$. Em regiões com deficiência de partículas, a densidade tende a ser menor que a densidade de referencia do fluido $\bar{\rho}^{f}$, então caso $\rho_{i}^{f}<0.7 \bar{\rho}^{f}$ a partícula $i$ também é considerada de fronteira. Resumindo as duas condições temos que uma partícula $i$ é considerada como pertencente à fronteira do fluido caso:

$$
A s y_{i}^{f}>0.3 h \quad \text { ou } \quad \rho_{i}^{f}<0.7 \bar{\rho}^{f}
$$

Os resultados mostrados no artigo, apesar de poucos, apenas três instantes de uma simulação 2D, apresentam bons resultados, como pode ser visto na Figura 2.1. Mas em alguns casos os resultados podem variar em diferentes regiões, resultando em uma alta taxa de falsos negativos, mas com uma taxa de falsos positivos praticamente nula. A Figura 2.2 traz alguns dos resultados obtidos usando esse método, na qual fica clara uma de suas deficiências: detectar a borda de cavidades no sistema.

\subsection{Física computacional}

$\mathrm{Na}$ literatura de física computacional, foram encontrados dois trabalhos dedicados ao problema de detecção de fronteira em sistemas de partículas: o de Marrone et al. [MCLTG10] e o de Haque et al. [HD07]. O trabalho de Haque et al. é uma extensão do trabalho apresentado anteriormente por Dilts [Dil00]. Esses métodos buscam uma qualidade maior nos resultados e apresentam soluções com maior custo computacional. 

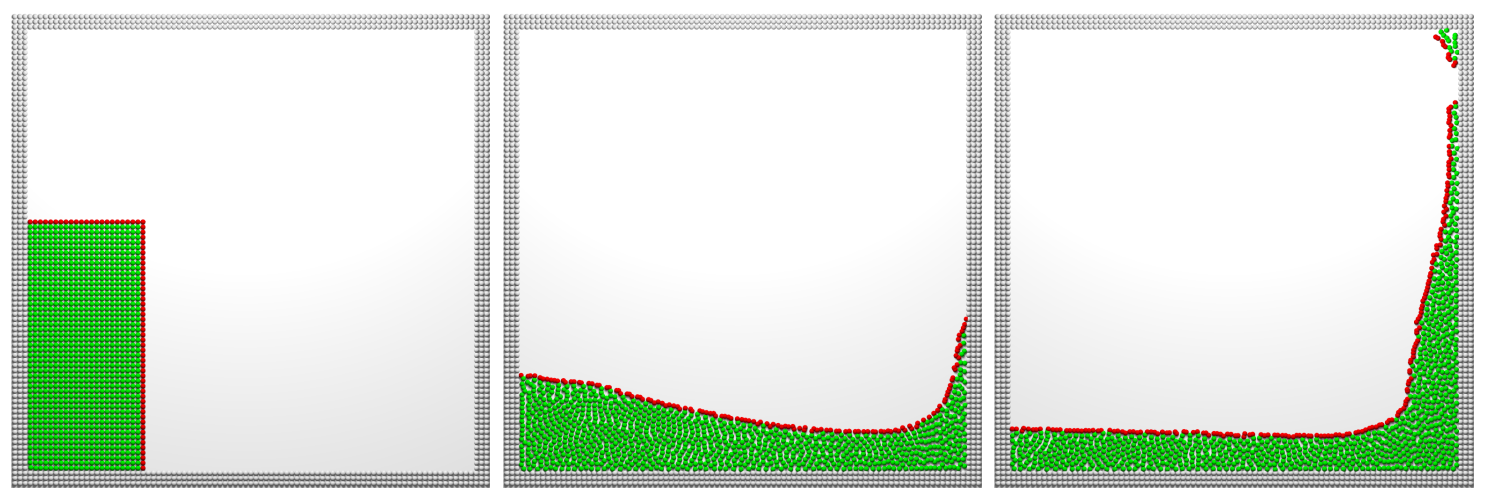

Figura 2.1: Resultado da detecção de borda utilizando o metodo de He et al. Imagem retirada de [HLW $\left.{ }^{+} 12\right]$.
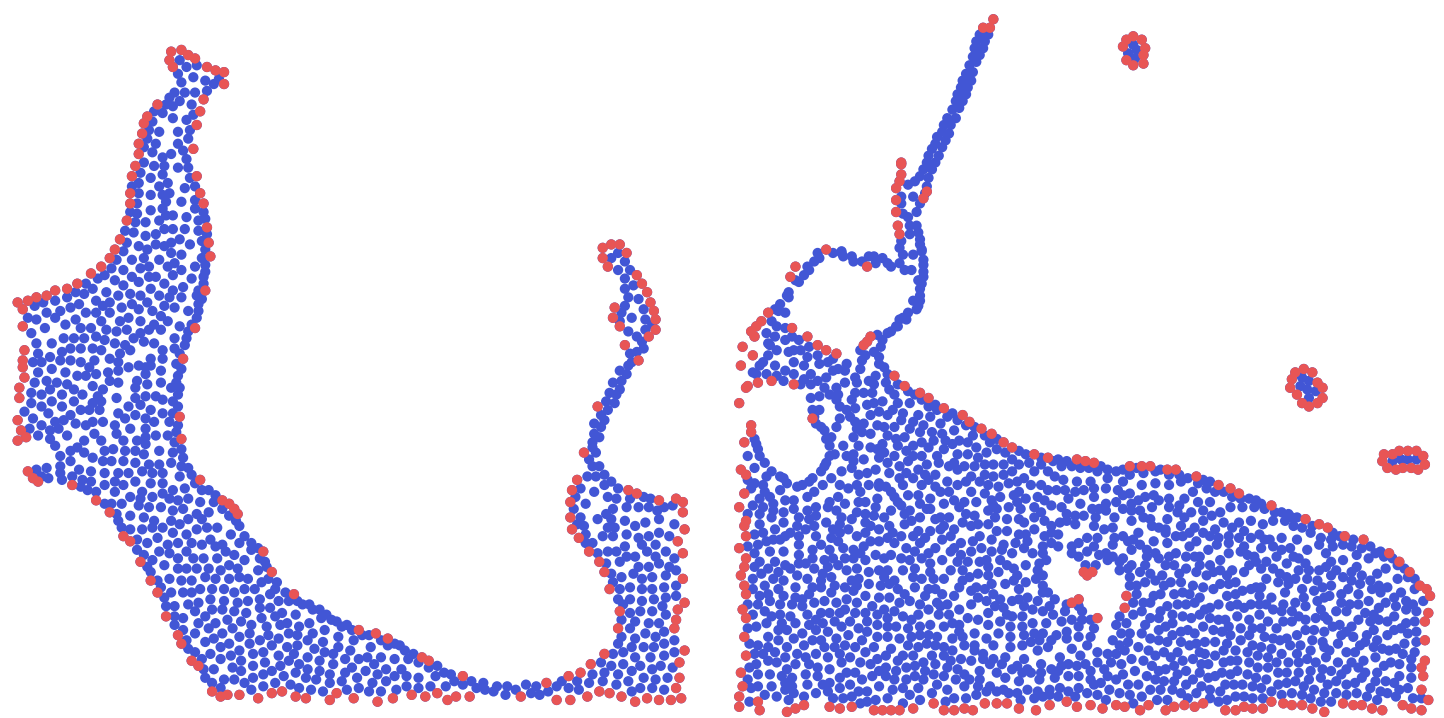

Figura 2.2: Resultado da detecção de borda utilizando o metodo de He et al.

\subsubsection{Análise da sobreposição de esferas de raio fixo}

O trabalho de Dilts [Dil00] é um importante trabalho sobre o método SPH na área de física computacional, pois trata da instabilidade dos interpoladores SPH usando mínimos quadrados móveis, em inglês: Moving Least Squares (MLS). Mas as soluções envolvendo SPH e MLS dependem da imposição de condições de contorno para o fluido, logo a detecção de fronteira é um ponto importante para o método.

Dilts cita brevemente soluções apresentadas anteriormente por outros autores, como as de autoria de Müller et al. [MCG03] e He et al. [HLW $\left.{ }^{+} 12\right]$, que se baseiam no somatório de funções núcleo para obter informações de fronteira. O autor nota a sensibilidade desse tipo de método à distribuição das partículas no sistema, que leva a erros quando ela é irregular.

Para contornar esse tipo de problema é proposto um método puramente geométrico, que em duas dimensões consiste em analisar círculos de raio $1 h$ e com centro nas posições das partículas. Uma partícula $i$ com circunferência de raio $1 h$ que não esteja totalmente contida dentro dos círculos de raio $1 h$ das demais partículas é considerada partícula de fronteira. Essa ideia, apesar de sim- 
ples, não pode ser implementada de forma direta, então o autor apresenta três possíveis soluções para o problema, mostradas na Figura 2.3, que possuem diferentes complexidades e qualidade dos resultados.
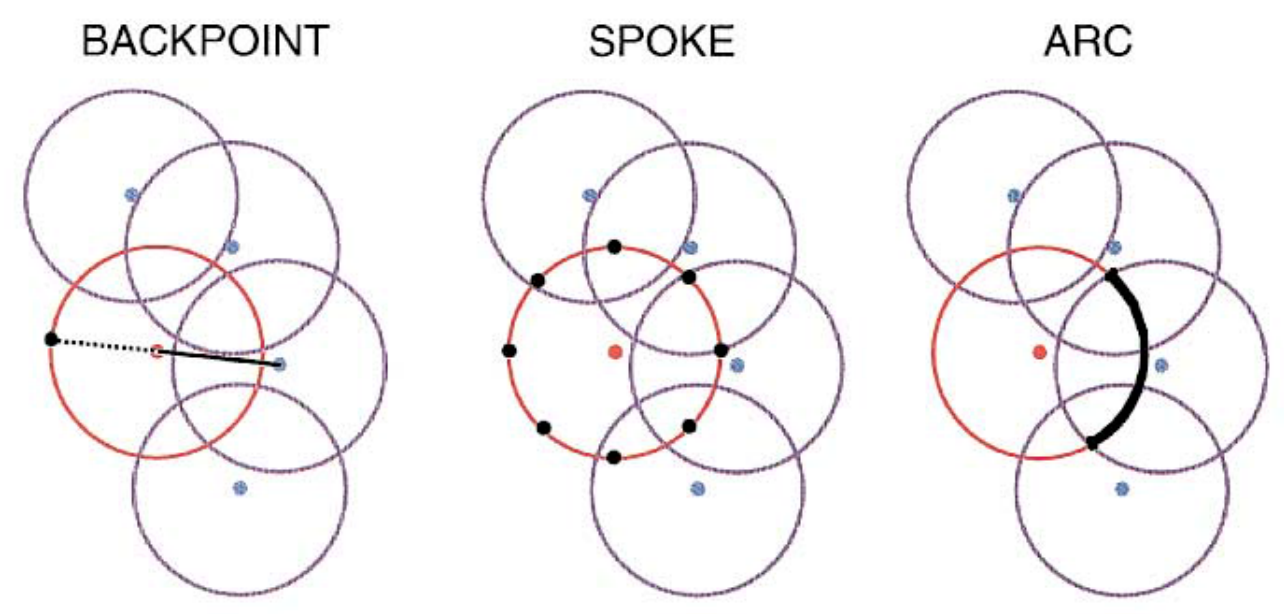

Figura 2.3: Diferentes métodos para analisar a cobertura de uma circunferência $1 h$. Imagem retirada de [Dil00].

A primeira solução mostrada é chamada de backpoint, e se resume a: traçar uma semi-reta $r$ do centro de uma partícula vizinha $j$, atravessando o centro da partícula $i$ sendo analisada, até a circunferência de $i$ no lado oposto de $j$. A partir dessa reta, é verificado se o ponto de interseção entre $r$ e a circunferência de $i$ está contida no círculo de alguma partícula vizinha de $i$. Esse método é bastante simples mas apresenta problemas em configurações simples, como pode ser visto na Figura 2.4. Em casos onde há um alinhamento de partículas, os pontos de interseção podem estar contidos dentro de circunferências, fazendo com que estas sejam marcadas como internas mesmo que tais partículas pertençam à fronteira do sistema.

A segunda solução é uma extensão da primeira e é denominada de spoke. A diferença é que os pontos sobre a circunferência de $i$ que serão testados contra as circunferências das partículas vizinhas de $i$ são pré-definidos. Essa mudança resolve alguns problemas, mas pode levar a testes desnecessários.

A última solução é chamada de $\operatorname{arc}$, pois se baseia em separar as interseções da circunferência de $i$ com os círculos de suas vizinhas em arcos e verificar se a união desses arcos é igual à circunferência em si. Para verificar a união dos arcos, a circunferência e os arcos são mapeado para segmentos de reta, como pode ser visto na Figura 2.5. Os segmentos são então ordenados de acordo com sua coordenada inicial e o conjunto de segmentos é varrido para buscar falhas entre os segmentos. Para estender essa solução para três dimensões os segmentos de reta se tornariam regiões da fronteira de esferas mapeadas para uma região plana.

De acordo com o autor a terceira solução, além de obter resultados mais precisos que as demais, é também mais eficiente em relação ao tempo, pois se implementada corretamente possui um custo computacional menor. A Figura 2.6 mostra a analise de performance feita pelo autor. 
Figura 2.4: Problema causado pelo método backpoint. O alinhamento das partículas faz com que os pontos de interseção entre as semi-retas $r$ e as circunferências estejam localizados dentro da circunferência de outras partículas. Nesse caso não há uma verificação na direção perpendicular ao alinhamento, fazendo com que partículas que deveriam ser marcadas como fronteira sejam marcadas como internas. Imagem retirada de [Dil00].
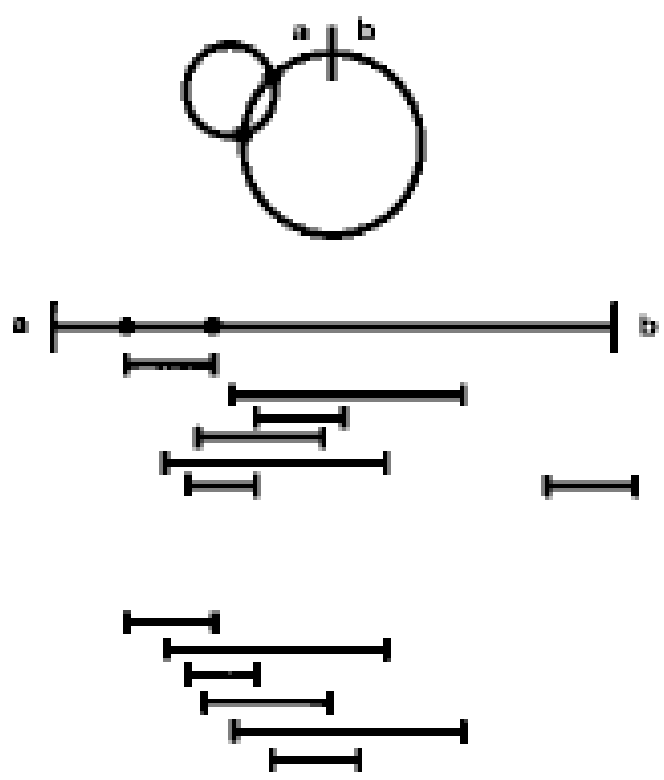

Figura 2.5: Segmentos representando arcos sobre a circunferência $1 h$ de uma partícula. Imagem retirada de [Dil00].

De um modo geral este método produz resultados com taxa de falsos positivos praticamente nula e taxa de falsos negativos muito baixa, sendo que esses falsos negativos encontram-se em regiões que podem ser consideradas ambíguas, com uma mesma partícula podendo ser considerada interna ou de fronteira, dependendo da definição de fronteira usada. O maior problema é a dificuldade de implementação, que não se estende de forma simples para três dimensões como visto no trabalho de Haque et al. Essa extensão além de trabalhosa resulta em um algoritmo custoso, com complexidade na ordem de $\mathrm{O}\left(n_{i}^{\epsilon}\right)$ por partícula no caso médio, onde $n_{i}$ é o número de vizinhos da partícula $i$ e $\epsilon \in[1.6,1.7]$ é uma constante dependente do problema. Mas uma simples análise do algoritmo mostra que no pior caso o desempenho pode degradar para $O\left(n_{i}^{2}\right)$ levando a 

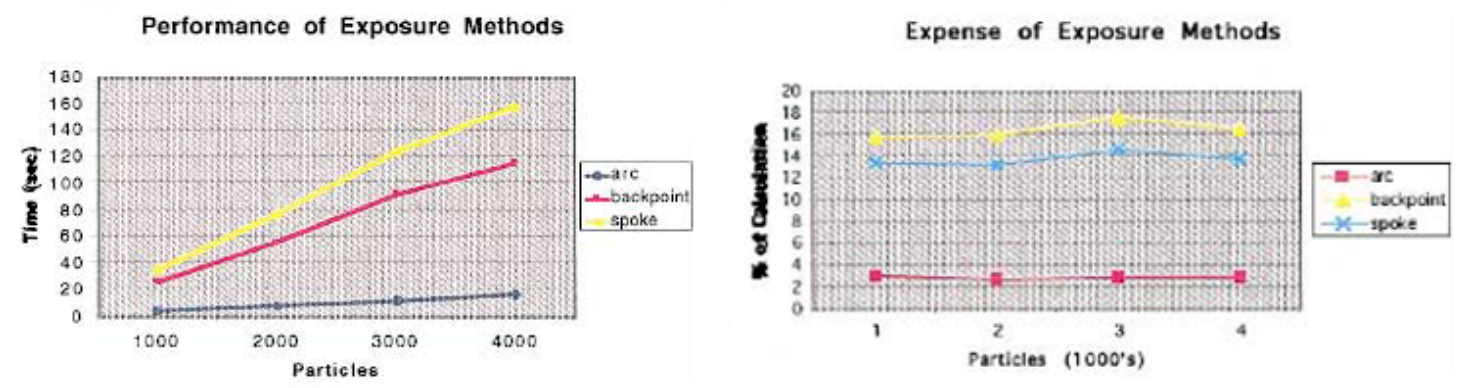

Figura 2.6: Análise de tempo para os métodos apresentados por Dilts. Imagem retirada de [Dil00], com qualidade e resolução restritas ao apresentado no artigo original. No lado esquerdo é mostrado um gráfico de tempo de processamento em milissegundos versus número de partículas, e no lado direito, um gráfico do percentual do tempo total de simulação de um passo gasto pela detecção de fronteira versus o número de partículas no sistema.

complexidade do algoritmo como um todo para $O\left(M n^{2}\right)$, onde $M$ é o número total de partículas no sistema e $n$ é o número médio de vizinhos por partícula. Essa extensão para três dimensões é apresentada no trabalho de Haque et al. [HD07], e resulta em um algoritmo trabalhoso de ser implementado mas com complexidade no pior caso ainda na ordem de $O\left(M n^{2}\right)$.

\subsubsection{Análise espectral e região de sondagem}

Usando a matriz de renormalização, que é semelhante à matriz de covariância, e uma região de sondagem criada a partir do trabalho de Dilts [Di100], Marrone et al. [MCLTG10] desenvolveu um método para separar as partículas de borda das internas de forma simples de ser entendida e aplicada. A Equação (2.6) mostra como é calculada a matriz de renormalização de uma partícula $i$, onde $\nabla W_{j}$ é o gradiente da função núcleo centrado na partícula $j$, que é vizinha de $i$, e $\Delta V_{j}$ é o volume da partícula $j$.

$$
\boldsymbol{B}\left(\boldsymbol{x}_{i}\right)=\left[\sum_{j} \nabla \mathrm{W}_{j}\left(\boldsymbol{x}_{i}\right) \otimes\left(\boldsymbol{x}_{j}-\boldsymbol{x}_{i}\right) \Delta \mathrm{V}_{j}\right]^{-1}
$$

Utilizando o menor autovalor $(\lambda)$ da inversa da matriz de renormalização $\left(\boldsymbol{B}^{-1}\right)$, as partículas são separadas em conjuntos de acordo com a Equação (2.7).

$$
\left\{\begin{array}{rlr}
i \in \mathbb{E} & \Leftrightarrow & \quad \lambda \leq 0.20 \\
i \in \mathbb{B} & \Leftrightarrow & 0.2<\lambda \leq 0.75 \\
i \in \mathbb{I} & \Leftrightarrow & 0.75<\lambda .
\end{array}\right.
$$

Partículas pertencentes ao conjunto $\mathbb{E}$ são consideradas de borda, as do conjunto $\mathbb{I}$ são internas, enquanto o conjunto $\mathbb{B}$ é avaliado utilizando a região de sondagem (Figura 2.7). Partículas do conjunto $\mathbb{B}$ que possuam sua região de sondagem vazia, regiões $S 1$ e $S 2$, pertencem à borda do sistema, caso contrário elas são consideradas partículas internas. 


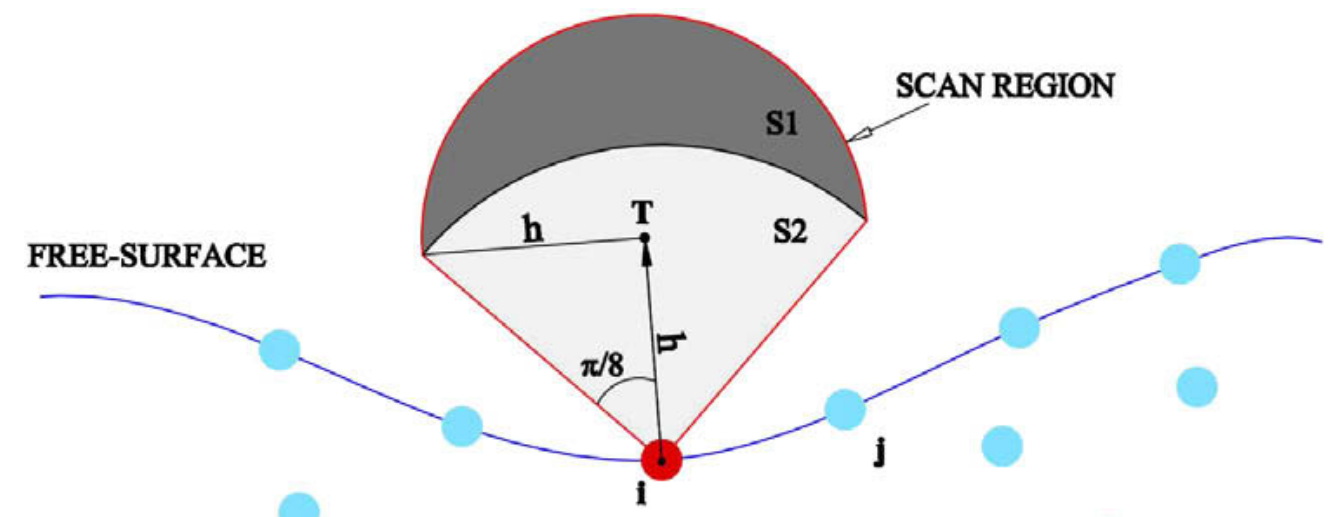

FLUID DOMAIN

Figura 2.7: Região de sondagem proposta por Marrone et al. para determinar se a partícula $i$ (em vermelho) pertence ou não à fronteira do sistema. Caso as regiões $S 1$ e $S 2$ estejam vazias, $i$ é considerada uma partícula de fronteira. Imagem retirada de [MCLTG10].

$\mathrm{Na}$ Equação (2.6) é utilizada uma função núcleo gaussiana renormalizada apresentada no trabalho de Colagrossi et al. [CL03], o que teoricamente garantiria que os autovalores da matriz $\boldsymbol{B}^{-1}$ estivessem dentro da faixa de valores esperados para o uso dos limiares da Equação (2.7). Nos testes realizados isso não ocorreu, devendo-se isso ao fato de que esta solução é bastante dependente da forma com que as partículas são distribuídas. No caso de ocorrerem sobreposição ou o espaçamento irregular entre partículas, como nos nossos testes, os próprios autores deixam claro que não há garantia de que os valores de limiares apresentados na Equação (2.7) separem devidamente as partículas, estes precisariam ser reavaliados e atribuídos novos valores para cada grupo.

Este método é dividido em duas fases: (1) divisão do sistema nos conjuntos $\mathbb{E}, \mathbb{B}$ e $\mathbb{I}$, e (2) filtragem do conjunto $\mathbb{B}$ usando a região de sondagem. O problema com essa divisão de fases é o custo das operações realizadas em cada uma das fases, o cálculo da matriz de renormalização e dos seus autovetores é uma operação com custo computacional alto se comparado com o custo da avaliação da região de sondagem. Dessa forma, uma operação de alto custo (1) é realizada sobre todas as partículas do sistema para reduzir número de operações de baixo custo (2) que serão realizadas. Outro ponto é a dependência da qualidade das normais utilizadas pela região de sondagem, uma variação na direção de uma normal pode levar a um alto número de falsos positivos, principalmente em regiões de alta curvatura. 

Neste capítulo são apresentados conceitos e ferramentas a serem usados no estudo e desenvolvimento de uma alternativa para as técnicas de detecção de fronteira existentes. As principais técnicas desse capítulo são: o operador HPR e a grade virtual para busca de vizinhos, as quais são a base do que é desenvolvido no Capítulo 4.

\subsection{Hidden Point Removal}

O operador HPR, do inglês Hidden Point Removal, foi originalmente apresentado em 2007 por Katz et al. [KTB07] e tem como objetivo eliminar pontos oclusos por outros pontos de uma nuvem de pontos. Naquele trabalho assume-se que a nuvem de pontos representa uma superfície ou curva a partir de um observador fixo. O problema que esse método busca resolver é como definir e detectar oclusão entre pontos, que não possuem volume ou área. Analisando este problema de uma forma direta, a resposta mais simples é que um ponto só está ocluso por outro ponto se ambos os pontos e o observador forem colineares (Figura 3.1), caso contrário todo ponto sempre será visível.

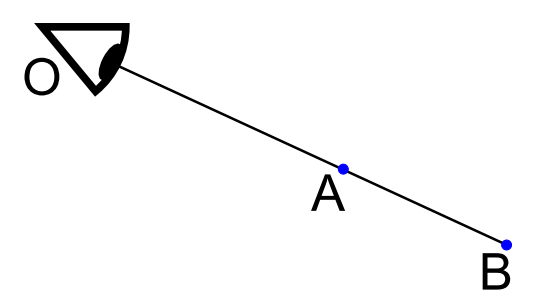

Figura 3.1: A oclude B a partir do observador O. 
Essa definição de visibilidade não é suficiente para classificar pontos que representam uma superfície. Sendo assim, é proposta uma definição de visibilidade e oclusão baseada na densidade dos pontos: Supondo que $S$ é uma superfície e $P$ é uma amostra de $S$ com densidade $\rho$, cada ponto $\mathbf{p}_{i} \in P$ pode ser envolvido por uma esfera de raio $\rho$ de forma que $S$ esteja contida na união dessas esferas. Nesse caso um ponto $\mathbf{p}_{i}$ é visível a partir de um observador $O$ caso ele ou sua esfera correspondente não sofra total oclusão por parte de nenhuma das esferas dos outros pontos pertencentes a $P$.

Esse método é divido em duas partes simples: inversão e construção do fecho convexo. A parte de inversão consiste em transformar os pontos de $P$ em torno do observador $O$ obtendo $\hat{P}$ de tal forma que os pontos do fecho convexo de $\hat{P} \cup\{O\}$ sejam os pontos correspondentes àqueles pertencentes a $P$ e visíveis a partir de $O$.

\subsubsection{Inversão}

No artigo de Katz et al. [KTB07] são apresentadas duas possíveis funções para realizar a inversão dos pontos de $P$ : inversão esférica e inversão exponencial, cada uma delas com diferentes comportamentos e que necessitam de diferentes análises para explicar seu comportamento e exatidão. O artigo de Katz et al. tem o foco na inversão esférica, Equação (3.1), onde $R$ é um parâmetro fixo que representa o raio da esfera em torno da qual será realizada a inversão, $\mathbf{p}_{i} \in P$ e $\hat{\mathbf{p}}_{i}$ é a inversão de $\mathbf{p}_{i}$ :

$$
\hat{\mathbf{p}}_{i}=f\left(\mathbf{p}_{i}\right)=\mathbf{p}_{i}+2\left(R-\left\|\mathbf{p}_{i}\right\|\right) \frac{\mathbf{p}_{i}}{\left\|\mathbf{p}_{i}\right\|} .
$$

O que essa inversão realiza é refletir $\mathbf{p}_{i}$ ao longo do raio que sai de $O$ e passa por $\mathbf{p}_{i}$ para sua imagem fora da esfera de raio $R$. A Figura 3.2 mostra um exemplo resultante dessa inversão e do cálculo o fecho convexo de $\hat{P} \cup\{O\}$.

\subsubsection{Fecho convexo}

A afirmação de que o fecho convexo de $\hat{P} \cup\{O\}$ é composto por $O$ e pela inversão dos pontos de $P$ visíveis a partir de $O$ é a principal contribuição do trabalho de Katz et al. Para dar suporte a essa afirmação é apresentada uma análise em duas dimensões da inversão esférica que mostra porque o fecho convexo produz os resultados esperados.

Considere um ponto $\mathbf{p}_{i} \in P$ sobre o eixo $x$, este ponto pode ser escrito em coordenadas polares como $\mathbf{p}_{i}=\left(\mathbf{r}_{i}, 0\right)$, onde $\mathbf{r}_{i}$ é distância de $\mathbf{p}_{i}$ até a origem $O$ e o ângulo com o eixo $x$ igual a zero. Considere também uma linha reta $\hat{L}$ que passa por $\hat{\mathbf{p}}_{i}$ e por outro ponto $\hat{\mathbf{p}} \in \hat{P}$, formando um ângulo $\beta$ com o eixo $x$. O ângulo $\alpha$ é formado pelo eixo $x$ e pela reta que passa por $\mathbf{p}$ e por $\hat{\mathbf{p}}$, e $R$ é o raio da esfera usada na inversão, presente na Equação (3.1). A Figura 3.3 ilustra essa configuração.

A partir disso, o objetivo é obter a curva $L=(r(\alpha), \alpha)$ que gera a reta $\hat{L}$ através da inversão esférica. Usando a lei dos senos, obtém-se: 

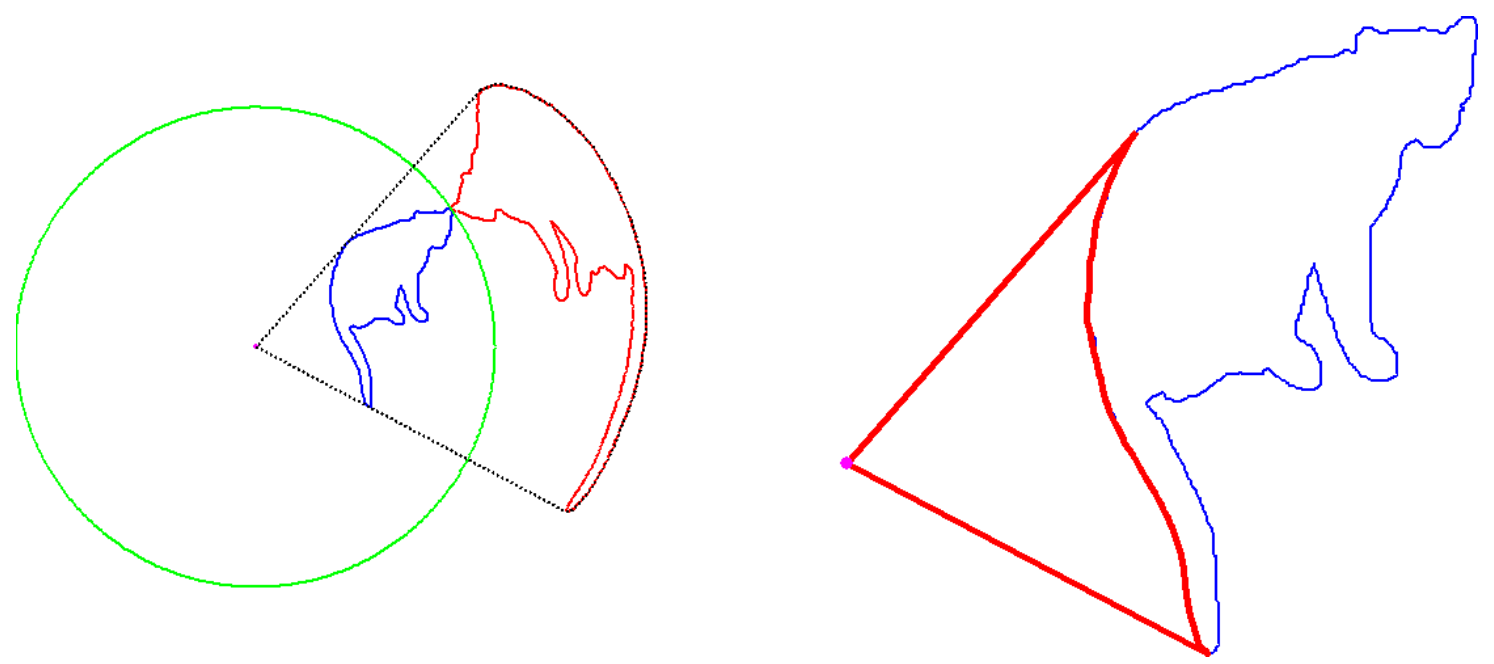

Figura 3.2: Esquerda: inversão esférica (em vermelho) de uma curva (azul) usando uma esfera (em verde) com centro no observador (magenta). Direita: projeção inversa dos pontos do fecho convexo. Imagem retirada de [KTB07].

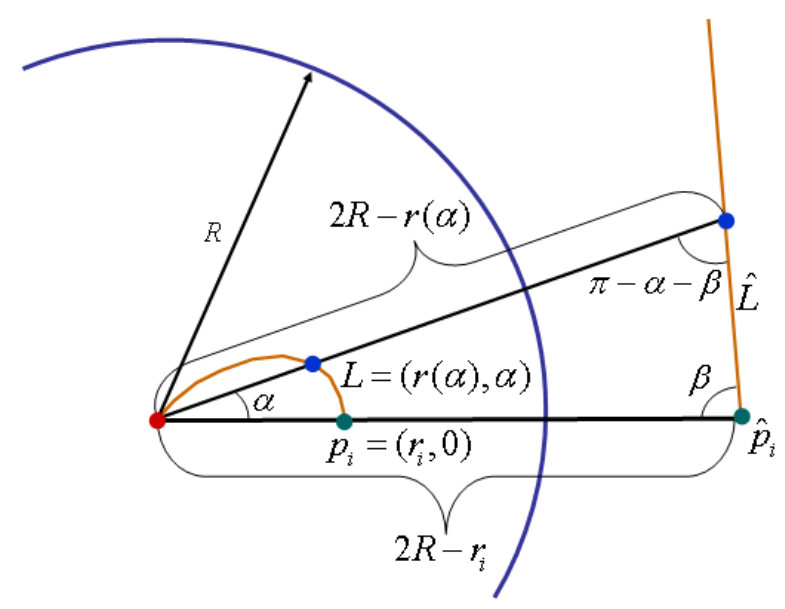

Figura 3.3: Geometria do problema tratado pelo operador HPR. O ponto em vermelho representa o observador $O$ e a curva $L$ que passa por $O$ e $\mathbf{p}_{i}$ é transformada na reta $\hat{L}$. Imagem retirada de [KTB07].

$$
\frac{2 R-\mathbf{r}_{i}}{\operatorname{sen}(\pi-\alpha-\beta)}=\frac{2 R-r(\alpha)}{\operatorname{sen} \beta}
$$

Logo,

$$
L=(r(\alpha), \alpha)=\left(2 R+\frac{\left(\mathbf{r}_{i}-2 R \operatorname{sen} \beta\right)}{\operatorname{sen}(\alpha+\beta)}, \alpha\right) .
$$

A curva $L$ atravessa $\mathbf{p}_{i}$ e $O$ e em coordenadas cartesianas é expressa como um polinômio de quarto grau. A Figura 3.4 mostra a forma da curva $L$ de acordo com o ângulo $\beta$; na qual se constata que a região entre a curva $L$ e o eixo $x$ diminui conforme $\beta$ cresce.

A região entre a curva $L$ e o eixo $x$ determinam uma região vazia associada a $\mathbf{p}_{i}$, a visibilidade de $\mathbf{p}_{i}$ é definida de acordo com o tamanho dessa região. Quanto maior a região vazia associada a 


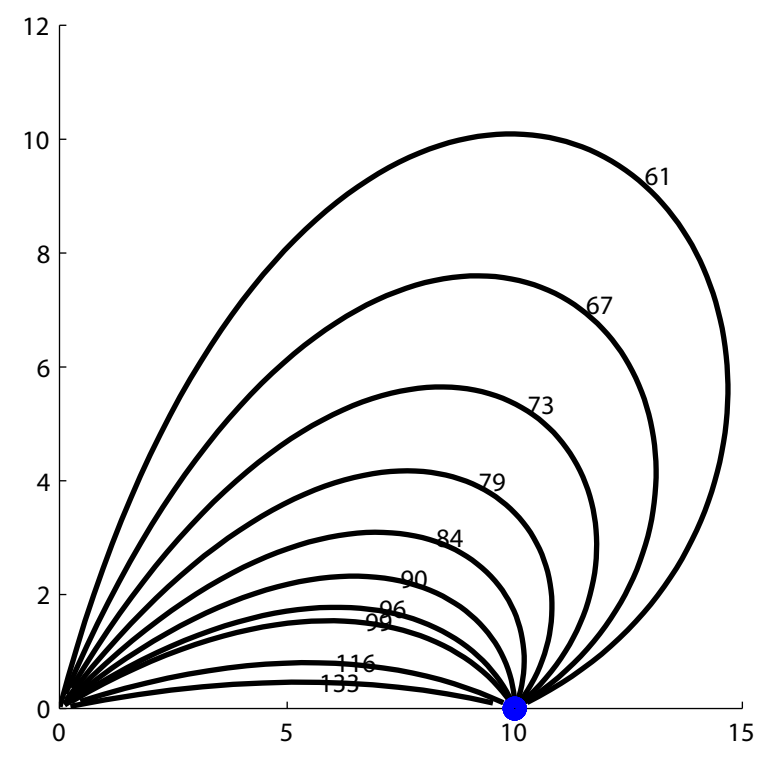

Figura 3.4: As formas da curva $L$ em função do ângulo $\beta$, onde $\mathbf{p}_{i}=(10,0), O=(0,0)$ e $R=30$. Imagem retirada de [KTB07].

$\mathbf{p}_{i}$, maior a visibilidade de $\mathbf{p}_{i}$. No operador HPR essa região é definida pelos pontos vizinhos de $\mathbf{p}_{i}$. Para cada ponto $\mathbf{p}_{i}$, existem dois pontos $\mathbf{p}_{j}$ e $\mathbf{p}_{k} \in P$ que definem as regiões entre as curvas $L_{j}=\left(r_{j}\left(\alpha_{j}\right), \alpha_{j}\right)$ saindo de $\mathbf{p}_{i}$ e passando por $\mathbf{p}_{j}$, e $L_{k}=\left(r_{k}\left(\alpha_{k}\right), \alpha_{k}\right)$ saindo de $\mathbf{p}_{i}$ e passando por $\mathbf{p}_{k}$. A união das regiões definidas por $L_{j}$ e $L_{k}$ é a maior região vazia possível como pode ser visto na Figura 3.5.

De acordo com a Equação (3.3), deduz-se que o tamanho da região é inversamente proporcional ao ângulo $\beta$. Isso significa que $\beta_{j}$ e $\beta_{k}$ que correspondam à maior região vazia possível são os menores possíveis para $\mathbf{p}_{i}$. Para $\mathbf{p}_{i}$ ser visível, a soma de $\beta_{j}$ e $\beta_{k}$ deve satisfazer $\beta_{j}+\beta_{k} \leq c$. Isso define um limite para o tamanho da região vazia para que $\mathbf{p}_{i}$ seja considerado visível. Fixar $c=\pi$, significa que não há necessidade de buscar pontos $\mathbf{p}_{j}$ e $\mathbf{p}_{k}$ que maximizem o tamanho da região vazia, basta calcular o fecho convexo de $\hat{P} \cup\{O\}$. Isso acontece pois o ponto $\hat{\mathbf{p}}_{i}$ pertence ao fecho convexo de $\hat{P} \cup\{O\}$ somente se todos os pontos de $\hat{P} \cup\{O\}$ residem em um dos semi-espaços definidos por $\overline{\mathbf{p}_{i}, \mathbf{p}_{j}}$ e $\overline{\mathbf{p}_{i}, \mathbf{p}_{k}}$. No caso do operador HPR, uma vez que as regiões definidas por $L_{j}$ e $L_{k}$ são vazias, as regiões além de $\hat{L}_{j}$ e $\hat{L}_{k}$ devem ser vazias, como pode ser visto na Figura 3.5.

A possibilidade de substituir a busca de pontos $\mathbf{p}_{j}$ e $\mathbf{p}_{k}$ que minimizam a região vazia de $\mathbf{p}_{i}$ pelo cálculo do fecho convexo de $\hat{P} \cup\{O\}$ é o que faz com que o operador HPR seja eficiente, dependendo apenas da complexidade do algoritmo usado para computar o fecho.

\subsubsection{Aproximação do parâmetro $R$}

O parâmetro $R$ usado pela inversão esférica pode ser fornecido pelo usuário do método ou ser computado automaticamente através da posição do observador e dos pontos pertencentes ao conjunto $P$. No trabalho de Katz et al. [KTB07] é apresentada uma implementação funcional do 

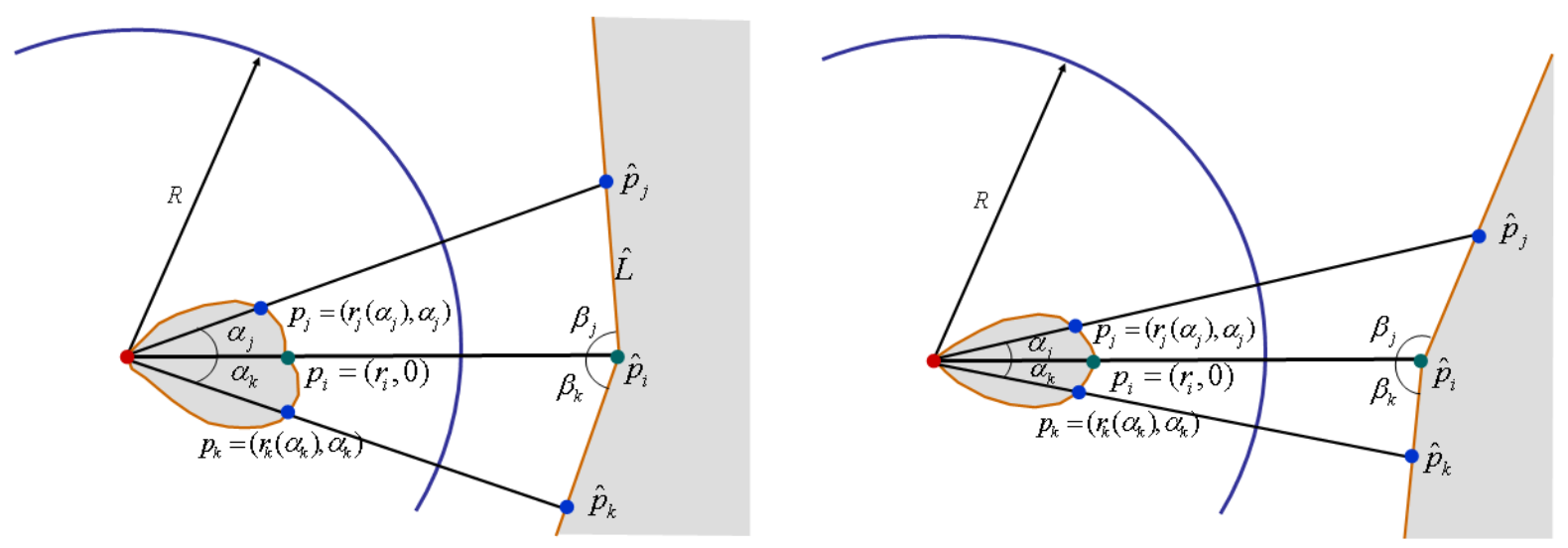

Figura 3.5: Regiões vazias de acordo com o operador HPR. À esquerda $\beta_{j}+\beta_{k}<\pi$ e à direita $\beta_{j}+\beta_{k}>\pi$. Imagem retirada de [KTB07].

operador HPR em Matlab ${ }^{\circledR}$ usando inversão esférica e com aproximação do parâmetro $R$. Essa aproximação é feita da seguinte forma: considerando $D$ como o conjunto das distâncias dos pontos de $P$ até o observador $O, R=10^{c} \max (D)$ onde $c$ é uma constante fornecida pelo usuário. Não é fornecido um intervalo de valores aceitáveis para o parâmetro $c$, mas em geral os testes produzem bons resultados com $c \in[1,2]$. Ao solicitar o valor de $c$ como parâmetro no lugar de $R$, é possível estabelecer um parâmetro que se adapta a problemas de diferentes escalas mas que fornece pouco controle sobre os limites de visibilidade.

Ainda no trabalho de Katz et al. [KTB07], é discutida a possibilidade de utilização de técnicas mais sofisticadas para a aproximação do parâmetro $R$. Uma dessas técnicas inclui a criação de um segundo observador oposto ao original e maximização do números de pontos visíveis por apenas um dos observadores através do uso do gradiente descendente. O problema com essa possível técnica é o fato dela ser explicada apenas brevemente, não possuir codigo disponibilizado como o restante do operador HPR, e nos resultados do artigo não existirem referências claras sobre qual forma de aproximação foi de fato usada para cada exemplo.

\subsubsection{Extensões e trabalhos relacionados}

Após o trabalho original de Katz et al. de 2007, foram publicados outros trabalhos que utilizam o operador HPR ou fazem uma análise do mesmo em situações diversas. O trabalho de 2010 de Mehra et al. [MTSM10] traz uma análise detalhada do comportamento do operador HPR para nuvens de pontos com ruído e uma versão mais robusta do operador HPR para tratar esses casos, além da análise da função de inversão exponencial e reconstrução de superfície explícita usando os resultados do operador HPR. Em 2012 Machado e Silva et al. [MeSEO12], publicaram um trabalho que apresenta uma implementação em GPU de um algoritmo para o cálculo do fecho convexo usado pelo operador HPR para tornar viável seu uso em aplicações interativas. Recentemente foi publicada também uma extensão desse trabalho [MeSEMO14] que inclui também amostragem de nuvem de pontos e realização de operações no espaço de imagem. Em 2013 um trabalho também 
feito por Katz et al. [KT13] apresenta um problema considerado dual ao operador HPR, chamado de Target Point Occlusion - TPO, que tem como objetivo buscar pontos que causem a oclusão de um ponto específico a partir de observadores no infinito. Além disso é mostrada uma análise que relaciona os resultados do operador HPR com a curvatura local dos pontos da nuvem.

\subsection{Grade virtual}

Em métodos que utilizam sistemas de partículas, as operações sobre uma partícula dependem das propriedades das suas partículas vizinhas. Num sistema onde a cada passo de tempo as partículas se rearranjam no espaço, modificando o que pode ser chamado de conjunto de vizinhos de uma partícula, manter esse conjunto é um trabalho que deve ser feito continuamente e possui um custo computacional elevado. Realizar a detecção de vizinhos de forma eficiente contribui consideravelmente para o desempenho do sistema. Das diferentes formas existentes para computar o conjunto $\boldsymbol{V}_{i}$ de vizinhos de uma partícula $i$, aqui são discutidos alguns dos mais simples e a sua mudança para obter uma estrutura adaptativa que possa ser usada em diferentes cenários: arquiteturas com apenas um núcleo ou diversos núcleos computacionais como processadores multi-núcleo ou GPUs.

O algoritmo mais simples é considerar cada par de partículas $i$ e $j$, e verificar a distância entre elas, em um algoritmo de força bruta. Se esta distância for inferior a $\kappa h$ (raio de influência da função núcleo usada), $i$ e $j$ são vizinhas. Este algoritmo requer um esforço computacional alto e pouco trabalho de raciocínio. Considerando que o sistema tem $M$ partículas e em média $n$ vizinhos, onde $M$ é na ordem de milhares a centenas de milhares e $n$ apenas de algumas dezenas, o tempo de busca será o número de pares distintos ordenados de partículas multiplicado pelo tempo de encontrar os pares $(i, j)$ e efetuar os testes para verificar se são duas partículas vizinhas, e ainda o tempo de retornar as $M n$ vizinhas. Se $M$ for grande, o tempo cresce como $O\left(M^{2}\right)$, o que pode significar um alto tempo de computação.

Este método pode ser melhorado a partir de algumas observações. Em caso de partículas que se movem pouco, seus vizinhos raramente mudam, assim seus vizinhos são computados apenas quando mudam; este processo é chamado de atualização preguiçosa. Para saber se uma partícula teve seu conjunto de vizinhos alterado, pode-se verificar se sua posição atual está a mais $1 / 2 h$ de distância desde a última atualização. Essa atualização é realizada em intervalos de tempo $t$, onde esse tempo é baseado na velocidade media de uma partícula.

Outra maneira de tentar melhorar o método é utilizar do fato que, se uma partícula $i$ é vizinha de $j$, então pode-se registrar que $j$ é vizinha de $i$, dessa forma o tempo de computação pode ser reduzido.

Apesar da sua simplicidade, o algoritmo força bruta apresenta um desempenho ruim quando falamos de uma aplicação interativa. Para melhorar o tempo de detecção de vizinhança e o desempenho da aplicação num todo, uma técnica comum é a divisão do espaço em células. O espaço 
dividido em células do mesmo tamanho, de forma regular, é chamado de grade regular ou simplesmente grade.

A maior vantagem de uma grade regular é descartar partículas que estão a uma distância maior que o raio de influência de uma partícula; dessa forma uma grande quantidade de testes de distância entre partículas é eliminada. Ao dividir o domínio da simulação em células com lado igual a $\kappa h$, os vizinhos de uma partícula estarão localizados na mesma célula que ela ou nas células adjacentes, fazendo com que a busca de vizinhos fique restrita a $3^{d}$ células vizinhas, onde $d=2,3$ é a dimensão do espaço de simulação.

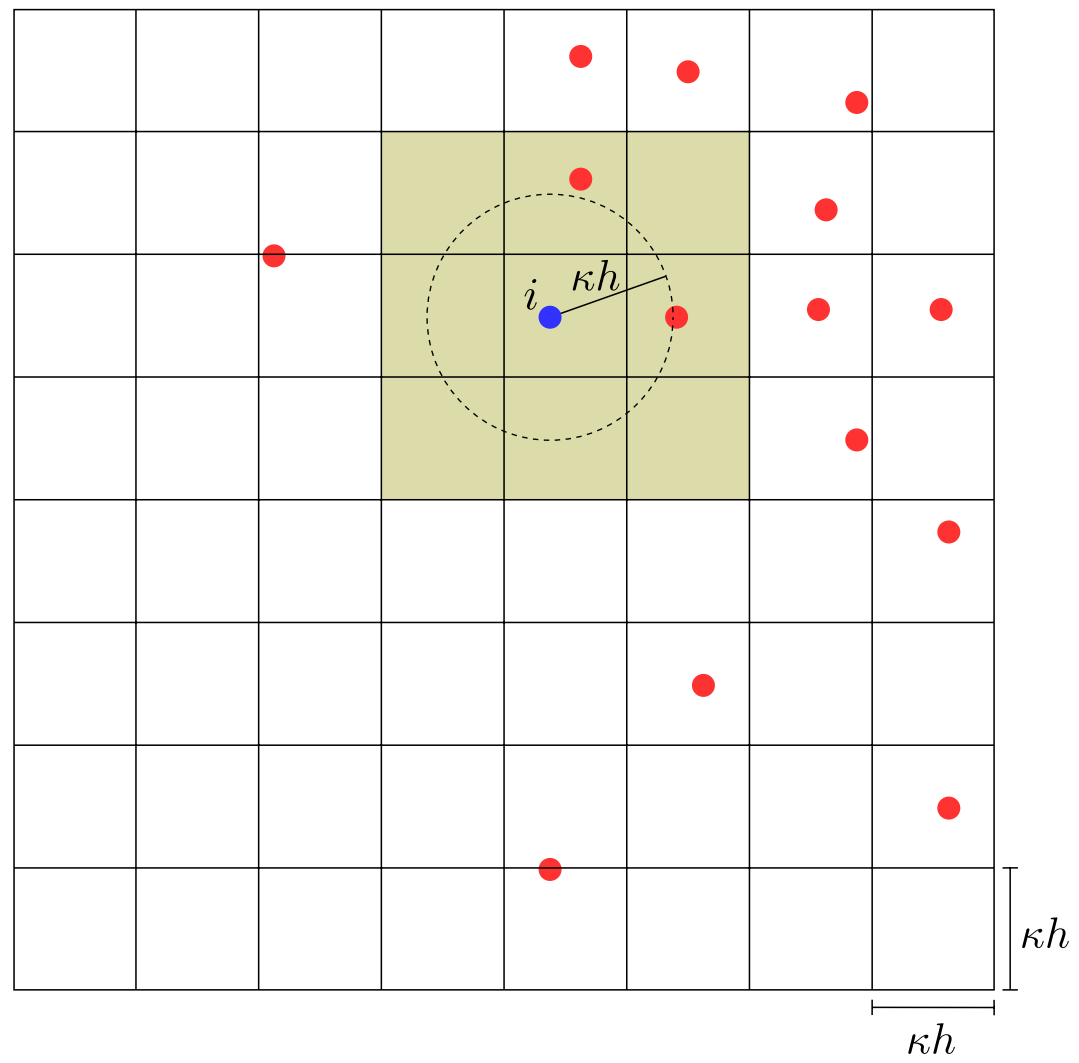

Figura 3.6: Grade regular num espaço bi-dimensional, as células destacadas representam as células que contêm os vizinhos da particula $i$.

A Figura 3.6 mostra num espaço bi-dimensional uma partícula $i$ e as células onde será realizada a busca dos seus vizinhos. Essa técnica é eficiente quando o domínio da simulação é compacto e a densidade de partículas é grande, pois o número de partículas por célula da grade tende a ficar distribuído de forma homogênea.

O ponto mais fraco no uso de grades regulares é que em aplicações onde as partículas são mais dispersas, diversas células ficam vazias enquanto outras podem ficar com um número alto partículas. Outro ponto é o fato de grades regulares serem divididas em células com lado igual ao raio de suavização das partículas, o que impede de serem utilizadas partículas com diferentes raios de suavização.

Para melhorar o uso de memória e permitir que a grade cubra uma região ilimitada do espaço, o sistema de grade regular pode ser melhorado com algumas modificações. Uma delas é a utilização 
de uma grade regular virtual, que permite economizar memória e reduzir o número de células vazias. Isso é feito através do mapeamento de diferentes regiões do espaço de simulação para uma grade de tamanho fixo, que utiliza uma quantidade fixa de memória e permite que o espaço de simulação se estenda de forma indefinida.

Considere o caso em duas dimensões de uma grade virtual com dimensões de $W \times H$ células, cada célula com lado igual a $\kappa h$ e tendo uma partícula com posição $p=(x, y)$. Inicialmente a Equação (3.4) fornece os índices $i$ e $j$ da célula onde a partícula seria armazenada em uma grade comum. Com os índices $i$ e $j$, a Equação (3.5) fornece os índices $i^{\prime}$ e $j^{\prime}$ de onde a partícula $p$ será armazenada na grade virtual. Isso pode ser interpretado como a mesma grade sendo replicada diversas vezes para cobrir todo o espaço usado pela simulação, como pode ser visto na Figura 3.7.

$$
(i, j)=\left(\frac{x}{\kappa h}, \frac{y}{\kappa h}\right)
$$

$$
\left(i^{\prime}, j^{\prime}\right)=(i \bmod W, j \bmod H)
$$

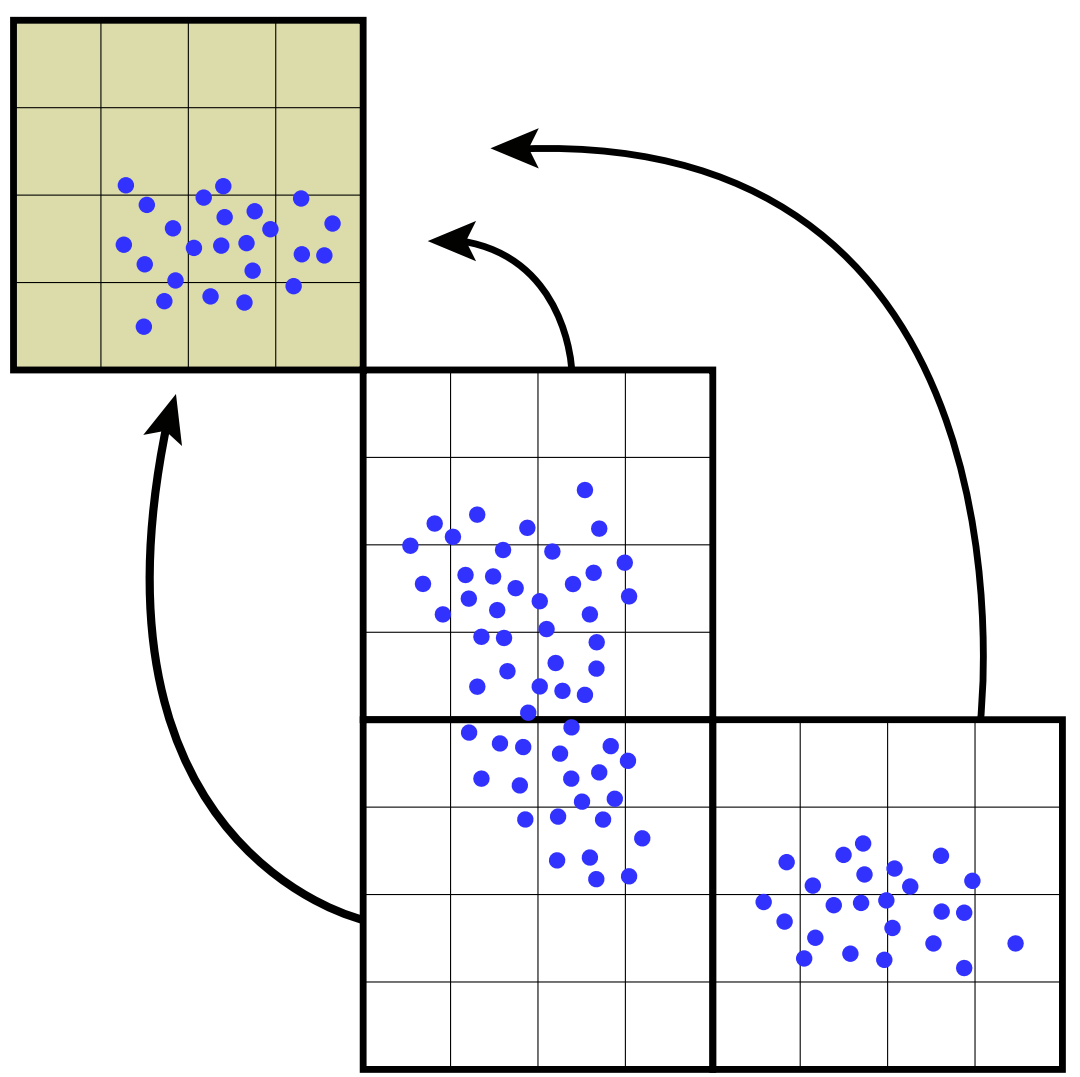

Figura 3.7: Grade virtual num espaço bi-dimensional, as grades em branco representam repetições da grade original de tamanho $4 \times 4$ localizada no canto superior esquerdo.

Com o uso de uma grade virtual, as células vizinhas podem conter partículas que não são de fato vizinhas da partícula em questão, mas esse é um problema que pode ser facilmente contornado verificando a distância entre as partículas. Esse problema de falsos vizinhos depende da quantidade 
de sobreposições necessárias para mapear o domínio de simulação, então isso pode ser controlado através das dimensões $W \times H$ da grade: grades maiores utilizam mais memória mas resultam em menos sobreposições, enquanto grades menores são mais econômicas em termos de memória mas podem levar a um número elevado de sobreposições e, consequentemente, de falsos vizinhos. Outro ponto importante do uso de uma grade virtual é a possibilidade de organizar os dados das partículas na memória de forma linear, para tirar proveito da localidade espacial e temporal da cache de memória. Em suma, o uso de uma grade virtual permite um grau maior de liberdade em relação ao domínio mapeado, possui um uso de memória mais eficiente que uma grade regular simples, mas possui o problema de falsos vizinhos.

\subsection{Cálculo de vetor normal usando PCA}

Para aproximar o vetor normal da superfície na posição das partículas pertencentes a ela, pode ser usada a noção de que existe uma deficiência na distribuição das partículas na direção da normal e uma distribuição mais homogênea nas direções pertencentes ao plano tangente da superfície na posição da partícula. Então uma base ortonormal composta pelos vetores tangente, normal e binormal (TNB) à superfície na posição da partícula em questão, também conhecida como triedro de Frenet-Serret, pode ser aproximada através da análise de componentes principais (Pricipal Component Analysis - PCA) na vizinhança da partícula. A Figura 3.8 ilustra essa situação em duas dimensões, onde o vetor $\mathbf{T}$ representa a direção de maior variação dos dados e o vetor $\mathbf{N}$, a direção de menor variação, que podem ser usados como uma aproximação para os vetores tangente e normal no ponto.

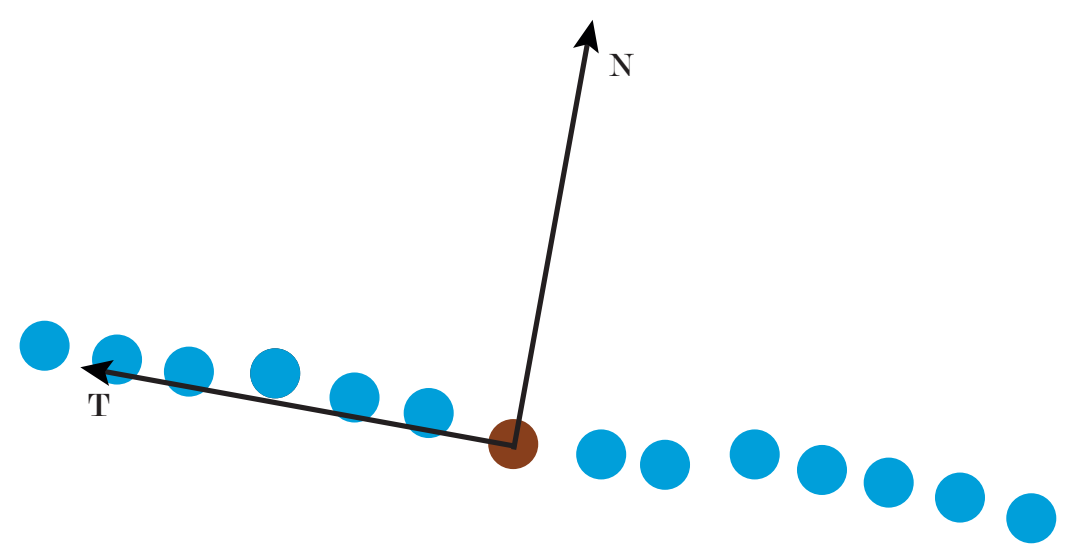

Figura 3.8: Aproximação da normal de um conjunto de pontos através de PCA e normalização dos vetores $\mathbf{N}$ e $\mathbf{T}$.

Para o cálculo das principais direções de variação dos dados através do PCA é usada uma simplificação do método da covariância. Considerando uma partícula $i$, é calculada a matriz de covariância $\mathrm{C}_{i}$ usando apenas a vizinhança de $i$ através da Equação (3.6) onde $\boldsymbol{V}_{i}$ corresponde à vizinhança de $i$, e $\mathbf{p}_{i}$ e $\mathbf{p}_{j}$ são as posições das partículas $i$ e $j$, respectivamente. 


$$
\mathrm{C}_{i}=\sum_{j \in \boldsymbol{V}_{i}} \mathbf{p}_{i} \otimes \mathbf{p}_{j}
$$

Após o cálculo da matriz $\mathrm{C}_{i}$, é realizada a decomposição em autovalores e autovetores de $\mathrm{C}_{i}$. Em três dimensões, os autovalores reais da matriz de covariância podem ser ordenados em ordem crescente, resultando em $\left(\lambda_{1}, \lambda_{2}, \lambda_{3}\right)$, onde $\lambda_{1} \leq \lambda_{2} \leq \lambda_{3}$ e seus respectivos autovetores $\left(\boldsymbol{v}_{1}, \boldsymbol{v}_{2}, \boldsymbol{v}_{3}\right)$. Dessa forma, o autovetor $\boldsymbol{v}_{1}$ corresponde ao menor autovalor $\lambda_{1}$ de $C_{i}$, podendo ser usado como uma aproximação do vetor normal à superfície em $\mathbf{p}_{i}$.

Um dos problemas de usar essa estratégia para aproximar as normais das partículas do sistema é o fato de que o sentido dos vetores obtidos é inconsistente: em alguns casos as normais apontam de dentro para fora do sistema, em outros no sentido oposto. Para obter um conjunto de normais com orientação consistente, elas devem ser reorientadas manualmente. Uma das formas mais simples é usar outros vetores cuja orientação seja conhecida, e orientar as normais de acordo com um desses vetores. Alguns possíveis vetores são: o gradiente da função característica, o vetor deslocamento entre uma partícula e o centroide da sua vizinhança (para partículas próximas à fronteira) ou o vetor deslocamento entre a partícula e o centro da célula vazia da grade de busca que esteja mais próxima. 


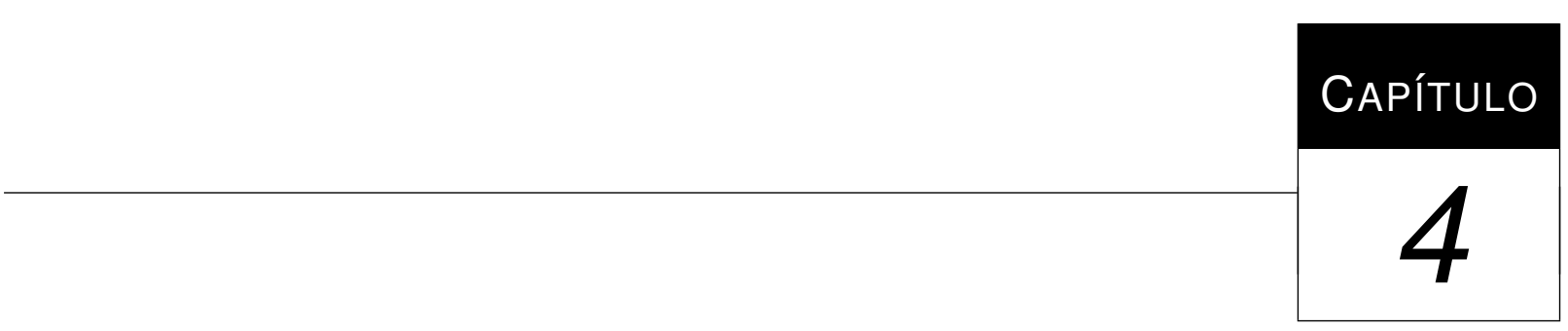

\section{HPR local para detecção de fronteira}

Para a detecção da fronteira do fluido, a técnica proposta utiliza o operador HPR em um contexto diferente daquele onde ele foi originalmente desenvolvido e aplicado. A principal mudança está em aplicar o operador HPR de forma local no lugar da clássica aplicação global. Como o operador HPR foi desenvolvido para processar dados superficiais e os dados provenientes de simulações de fluido em geral são dados volumétricos, o número de pontos a serem processados é muito maior nesse segundo caso o que pode tornar proibitivo a aplicação global do operador. Ao aplicar o operador HPR de forma local, o conjunto de pontos a serem invertidos e fecho convexo a ser computado possuem um número muito menor de elementos quando comparado à aplicação global.

A aplicação local do operador HPR é descrita a seguir, dividida em duas partes: escolha dos observadores na Seção 4.1.1 e aplicação do operador HPR em dados volumétricos na Seção 4.2.

\subsection{Escolha de observadores}

Foram estudadas diferentes abordagens para a definição dos observadores a serem usados na aplicação local do operador HPR, mantendo o foco na simplicidade desse passo para que ele tenha uma complexidade computacional por partícula menor que a aplicação local do operador HPR considerando que a complexidade no pior caso do operador HPR é $O(n \log n)$ devido ao cálculo do fecho convexo - a escolha dos observadores idealmente deve possuir uma complexidade menor ou igual a $O(n \log n)$. Sendo assim, as duas principais técnicas usadas para escolha dos observadores são baseadas na própria grade de busca de vizinhos e no deslocamento entre uma partícula e o centroide da sua vizinhança. 


\subsubsection{Grade de busca}

Nessa técnica é empregada a grade regular virtual utilizada na busca de vizinhos e a caixa envolvente do sistema de partículas $P$. Por simplicidade o método é descrito considerando um sistema de partículas em duas dimensões, uma vez que a extensão para três dimensões segue exatamente o mesmo processo.

O objetivo é encontrar um conjunto de observadores que estejam distribuídos de forma homogênea em torno da fronteira do sistema de partículas, incluindo cavidades e regiões de alta curvatura. Esse conjunto de observadores será usado na execução local do operador HPR para a detecção da fronteira do sistema, por isso a vizinhança desse conjunto deve abranger toda a extensão da fronteira do fluido. O conjunto de observadores possui um número de elementos igual a $K$, onde $M \gg K$, lembrando que $M$ é o número total de partículas do sistema. O número total de observadores deve ser o menor possível, uma vez que a complexidade final do método depende de $K$.

As posições dos observadores são definidas nos pontos centrais de células vazias adjacentes a células não-vazias. Uma célula vazia é uma célula da grade (virtual ou não) que não contém nenhuma partícula, e uma célula não-vazia é aquela que contém ao menos uma partícula do sistema. Dessa forma é obtido um conjunto de observadores bem distribuído e com visão, de acordo com a definição de visibilidade do operador HPR, de todas as partículas de fronteira do sistema.

O cálculo da caixa envolvente consiste apenas em armazenar dois pontos $\mathbf{p}_{1}$ e $p_{2}$ que representam os pontos mínimo e máximo da caixa. O ponto mínimo é composto pelos valores mínimos das coordenadas de todos os pontos de $P$ e o ponto máximo pelos valores máximos das coordenadas de todos os pontos de $P: \mathbf{p}_{1}=\left(\min P^{x}, \min P^{y}\right)$ e $\mathbf{p}_{2}=\left(\max P^{x}, \max P^{y}\right)$, onde $P^{x}$ é o conjunto dos valores das coordenadas $x$ de todos os pontos de $P$ e $P^{y}$ é o conjunto das coordenadas $y$. Essa é uma operação simples e pode ser realizada durante a leitura dos dados ou durante a integração temporal das posições das partículas.

A partir dos valores de $\mathbf{p}_{1}$ e $\mathbf{p}_{2}$ são calculados os índices $\left(i_{1}, j_{1}\right)$ e $\left(i_{2}, j_{2}\right)$, através da Equação (3.4), que correspondem aos índices das células da grade que contêm $\mathbf{p}_{1} \mathrm{e} \mathbf{p}_{2}$. Então, para toda célula com índices $\left(i_{c}, j_{c}\right)$ tal que $i_{c} \in \mathbb{I}, i_{1}<i_{c}<i_{2}$ e $j_{c} \in \mathbb{I}, j_{1}<j_{c}<j_{2}$, são verificados o conteúdo da célula e a sua vizinhança para buscar aquelas que sejam vazias e adjacentes a células não-vazias. No caso da grade virtual podem ocorrer casos de falsos vizinhos para os observadores, então é usada a norma do máximo para eliminar rapidamente partículas que estejam a uma distância maior que $\kappa h$ do ponto candidato a observador. A Figura 4.1 mostra os passos realizados nesse método de seleção.

Após a escolha dos observadores, apenas a vizinhança de raio $\kappa h$ é utilizada na aplicação do operador HPR. A união das vizinhanças dos observadores escolhidos forma uma vizinhança tubular que engloba toda a fronteira do fluido. Com isso, grande parte das partículas que pertencem ao interior do sistema são eliminadas antes da aplicação do operador HPR. 


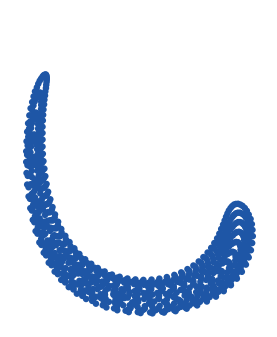

(a)

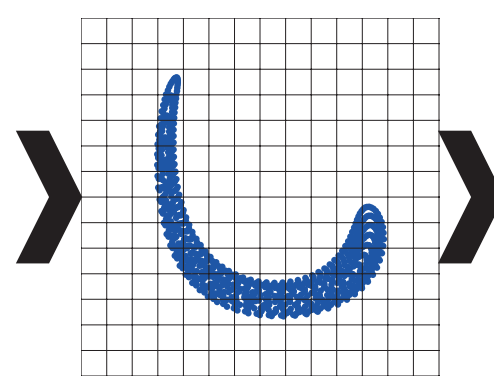

(b)

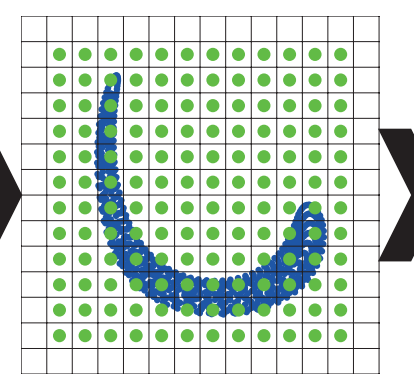

(c)

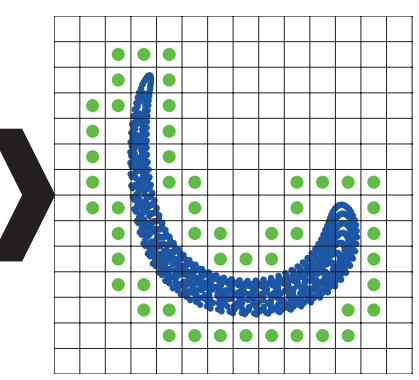

(d)

Figura 4.1: Pipeline do método de escolha de observadores em duas dimensões usando a grade de busca. O sistema de partículas (a) é mapeado para uma grade de busca de vizinhos (b); em seguida são gerados candidatos a observadores a partir do centro das células da grade contidas na caixa envolvente do sistema (c); finalmente, os candidatos são filtrados, mantendo apenas aqueles contidos em células vazias adjacentes a células não vazias (d).

\subsubsection{Deslocamento do centroide}

Uma propriedade importante mas bastante simples de se obter de uma partícula é o centroide da sua vizinhança. $\mathrm{O}$ centroide $\hat{\mathbf{x}}_{i}$ da vizinhança $\boldsymbol{V}_{i}$ de uma partícula consiste no ponto que minimiza a soma das distâncias de $\hat{\mathbf{x}}_{i}$ até as partículas pertencentes a $\boldsymbol{V}_{i}$ de acordo com a Equação (4.1). A forma mais simples de se obter $\hat{\mathbf{x}}_{i}$ é através da Equação (4.2) que faz uma média dos pontos de $\boldsymbol{V}_{i}$.

$$
\begin{gathered}
\underset{\hat{\mathbf{x}}_{i}}{\arg \min } \sum_{\mathbf{x}_{j} \in \boldsymbol{V}_{i}}\left\|\mathbf{x}_{j}-\hat{\mathbf{x}}_{i}\right\| . \\
\hat{\mathbf{x}}_{i}=\frac{\sum_{\mathbf{x}_{j} \in \boldsymbol{V}_{i}} \mathbf{x}_{j}}{\left\|\boldsymbol{V}_{i}\right\|} .
\end{gathered}
$$

Outra forma bastante comum de obter uma aproximação do centroide de $\boldsymbol{V}_{i}$ é utilizar uma suavização por uma função núcleo normalizada como na Equação (4.3). Esse tipo de aproximação é muito comum na literatura de SPH, pois é similar à forma que as demais propriedades das partículas são calculadas.

$$
\hat{\mathbf{x}}_{i}=\frac{\sum_{j} \mathbf{x}_{j} W\left(\mathbf{x}_{i}-\mathbf{x}_{j}, h\right)}{\sum_{j} W\left(\mathbf{x}_{i}-\mathbf{x}_{j}, h\right)} .
$$

Independentemente da fórmula escolhida para $\hat{\mathbf{x}}_{i}$, pode-se computar um vetor deslocamento da partícula até o centroide da sua vizinhança: $\mathbf{d}_{i}=\mathbf{x}_{i}-\hat{\mathbf{x}}_{i}$. Seguindo a mesma ideia usada por He et al. $\left[\mathrm{HLW}^{+} 12\right]$, pode-se dizer que quanto mais próxima a partícula $i$ está da fronteira maior é o módulo do vetor $\mathbf{d}_{i}$ e que esse vetor sempre apontará de dentro para fora do sistema. Para partículas internas, o módulo de $\mathbf{d}_{i}$ é menor, mas a informação de direção e sentido do deslocamento entre partícula e centroide ainda existe. Então usando $\mathbf{d}_{i}$ e $\mathbf{x}_{i}$ é possível criar um ponto $\mathbf{c}_{i}$ que é um candidato a observador criado a partir de $i$ : 


$$
\mathbf{c}_{i}=\mathbf{x}_{i}+1.5 h \frac{\mathbf{d}_{i}}{\left\|\mathbf{d}_{i}\right\|}
$$

Para filtrar os candidatos e obter os observadores a serem usados na aplicação do operador HPR, é empregada a grade de busca descrita na Seção 3.2 para realizar consultas de vizinhança em torno dos candidatos de forma eficiente. Apenas candidatos que possuam uma vizinhança de raio $h$ completamente vazia são mantidos; assim, todos aqueles que por ventura tenham sido posicionados em regiões internas do fluido ou muito próximos à fronteira são facilmente eliminados. Dessa forma obtém-se de forma simples um conjunto conciso de observadores distribuídos por toda a fronteira do fluido e em cavidades que comportem uma esfera vazia de raio $h$. A Figura 4.2 mostra os passos desse método de escolha.

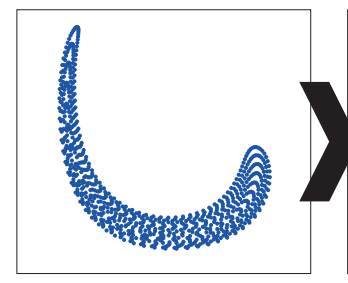

(a)

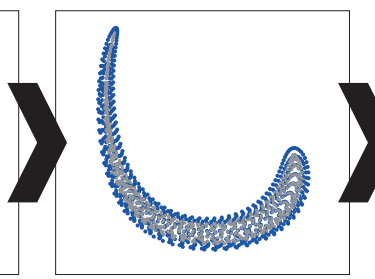

(b)

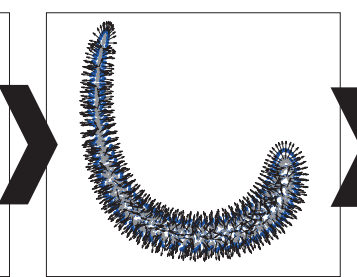

(c)

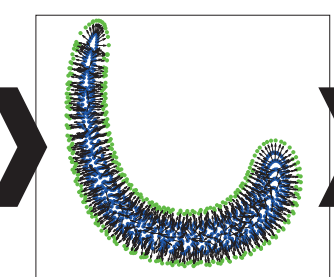

(d)

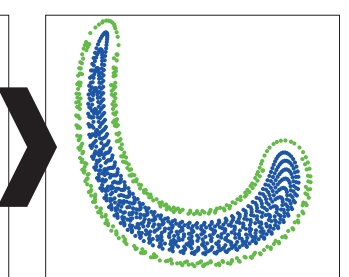

(e)

Figura 4.2: Pipeline do método de escolha de observadores em duas dimensões usando deslocamento do centroide. Para cada partícula do sistema (a) é calculado o centroide de sua vizinhança (b), representado em cinza, e o vetor deslocamento $\mathbf{d}_{i}=\mathbf{x}_{i}-\hat{\mathbf{x}}_{i}$ (c); os candidatos são posicionados de acordo com a Equação (4.4) (d); e filtrados para que tenham uma região vazia em torno de cada um deles (e).

\subsection{HPR local usando inversão exponencial}

Após a escolha dos observadores, o operador HPR é aplicado localmente na vizinhança de cada um deles e as partículas visíveis a partir de qualquer um dos observadores são marcadas como pertencentes à fronteira do fluido. Uma questão a ser levantada nesse ponto é a ocorrência de falsos positivos: partículas que pertencem ao interior do fluido mas que são classificadas como de fronteira. A principal causa de falsos positivos é o fato de que o operador HPR não foi desenvolvido para tratar problemas dessa natureza, onde o observador está localizado próximo aos pontos de uma nuvem contendo dados volumétricos. Para analisar esses casos, foi criado um teste simples mas que aproxima o caso problema citado: dados volumétricos e observador próximo das partículas, como pode ser visto na Figura 4.3.

Na Figura 4.3 o conjunto de pontos, ou partículas, $P$ será transformado em $\hat{P}$ através de uma função de inversão $f$ em torno o observador $O$. O conjunto $D$ representa as distâncias de todo ponto $\mathbf{p}_{i} \in P$ até o ponto $O, \mu_{D}$ a média dessas distâncias e $\sigma_{D}$ o seu desvio padrão. De forma análoga, tem-se o conjunto $\hat{D}$ com as distâncias após a inversão, $\mu_{\hat{D}}$ e $\sigma_{\hat{D}}$.

O primeiro teste realizado utiliza a inversão esférica, Equação (3.1), e a aproximação do parâmetro $R$ como proposto por Katz et al. Através da aproximação proposta, usando um parâmetro 


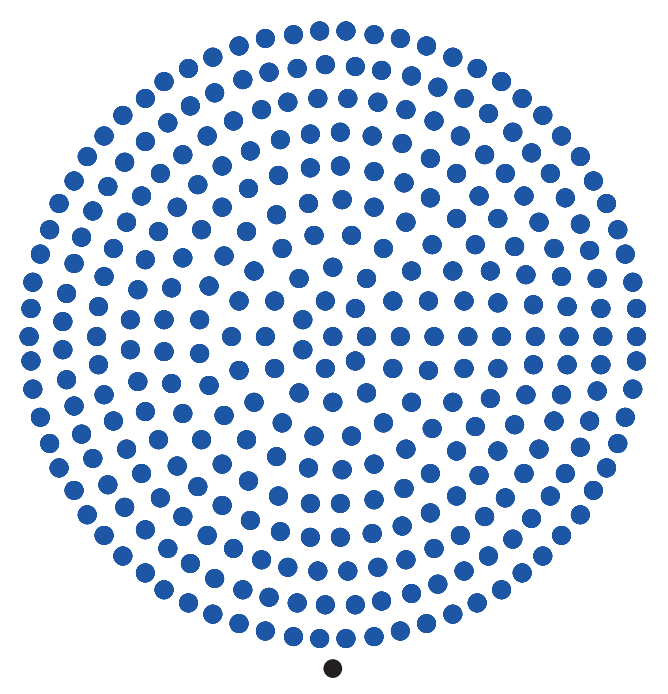

Figura 4.3: Organização do teste de inversão: os pontos originais (azuis) possuem um espaçamento $d x \approx$ 0.11 entre eles distribuídos em um círculo de raio unitário, e o observador (preto) está localizado a uma distancia de 0.1 do ponto mais próximo a ele.

igual a 1 , é obtido $R \approx 21$ para o caso descrito na Figura 4.3, resultando em uma inversão que distribui os pontos a uma distância média $\mu_{\hat{D}} \approx 40.75$ do observador, com desvio padrão $\sigma_{\hat{D}}=0.5$, como ilustrado na Figura 4.4. Isso significa que os pontos são mapeados para uma distância relativamente grande do observador, mas com pouca variação entre eles para facilitar a distinção entre pontos internos ou de fronteira. Ao computar o fecho convexo dos pontos invertidos, diversos falsos positivos surgem devido a essa falta de distinção entre os dados. A Figura 4.4 mostra o resultado dessa inversão.

Removendo a aproximação automática do raio de inversão e fixando $R=2$, o resultado da inversão é um conjunto menos disperso e com uma maior variação em relação à média de distância ao observador: $\mu_{\hat{D}} \approx 2.7$ e $\sigma_{\hat{D}} \approx 0.5$. Essa maior variação relativa à distância média associada ao tratamento de casos degenerados pelos algoritmos de fecho convexo resulta em um menor número de falsos positivos, como pode ser visto na Figura 4.5.

Mesmo com essa maior variação relativa, a distância entre os pontos interiores e de fronteira após a inversão ainda é pequena, dificultando a sua separação e criando uma dependência do tratamento de casos degenerados realizada pelo algoritmo de fecho convexo. Para atacar esse problema a inversão exponencial, Equação (4.5), pode ser usada, uma vez que a distância do ponto até o observador após a inversão é inversamente proporcional a uma função exponencial aplicada à distância original do ponto ao observador.

$$
\hat{\mathbf{p}}_{i}=f\left(\mathbf{p}_{i}\right)=\frac{\mathbf{p}_{i}}{\left\|\mathbf{p}_{i}\right\|^{\gamma}}
$$

Usando a inversão exponencial no caso apresentado na Figura 4.3, obtém-se $\mu_{\hat{D}} \approx 2.5$ e $\sigma_{\hat{D}} \approx$ 2.3. O maior desvio padrão indica uma maior dispersão dos dados após a inversão, o que produz melhores resultados ao computar o fecho convexo, como mostrado na Figura 4.6. 


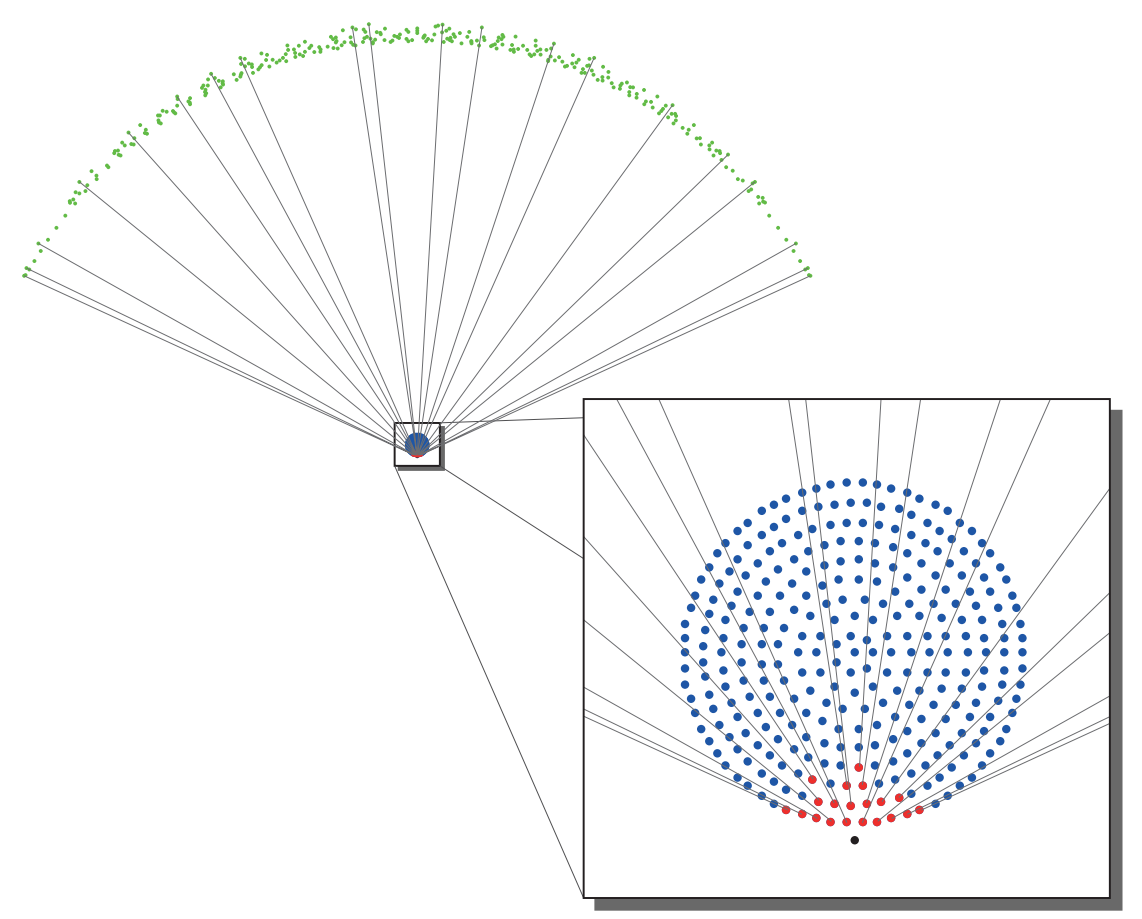

Figura 4.4: Teste com HPR usando inversão esférica e aproximação do parâmetro $R$. Os pontos invertidos (verdes) são posicionados a uma grande distancia do observador, mas com pouco espaçamento entre si, gerando problemas ao computar o fecho convexo. As linhas ligam cada um dos pontos pertencentes ao fecho convexo ao seu correspondente antes da inversão, considerados visíveis a partir de $O$.

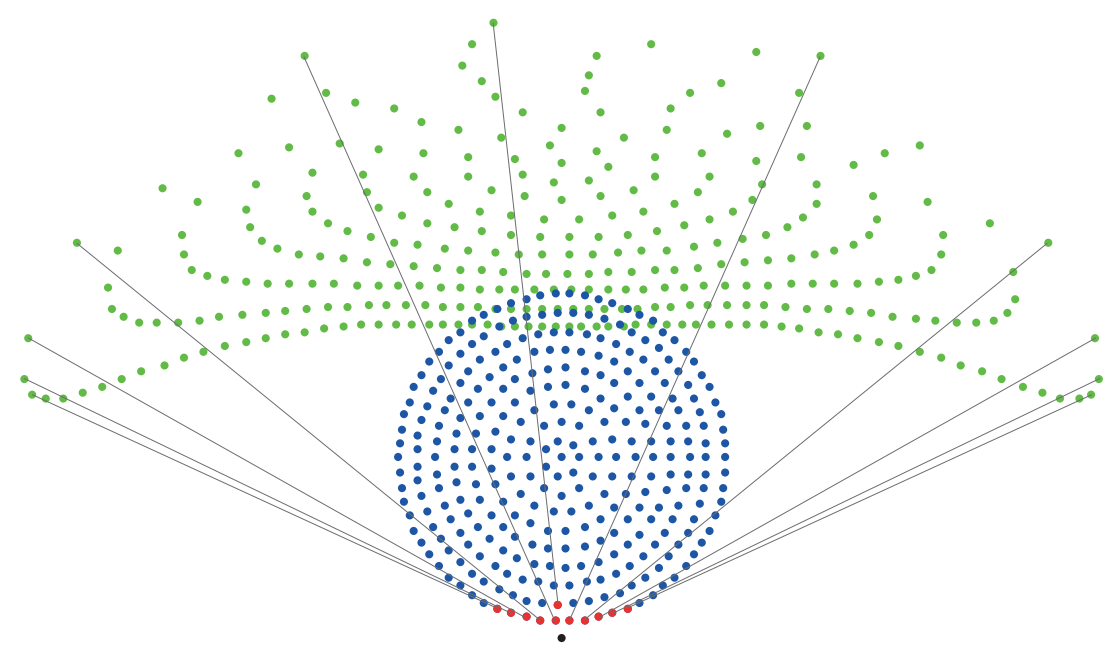

Figura 4.5: Teste com HPR usando inversão esférica e parâmetro $R=2$. Os pontos são invertidos para uma distância menor do observador mas com uma distribuição relativamente mais espaçada, reduzindo o número de falsos positivos.

A partir dos resultados obtidos através desses testes, fica clara a importância da escolha da função de inversão para que dados volumétricos sejam tratados devidamente. Nesse cenário a inversão exponencial, que já era conhecida mas pouco estudada, se destaca exatamente por criar uma maior separação entre os pontos mais próximos ao observador. A Figura 4.7 mostra um 


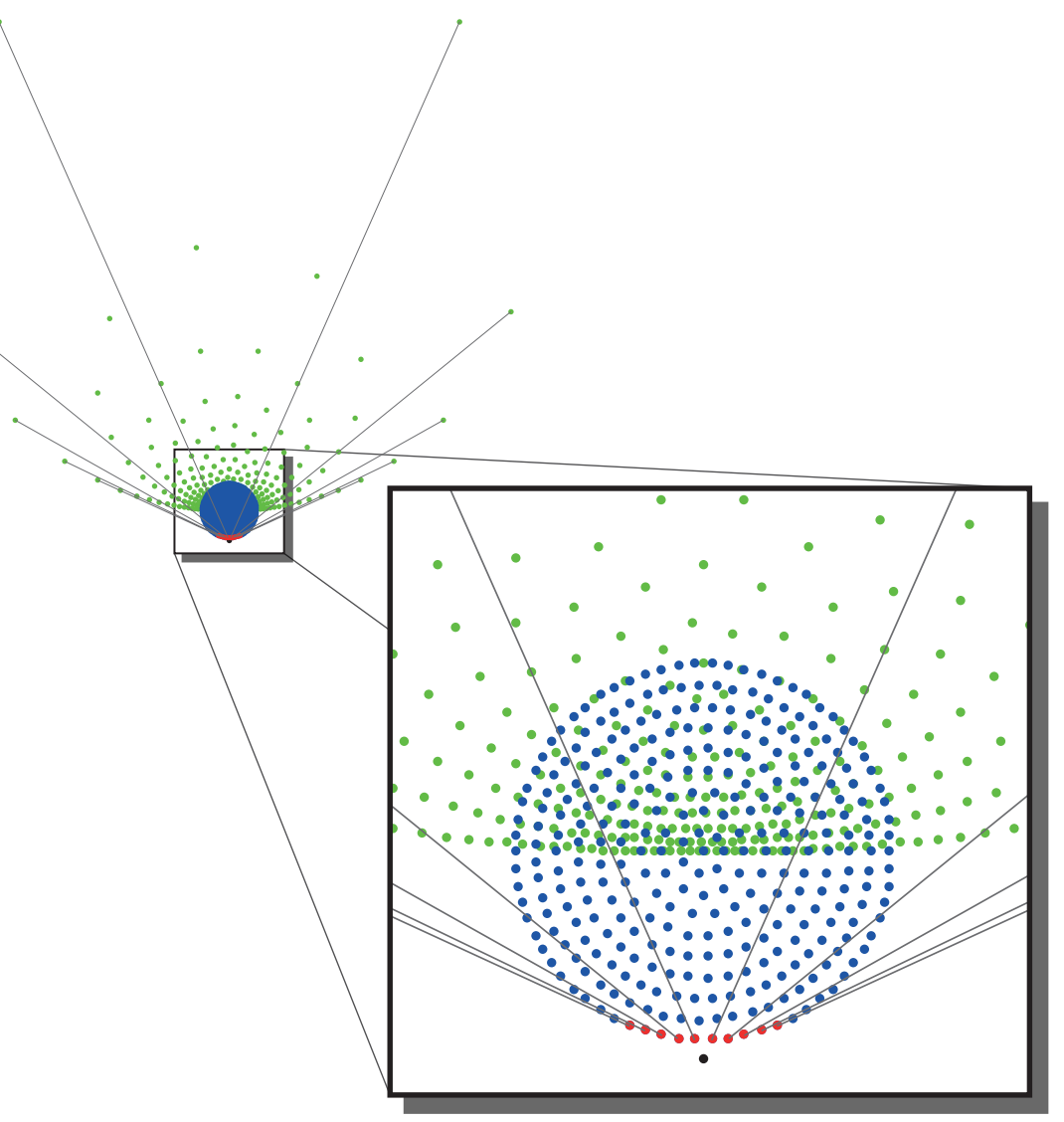

Figura 4.6: Teste com HPR usando inversão exponencial e parâmetro $\gamma=2$. Os pontos mais próximos do observador são invertidos para posições distantes, gerando uma maior distinção entre as camadas de pontos e resultando em um número de falsos positivos praticamente nulo.

gráfico da distância dos pontos até o observador antes e depois da inversão, $D \times \hat{D}$, para os três testes realizados.

A partir do gráfico das distâncias $D \times \hat{D}$ é possível notar a diferença do comportamento da função de inversão exponencial com relação à inversão esférica. Nos dois casos em que a inversão esférica foi aplicada, os pontos são invertidos para uma distância que decresce com a distância original, gerando uma curva que se aproxima de uma reta com coeficiente angular negativo. Na inversão exponencial, a curva obtida assemelha-se a uma função exponencial na forma $f(x)=b^{x}$ com $b<1$, fazendo com que pontos mais próximos ao observador sejam invertidos para uma distância maior dele e pontos mais distantes a uma distância de no mínimo 1 do observador. Isso pode ser observado através do comportamento assintótico da função, que tende para a reta $y=$ 1 quando a distancia original do ponto ao observador tende ao infinito. Considerando o caso volumétrico onde camadas de partículas a partir da fronteira possuem um espaçamento pequeno entre elas, as primeiras camadas seriam invertidas para posições mais distantes do observador e com um grande espaçamento entre elas, pois correspondem à região da função cujo gradiente possui maior módulo. Com isso fica claro que a inversão exponencial é capaz de tratar melhor 


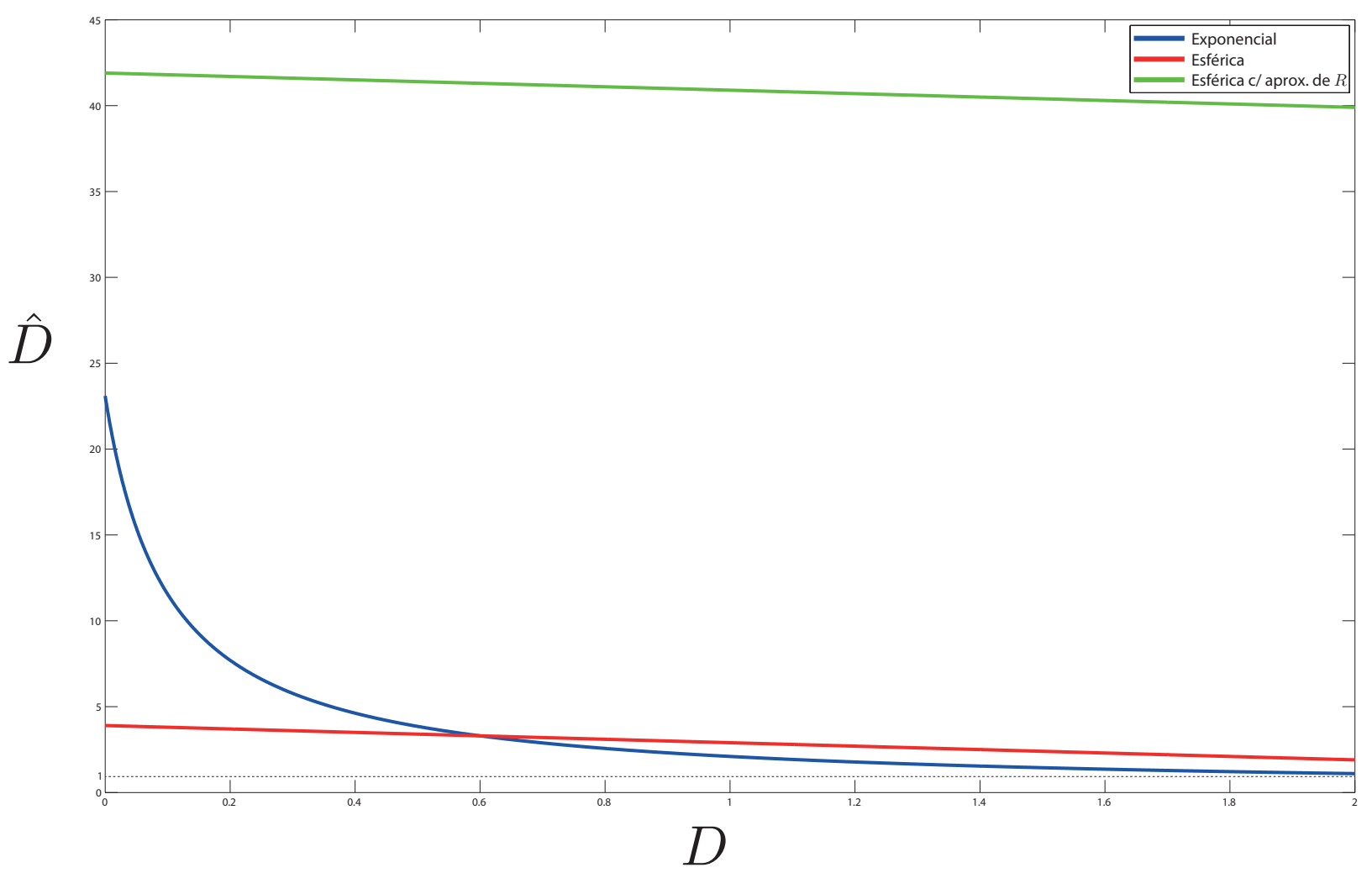

Figura 4.7: Gráfico da distância entre os pontos e o observador antes e depois da aplicação da função de inversão. O gradiente da curva relacionada à inversão exponencial é maior na região mais próxima ao observador, gerando um maior espaçamento dos pontos após a inversão.

dados volumétricos quando comparada à inversão esférica devido à separação dos dados mais próximos ao observador criada por ela.

\subsubsection{Curvatura local}

Como pode ser visto, o operador HPR é capaz de tratar com facilidade casos de superfícies planas ou convexas, mas no caso de superfícies côncavas alguns problemas tendem a surgir. Para entender melhor esses problemas, uma análise da relação entre o operador HPR e a curvatura local foi apresentada no trabalho de Katz et al. [KT13], que usa a Equação (4.6), onde $\gamma<0$, como função de inversão.

$$
\hat{\mathbf{p}}_{i}=f\left(\mathbf{p}_{i}\right)=\left\{\begin{array}{cc}
\mathbf{p}_{i}\left\|\mathbf{p}_{i}\right\|^{\gamma-1} & \mathbf{p}_{i} \neq 0 \\
0 & \mathbf{p}_{i}=0
\end{array}\right.
$$

Essa função de inversão produz os mesmos resultados que a Equação (4.5), mas foi reescrita dessa forma para simplificar a análise da relação entre a curvatura local e os resultados produzidos. No trabalho de Katz et al. [KT13] é dito que a eficiência do operador está relacionada a um limite na curvatura local $\kappa$. Em regiões onde a curvatura é maior que esse limite, o operador HPR passa 
a apresentar casos de falsos negativos. Então foi proposto o Lema 4.1, que relaciona o resultados do operador HPR, os pontos visíveis de fato e a curvatura local.

Lema 4.1. Um ponto $\mathbf{p} \in\left\{H P R_{\gamma}(P)\right\}$ se pé visível e a curvatura $\kappa$ satisfaz:

$$
\kappa<\frac{\gamma(1-\gamma) \operatorname{sen}(\beta)\left(\cos ^{2}(\beta)-\gamma \operatorname{sen}^{2}(\beta)\right)}{d\left(\gamma^{2} \operatorname{sen}^{2}(\beta)+\cos ^{2}(\beta)\right)^{\frac{3}{2}}}
$$

Esse lema indica que o operador HPR não é capaz de obter resultados satisfatórios caso a curvatura $\kappa$ seja maior que um certo limite. Logo, é necessário fazer um tratamento especial em regiões com concavidades de modo a reduzir o número de falsos negativos produzidos. $\mathrm{O}$ Apêndice A traz a prova desse lema, como apresentada por Katz et al. 

O método proposto e descrito no Capítulo 4 foi implementado usando Matlab ${ }^{\circledR}$ para geração de exemplos ilustrativos em duas dimensões e usando $\mathrm{C}++$ para testes de desempenho e com grande volume de dados. A implementação em $\mathrm{C}++$ é dividida em duas aplicações: uma ferramenta exploratória que permite abrir um conjunto de dados estático e realizar diversos testes do método sobre ele, e uma ferramenta para processamento em lote que trabalha aplicando o método em um conjunto de dados variante no tempo. Ambas utilizam OpenMP ${ }^{\circledR}$ para tirar proveito de computadores com múltiplos núcleos de processamento e assim acelerar o tratamento dos dados. A ferramenta exploratória também utiliza $\mathrm{Qt}^{\circledR}$ para a interface com o usuário. Sendo assim, os resultados e comparações são discutidos na seguinte ordem: testes em duas dimensões na Seção 5.1, exemplos estáticos em três dimensões e testes dinâmicos em três dimensões, ambos na Seção 5.2.

\subsection{Duas dimensões}

Para realizar uma comparação entre os métodos estudados e o proposto, foi realizada um conjunto de testes em duas dimensões utilizando dados de diferentes fontes. Os testes apresentados utilizam dados vindos do trabalho de Marrone et al. [MCLTG10], Bell et al. [BCG89] e do simulador de código aberto SPHysics.

\subsubsection{Marrone et al.}

O primeiro conjunto de dados apresentado foi obtido através de uma figura contida no trabalho de Marrone et al. [MCLTG10] que traz dois detalhes de uma simulação SPH em duas dimensões 
como principal exemplo ilustrativo. Este é um exemplo que apesar de pequeno, traz diversos casos críticos para métodos de detecção de fronteira: cavidades, regiões de alta curvatura, gotas e filetes.

O primeiro método a ser aplicado nesse conjunto de dados foi o de Müller et al. [MCG03], cujo resultado pode ser visto na Figura 5.1. Este é um método que, como visto anteriormente, requer um ajuste manual do parâmetro usado como limiar e depende de uma boa distribuição das partículas. Os resultados obtidos mostram uma boa detecção da borda em geral, principalmente em cavidades, mas também um alto número de falsos positivos em regiões onde a densidade de partículas é menor, e a incidência de falsos negativos em algumas poucas regiões. O maior problema desse método é que para sanar o problema dos falsos negativos, o limiar usado na função característica deve ser mudado, o que faz aumentar o número de falsos positivos uma vez que mais partículas serão consideradas como pertencentes à fronteira. Em geral, não há um controle local para definição da fronteira, uma vez que a função característica é calculada de acordo com a vizinhança de cada partícula mas o limite aplicado é global. Alterar o limiar usado para reduzir os falsos positivos também causa problemas, pois aumenta significativamente o número de falsos negativos.
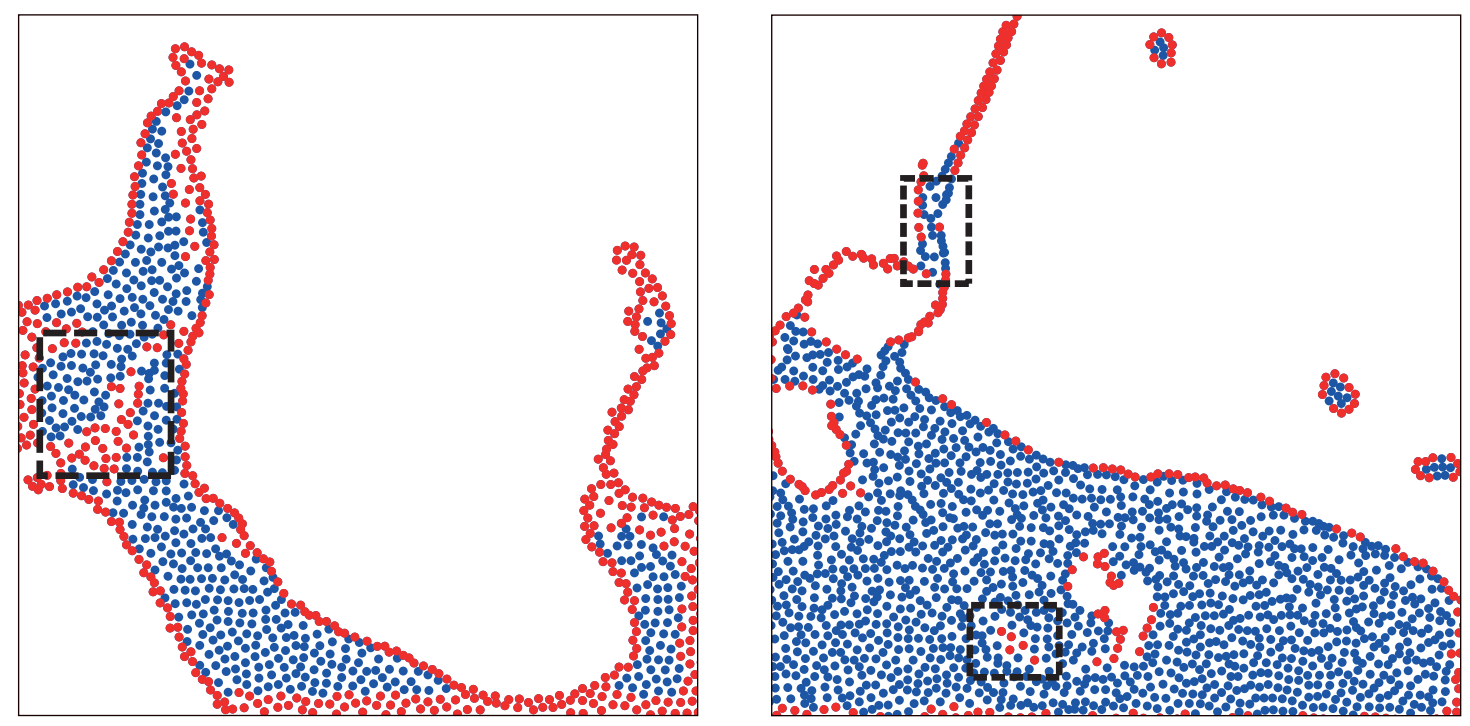

Figura 5.1: Resultado do método de Müller et al. [MCG03] no conjunto de dados extraído de [MCLTG10]. A regiões marcadas apresentam um elevado número de falsos positivos e negativos.

O método proposto por He et al. $\left[\mathrm{HLW}^{+} 12\right]$, apresenta um número praticamente nulo de falsos positivos, como pode ser visto na Figura 5.2. Em compensação o número de falsos negativos é bastante alto, principalmente em cavidades e filetes. Isso é causado pelo fato de que a assimetria $A s y_{i}^{f}$ dessas regiões é relativamente pequena. No caso dos filetes marcados na Figura 5.2 a vizinhança é simétrica, pois há deficiência de partículas em ambos os lados do filete. No caso de cavidades, partículas posicionadas em posições opostas em uma mesma cavidade contribuem para a redução na assimetria. Esses casos poderiam produzir melhores resultados caso a informação de densidade seja usada, porém esta informação não está disponível para esse conjunto de dados. A dependência da informação de densidade das partículas é um inconveniente que restringe o uso 
desse método apenas para simulações SPH, impossibilitando que ele seja aplicado em conjuntos de dados de fontes variadas.
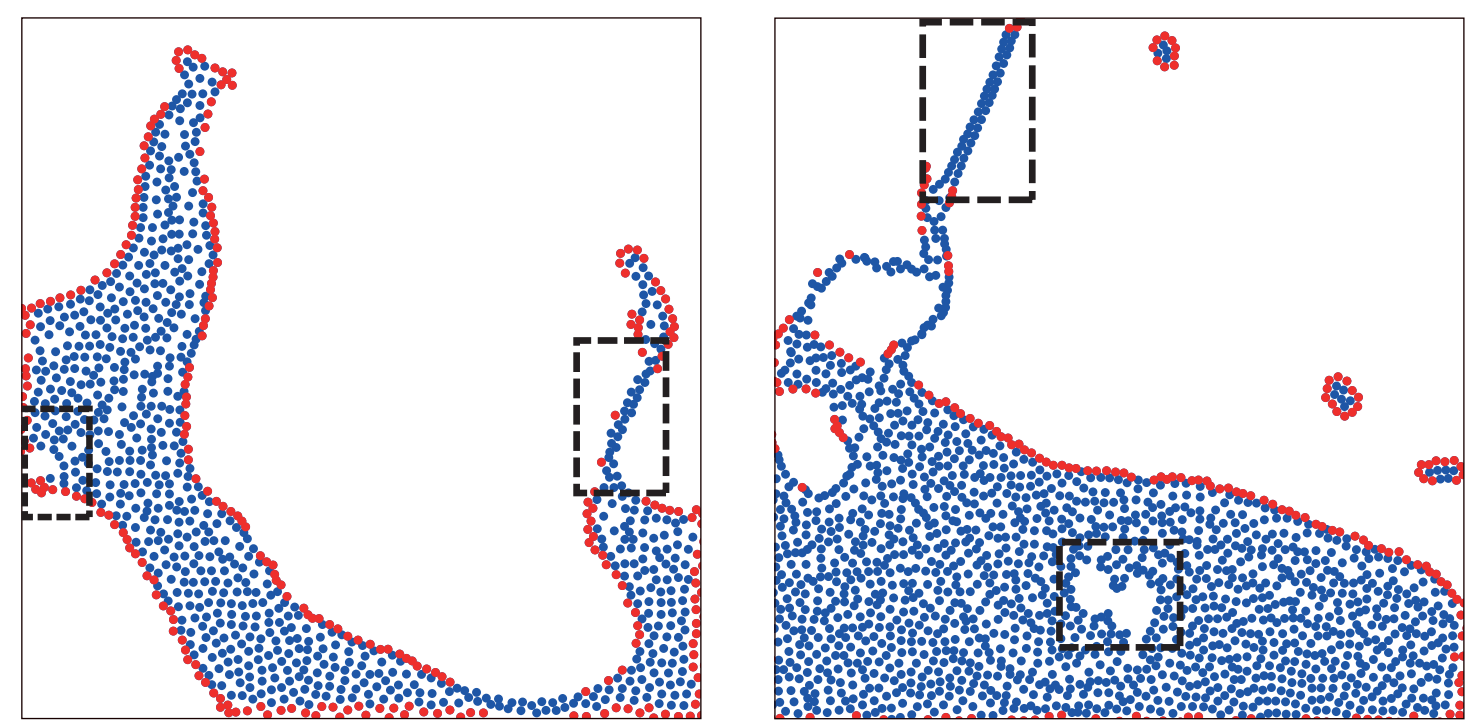

Figura 5.2: Resultado do método de He et al. $\left[\mathrm{HLW}^{+} 12\right]$. As regiões marcadas apresentam um elevado número de falsos negativos pois a assimetria das partículas é baixa.

O trabalho de Marrone et al. [MCLTG10], origem dos dados usados como exemplo nessa seção, possui uma forte dependência da qualidade das normais computadas a partir do conjunto de dados para que a região de sondagem produza bons resultados. O resultado obtido através desse método se aproxima bastante daquele mostrado por Marrone et al., com algumas diferenças em concavidades, onde a direção das normais é bastante sensível e pode variar dependendo do método e parâmetros usados para computá-las. Outro ponto a ser considerado sobre esse trabalho é a separação dos grupos $\mathbb{E}, \mathbb{B}$ e $\mathbb{I}$ usando a Equação (2.7), onde os limiares de 0.2 e 0.75 não são adequados para todos os casos possíveis como o próprio autor afirma. Então, nesse método é necessário o ajuste manual desses dois valores para que a primeira parte do método proposto produza bons resultados. Os resultados obtidos através desse método são mostrados na Figura 5.3.

Usando o método de Dilts [Dil00] os resultados obtidos são consistentes exceto por alguns casos esparsos de falsos negativos e uma cavidade que apresentou problemas em praticamente todos os métodos testados, como apresentado na Figura 5.4. Uma solução alternativa para esses casos é alterar o raio dos círculos a serem analisados pelo método de $1 h$ para um valor menor, o que permite que os falsos negativos apontados sejam detectados, mas que pode gerar falsos positivos em outras regiões. Este é um problema semelhante àquele encontrado com o método de Müller et al., onde não há um controle local para definição da fronteira. Em geral, esse método apresenta resultados com boa qualidade na maioria dos casos e a intuição por trás dele é simples, mas a sua complexidade de implementação e computacional podem tornar seu uso impraticável em alguns casos. 

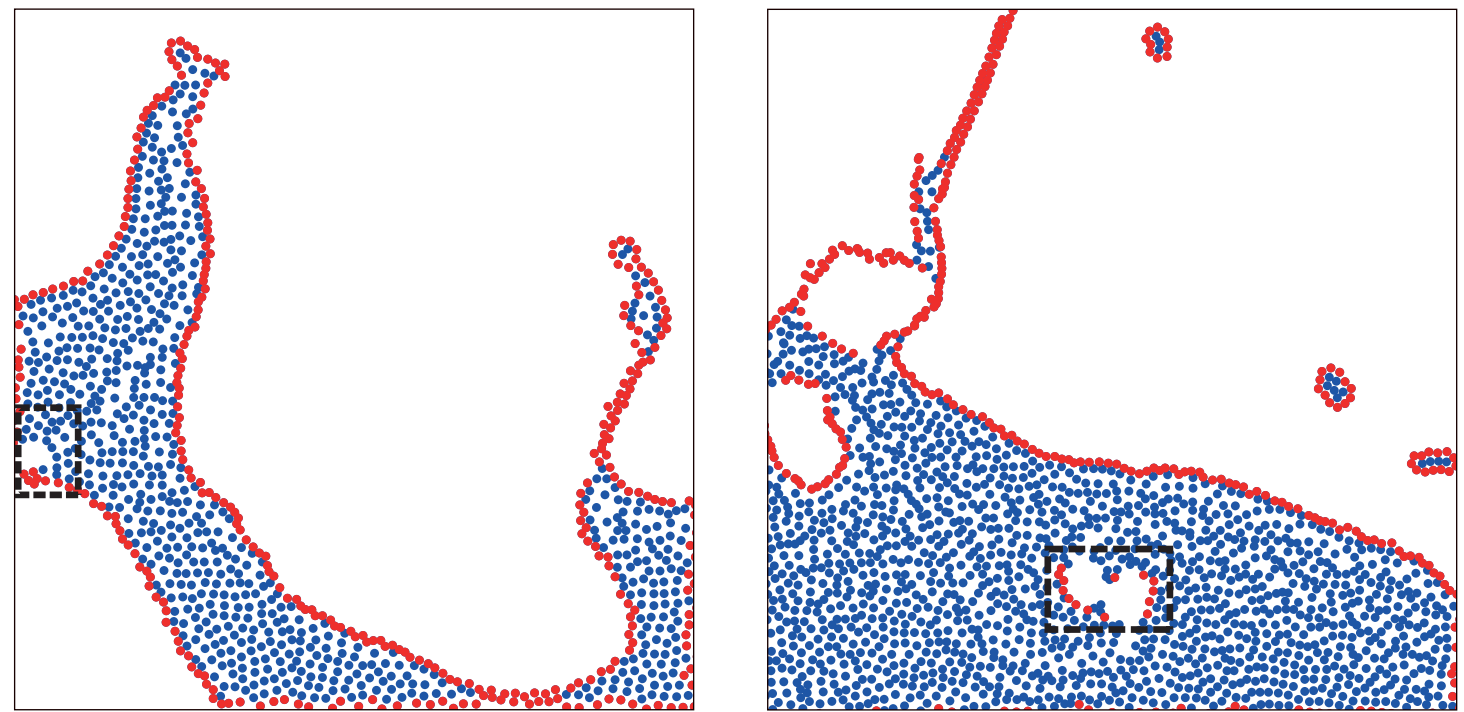

Figura 5.3: Resultado do método de Marrone et al. [MCLTG10], bastante próximo daquele mostrado pelo autor mas com algumas diferenças em concavidades.
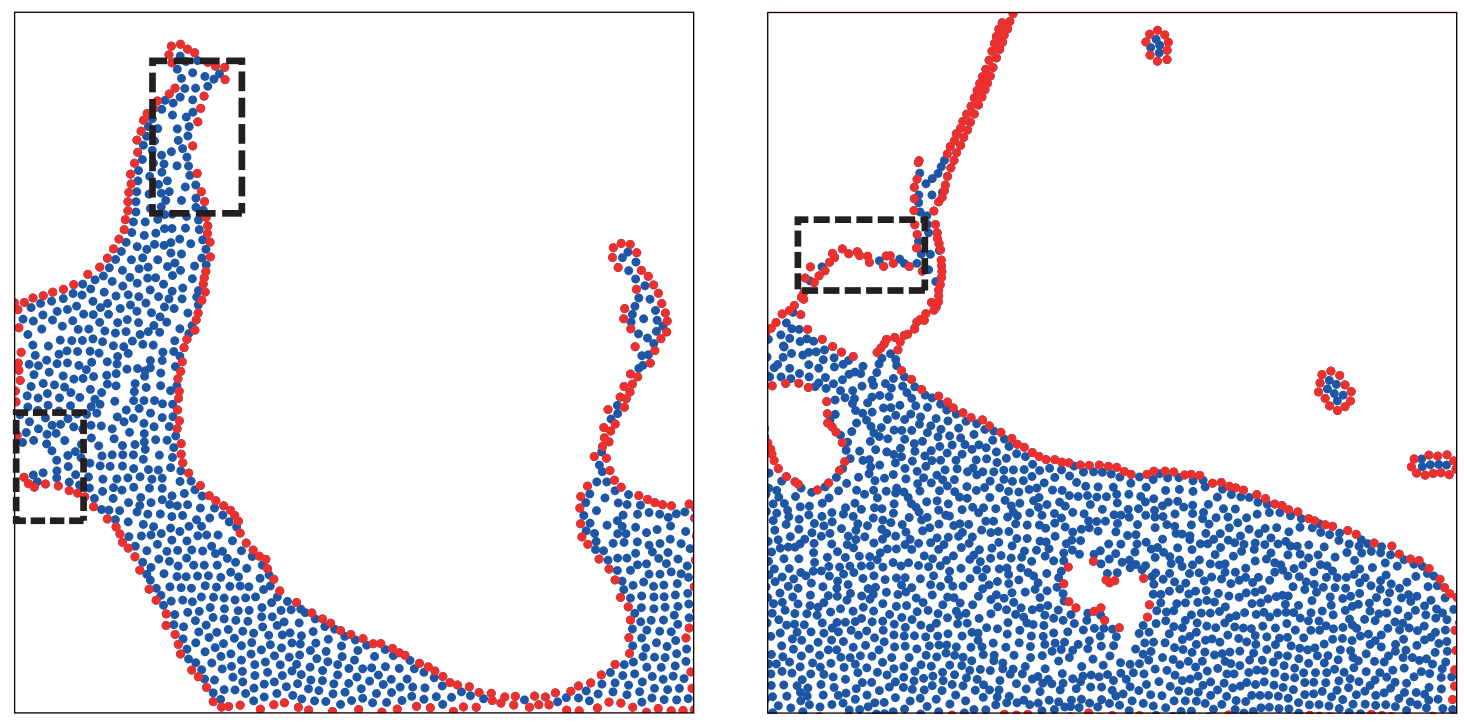

Figura 5.4: Resultado do método de Dilts [Dil00]. Nas regiões marcadas podem ser encontrados falsos negativos em regiões com baixa curvatura e em uma concavidade que gera problemas na maioria dos métodos testados.

A Figura 5.5 mostra o resultado do protótipo feito em Matlab ${ }^{\circledR}$ utilizando a escolha de observadores através da grade de busca descrita na Seção 4.1.1. Os resultados produzidos são semelhantes ao do trabalho de Dilts: poucos falsos positivos, alguns problemas em cavidades e um número praticamente nulo de falsos negativos. Porém, os problemas em cavidades são mais comuns, causados pelo mal posicionamento de observadores que são localizados no centro de células da grade de busca. Em alguns casos onde a cavidade localiza-se parcialmente em um conjunto de células, mas não há uma célula totalmente vazia localizada dentro da cavidade, um observador não será adicionado a ela, como pode ser visto na Figura 5.6. 

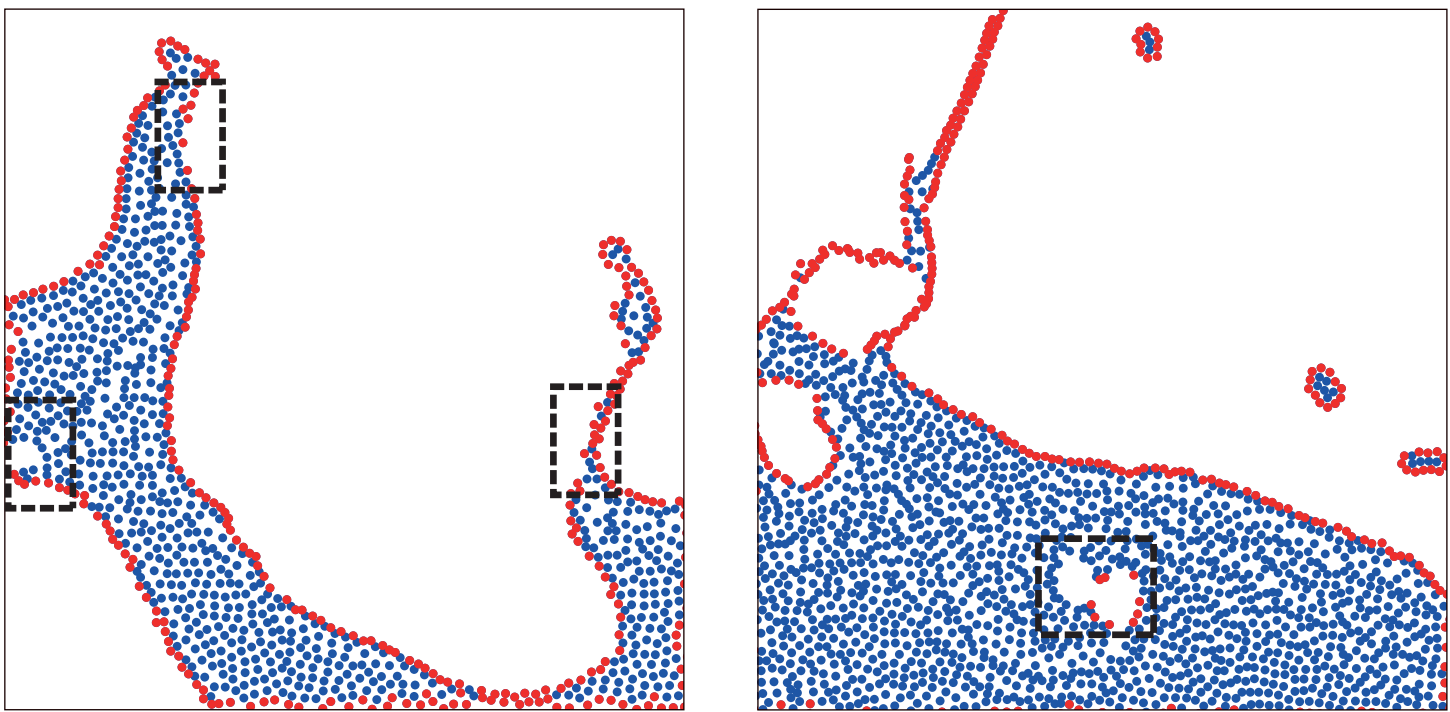

Figura 5.5: Resultado do método proposto usando escolha de observadores através da grade de busca. As regiões marcadas apresentam casos de falsos negativos, causados em sua maioria pelo posicionamento inadequado dos observadores dentro de cavidades.
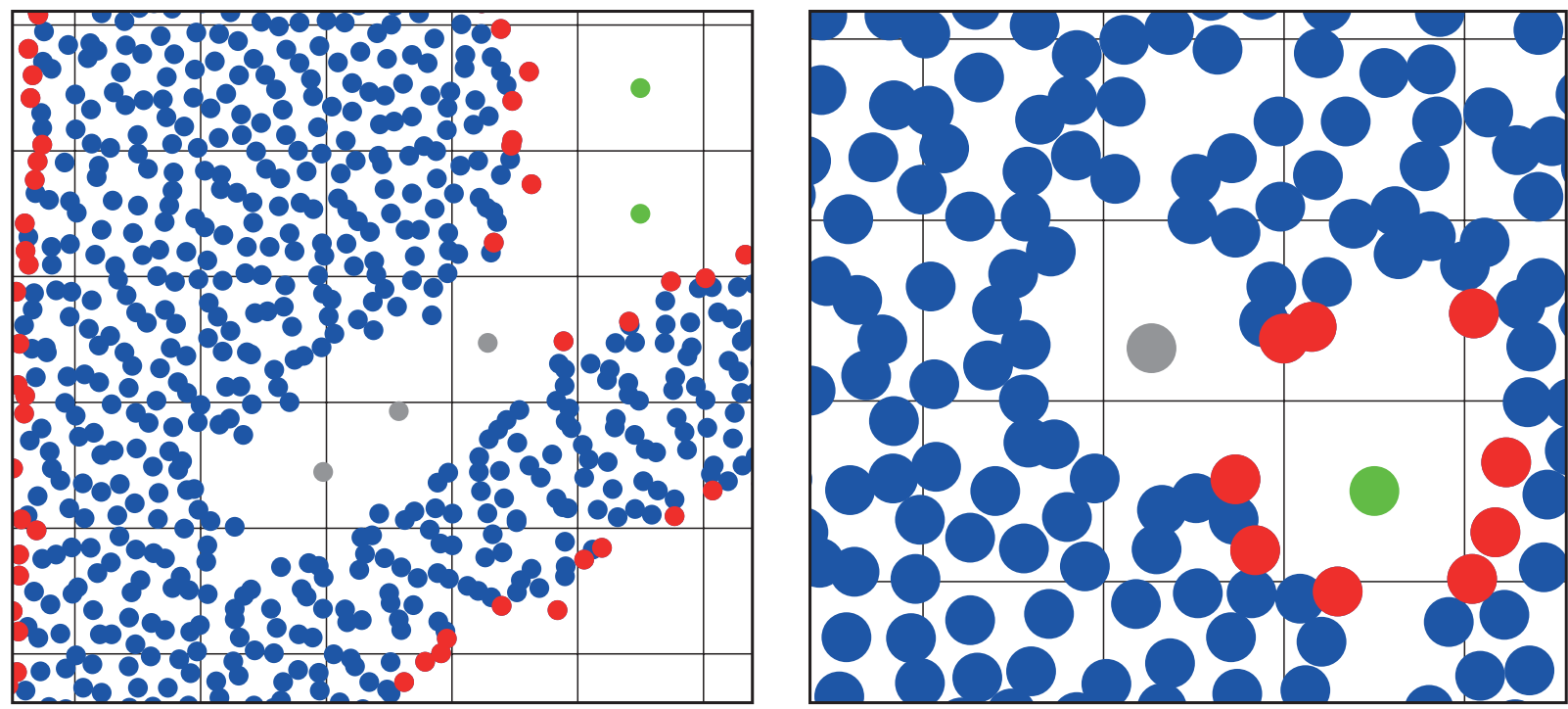

Figura 5.6: Problema causado pelo mal alinhamento entre a grade de busca e os dados. Os pontos em verde representam os observadores escolhidos através da grade, os vermelhos representam a fronteira detectada e os cinzas representam pontos onde seriam necessários observadores adicionais para uma detecção adequada da fronteira.

A ocorrência do problema de posicionamento de observadores através da grade de busca motivou o desenvolvimento da escolha de observadores usando o deslocamento do centroide. Este produz um conjunto de observadores mais coerente e menos dependente de fatores que não podem ser controlados como o alinhamento entre a grade de busca e os dados. A Figura 5.7 mostra os resultados obtidos com a escolha de observadores através do deslocamento do centroide e as melhorias em relação ao resultado usando a grade de busca. 

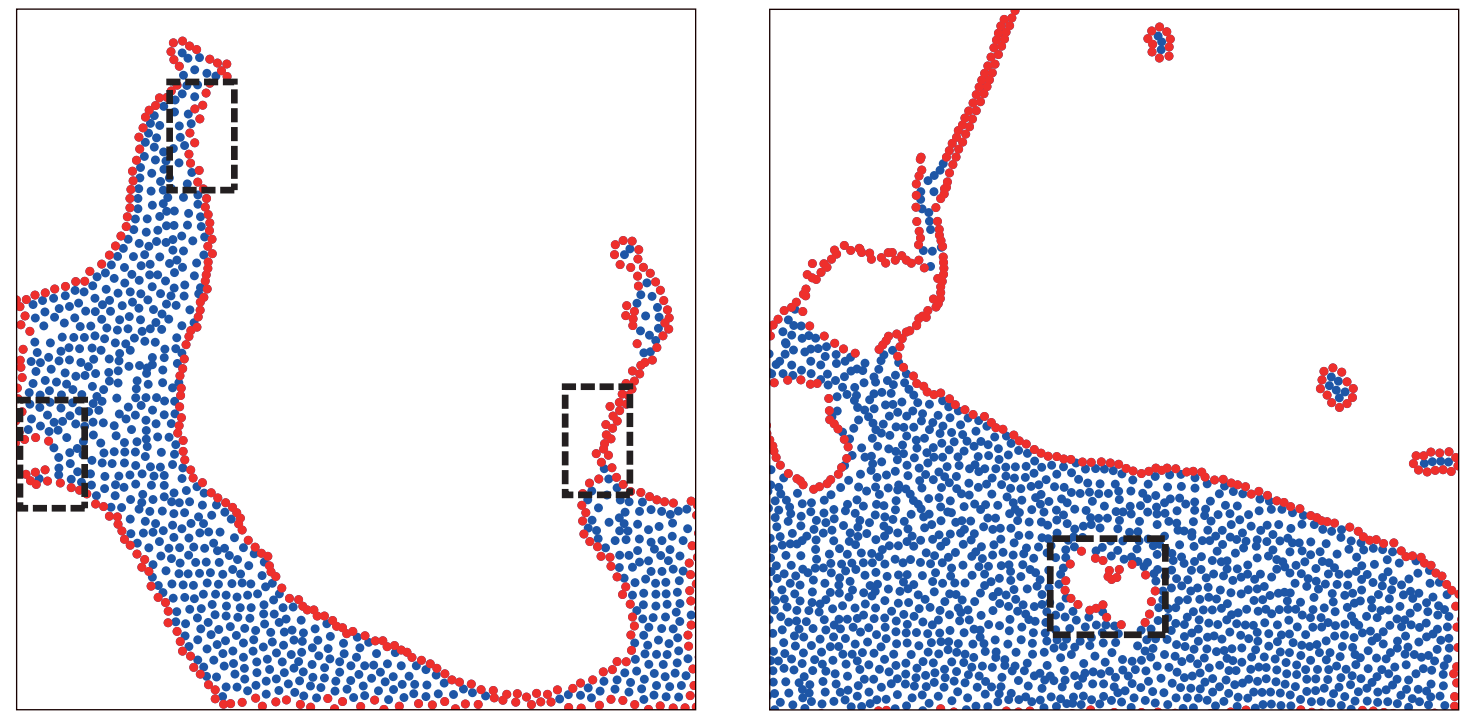

Figura 5.7: Resultado do método proposto usando escolha de observadores através do deslocamento do centroide. As regiões marcadas são as mesmas da Figura 5.5 e mostram a melhoria nos resultados.

\subsubsection{Bell et al.}

Um teste originalmente proposto por Bell et al. [BCG89] e relativamente comum na literatura sobre superfícies de nível, principalmente na área de física computacional, usa um vórtice em duas dimensões para analisar o comportamento da superfície em casos extremos. A geometria inicial consiste em um círculo com raio $r=1.5$, centrado em $(0.5,0.75)$ em um domínio quadrado unitário. É aplicado um campo de velocidades dado pela Equação (5.1) com passo de tempo $\Delta t=0.01$. Para aplicar os métodos estudados, o círculo inicial é preenchido com partículas que são transportadas pelo campo de velocidades usado, nenhuma força adicional de atração ou repulsão entre partículas é aplicada.

$$
\mathbf{v}(x, y)=2\left(\operatorname{sen}^{2}(\pi x) \operatorname{sen}(\pi y),-\operatorname{sen}^{2}(\pi y) \operatorname{sen}(\pi x)\right)
$$

Nesse trabalho esse mesmo teste foi usado para avaliar a detecção das partículas de fronteira pelos diferentes métodos estudados. Todos os métodos estudados apresentaram problemas devido à má distribuição das partículas, com sobreposição e formações de padrões em forma de estrias. Esses problemas ocorrem nesse exemplo pelo fato de se ter aplicado um campo de velocidades predefinido em todas as partículas, sem forças de atração ou repulsão entre elas. As técnicas que apresentaram mais problemas foram as de Müller et al., He et al. e Marrone et al., principalmente na região esquerda do conjunto, como pode ser observado na Figura 5.8. 


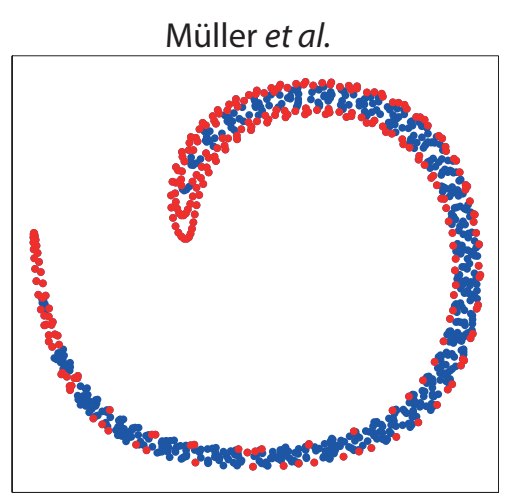

Marrone et al.

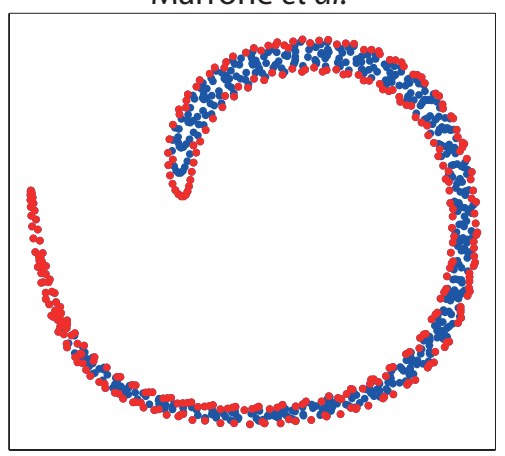

He et al.

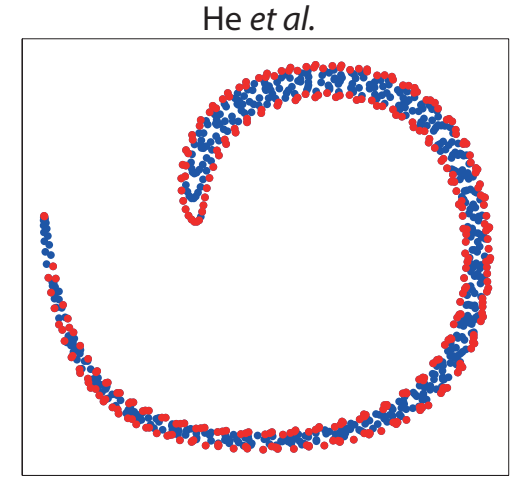

Dilts

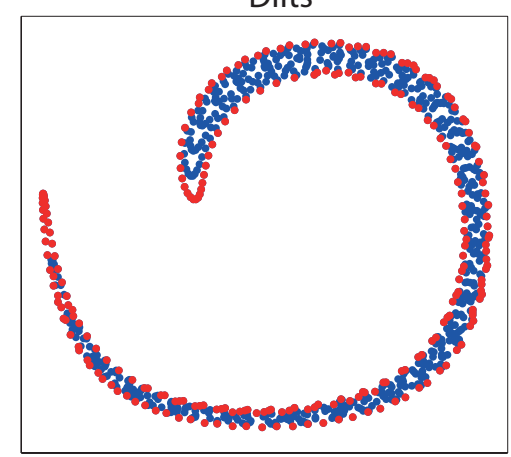

Proposto (Grade)

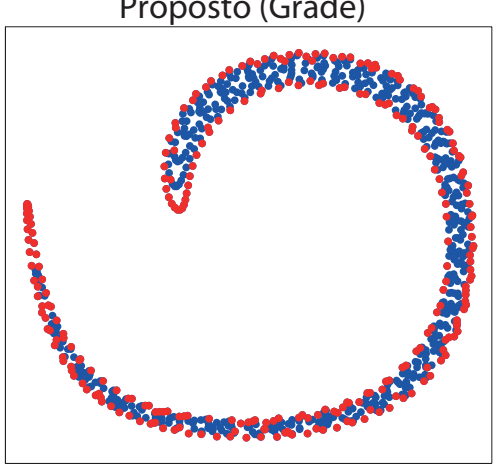

Proposto (Centroide)

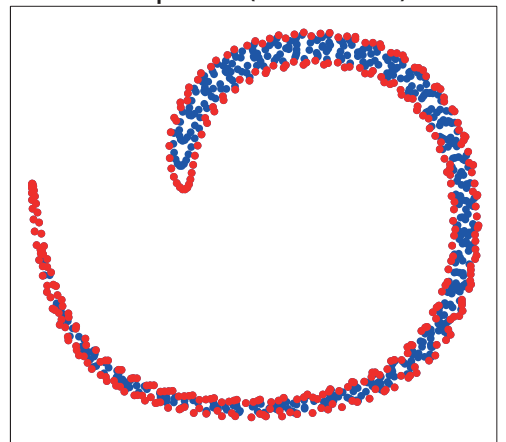

Figura 5.8: Resultados obtidos no teste usando o vórtice proposto por Bell et al. [BCG89]. Todos os métodos estudados e o proposto apresentaram problemas, especialmente os métodos de Müller et al., He et al. e Marrone et al. na região mais à esquerda do conjunto.

\subsubsection{SPHysics}

O último teste realizado em dados bidimensionais utiliza dados provenientes de simulações SPH realizadas através do SPHysics ${ }^{1}$. Este é um simulador de código aberto desenvolvido através de um esforço conjunto entre pesquisadores da Universidade Johns Hopkins (EUA), Universidade de Vigo (Espanha) e da Universidade de Manchester (Reino Unido), entre outras. Das diferentes versões disponíveis foi usada a DualSPHysics ${ }^{2}\left[\mathrm{GGRC}^{+} 12, \mathrm{GGCR}^{+} 12, \mathrm{CDB}^{+} 11\right]$, desenvolvida em C/C++, $\mathrm{Cuda}^{\circledR}$ e Java $^{\mathrm{TM}}$.

Foram extraídos dados de um passo de uma simulação de quebra de barragem usando um fluido de baixa viscosidade e nesse conjunto foram aplicados os métodos estudados e o proposto. Esses dados foram escolhidos pois contém casos críticos: distribuição irregular, gotas, filetes, cavidades e uma concavidade profunda.

Os métodos originados em computação gráfica, Müller et al. e He et al., apresentaram problemas relacionados à má distribuição das partículas em algumas regiões. A distribuição irregular das partículas gerou nesses casos diversos falsos negativos como pode ser visto na primeira linha da Figura 5.9. No caso do método de Müller et al., houve também um alto número de falsos positivos na região direita da cavidade presente nos dados. Já o método de He et al. apresentou mais falsos negativos no filete na parte superior esquerda do conjunto. Os elevados níveis de erro desses

\footnotetext{
${ }^{1}$ http://www. sphysics.org/

${ }^{2}$ http://dual.sphysics.org/
} 
métodos podem impedir o seu uso quando há necessidade de resultados consistentes, principalmente devido aos falsos negativos em regiões planas que gerariam grandes espaços em branco na fronteira do fluido.

Os resultados obtidos através dos métodos provenientes da literatura de física computacional, Marrone et al. e Dilts, foram mais consistentes e apresentaram menos problemas localizados. Nesses casos até mesmo a classificação manual de uma partícula é problemática, pois diversos casos são ambíguos e podem levar a diferentes interpretações. 

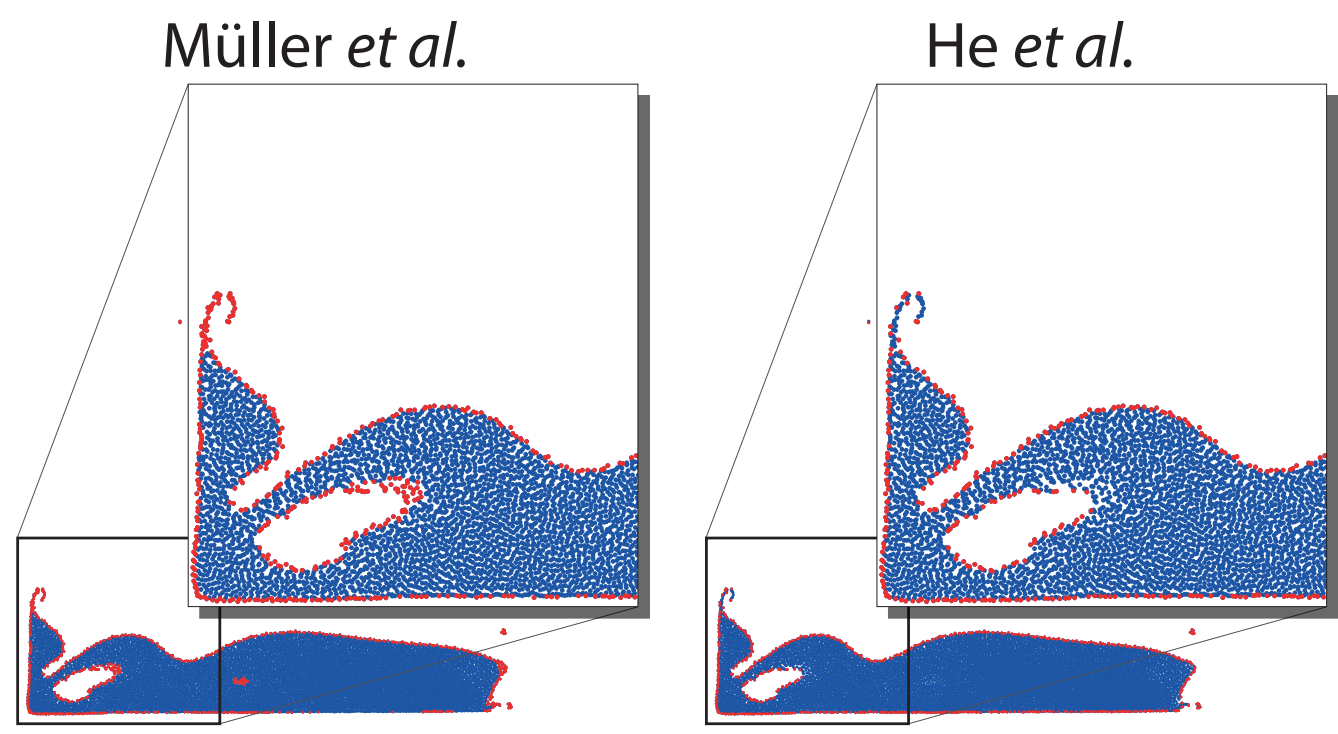

Marrone et al.

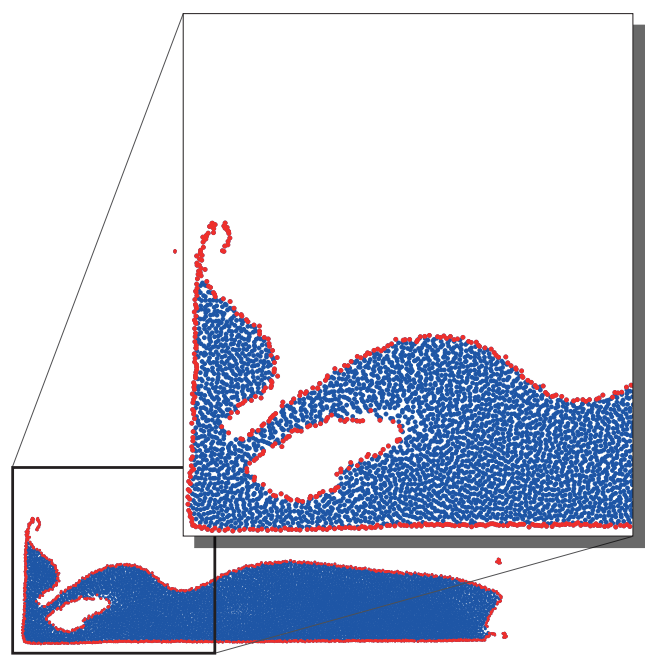

Dilts
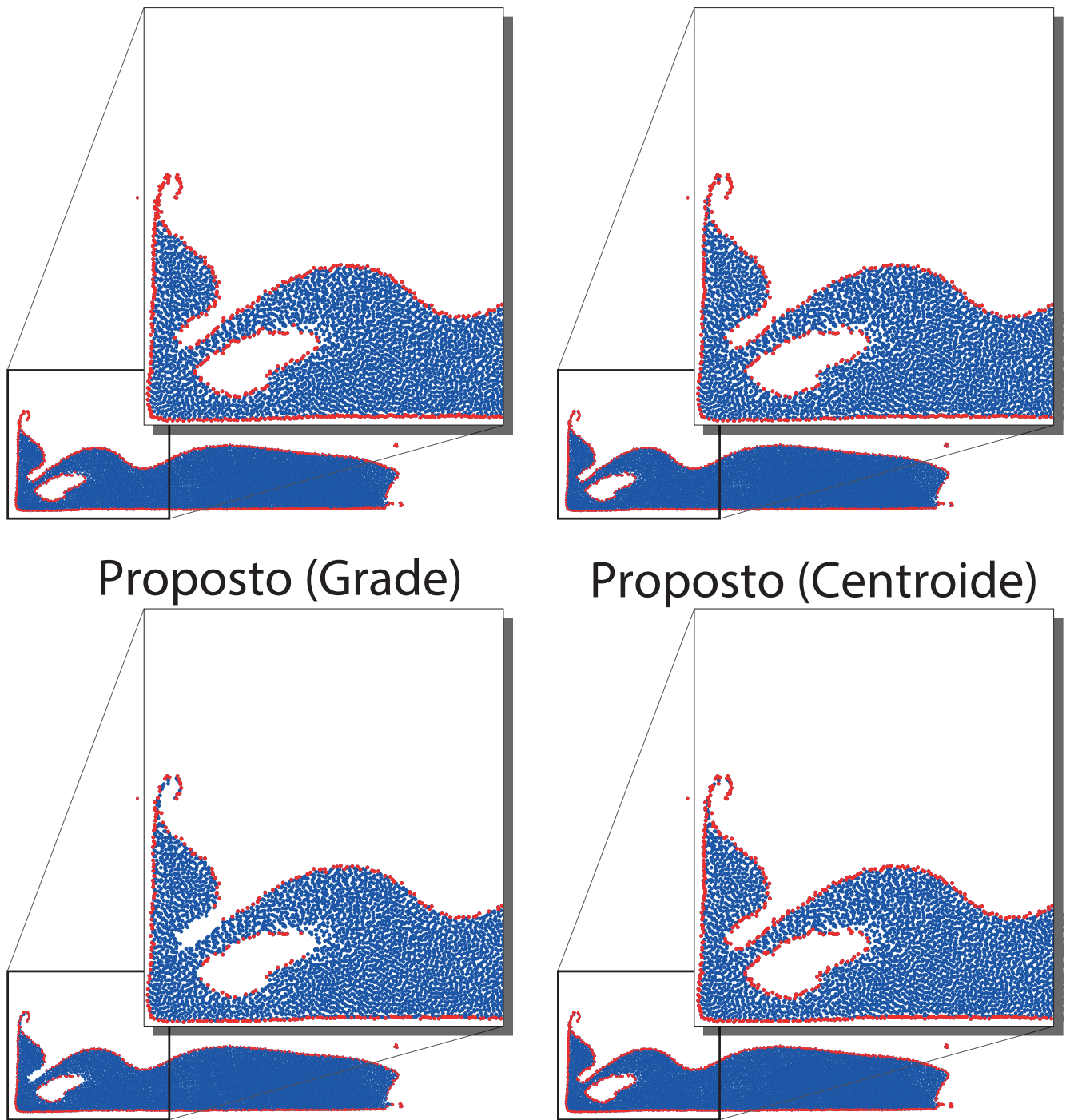

Figura 5.9: Resultados obtidos para o conjunto de dados produzido com o SPHysics. As regiões em destaque apresentam a maior variação nos resultados para as diferentes técnicas aplicadas, exceto no caso do método de Müller et al. onde há um alto número de falsos positivos na região inferior direita do conjunto. 


\subsection{Três dimensões}

Os testes em três dimensões foram realizados através da aplicação desenvolvida em C++ com diferentes conjuntos de dados, dentre eles dados de malhas estáticas e de simulações SPH. Nas figuras apresentadas nessa seção, esferas azuis representam partículas internas ou não classificadas, os observadores a serem usados na aplicação local do operador HPR são representados por esferas verdes e partículas classificadas como pertencentes à fronteira são representadas por esferas amarelas. Para alguns casos também é mostrado um conjunto de referência para análise dos resultados, composto por esferas vermelhas, que representa a solução considerada ideal para o conjunto de dados em questão. Nesses testes o método de Haque et al. [HD07] foi deixada de fora devido à sua alta complexidade de implementação, o que inviabiliza sua implementação para posterior comparação. Outro detalhe é a adição de uma melhoria ao método de Marrone et al. [MCLTG10]: o cálculo das normais é feito utilizando PCA além do gradiente da função característica, então é feita também uma comparação entre as duas possibilidades para esse método.

\subsubsection{Exemplos estáticos}

Os três principais exemplos estáticos utilizados são malhas bastante conhecidas nas áreas de computação gráfica e processamento geométrico: Stanford Bunny, Armadillo e Asian Dragon. Uma vez que essas malhas possuem apenas dados superficiais, foi necessário modificá-las para que passassem a possuir pontos internos como um conjunto de dados volumétricos comum. Essa modificação foi feita através da ferramenta Gmsh, de autoria de Geuzaine et al. [GR09], que é amplamente usada nas áreas de geração de malhas e elementos finitos. Essa ferramenta foi usada para geração de uma malha de tetraedros que ocupa todo o volume interno da malha com tetraedros compostos por arestas de comprimento $l \approx h$, onde $h$ é o equivalente ao raio de suavização de uma simulação SPH e é fixado para cada malha baseado no espaçamento médio dos vértices originais. A partir da malha de tetraedros, as arestas foram eliminadas, a informação da posição dos vértices usada como posição das partículas no sistema e vértices da malha original usados como referência para contagem de falsos positivos e falsos negativos. Os dados referentes às medidas de tempo são sumarizados ao final dessa seção nas Tabelas 5.1 e 5.2, e as contagens de falsos positivos e negativos na Tabela 5.3.

Stanford Bunny O conjunto de dados produzido a partir do Stanford Bunny possui 114137 partículas no total das quais 35688 pertencem à fronteira do conjunto. A Figura 5.10 mostra esse conjunto e na Figura 5.11 pode ser observado o conjunto de referência representado em vermelho.

Aplicando a técnica desenvolvida usando grade, são produzidos 4044 observadores em torno do conjunto. Após aplicação do operador HPR local a fronteira obtida é visualmente aceitável, mas essa é uma avaliação inadequada devido à oclusão causada pela sobreposição das esferas que representam as partículas. Então, através da contagem de falsos positivos e negativos, observa-se 


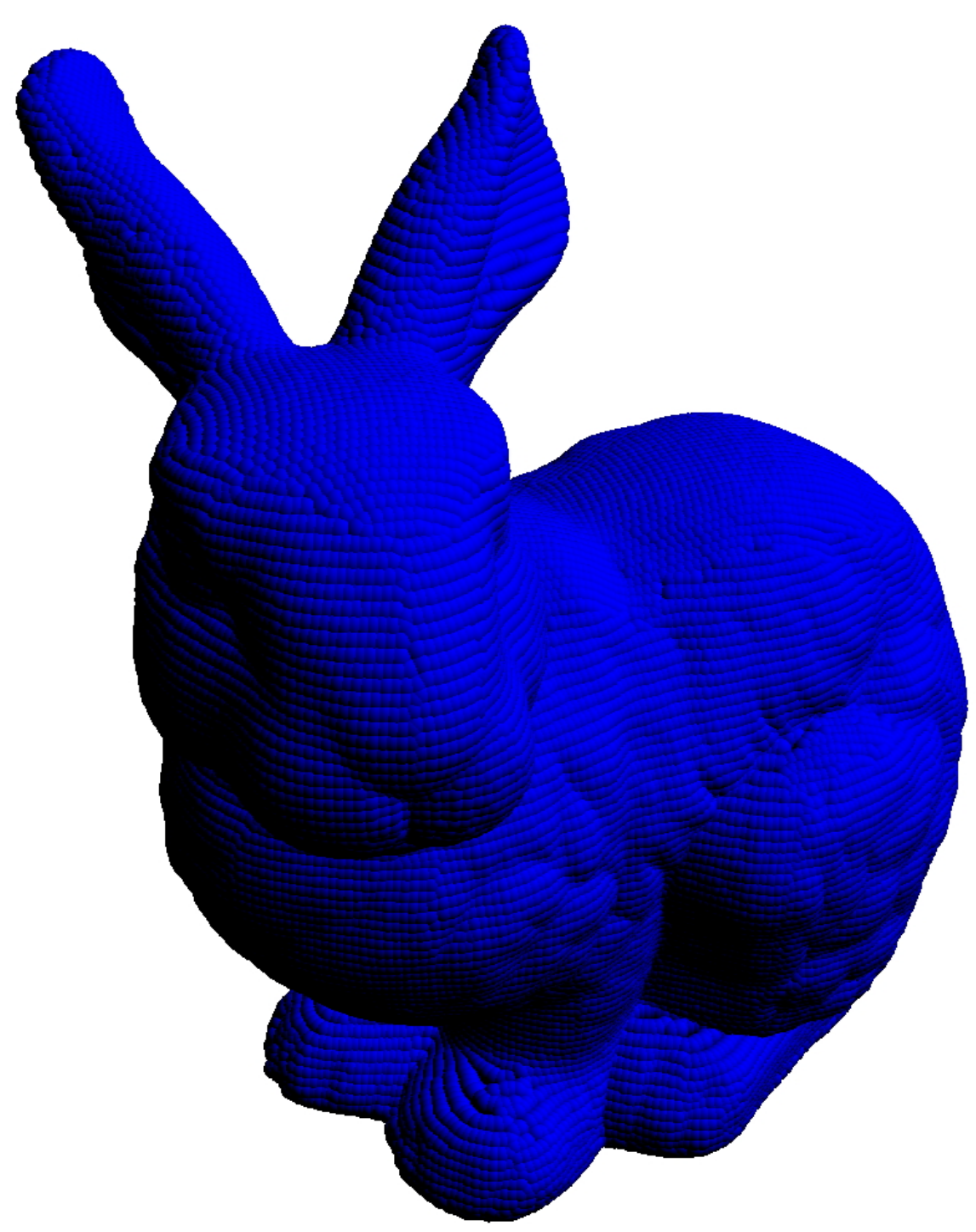

Figura 5.10: Conjunto de dados produzido a partir do modelo Stanford Bunny.

que foram produzidos 0 falsos positivos e 2534 falsos negativos, o que representa uma fronteira sem intrusões nas regiões internas mas com aberturas que representam $7.1 \%$ da fronteira de referência. A Figura 5.12 mostra os resultados obtidos através dessa técnica.

A versão baseada no deslocamento do centroide da vizinhança das partículas produz um número de observadores quase 9 vezes maior, 34506 no total, e com um espaçamento menor e mais regular como mostrado na Figura 5.13. Com o aumento do número de observadores, o tempo de execução cresce consideravelmente, como mostrado na Tabela 5.1. Quanto à taxa de erros, há uma redução no número de falsos negativos para 247 (0.69\% do total) mas há também o surgimento de 1 falso positivo isolado que nesse caso representa menos de $0.002 \%$ da fronteira.

Também foram aplicadas as técnicas de outros autores a esse conjunto de dados, como pode ser visto na Figura 5.14. A técnica de Marrone et al. [MCLTG10] possui uma forte dependência da qualidade das normais utilizadas, por isso foram usados PCA (Seção 3.3) e o gradiente da função característica. A técnica de Marrone et al. não produz falsos positivos, apenas 3922 (10.98\%) fal- 

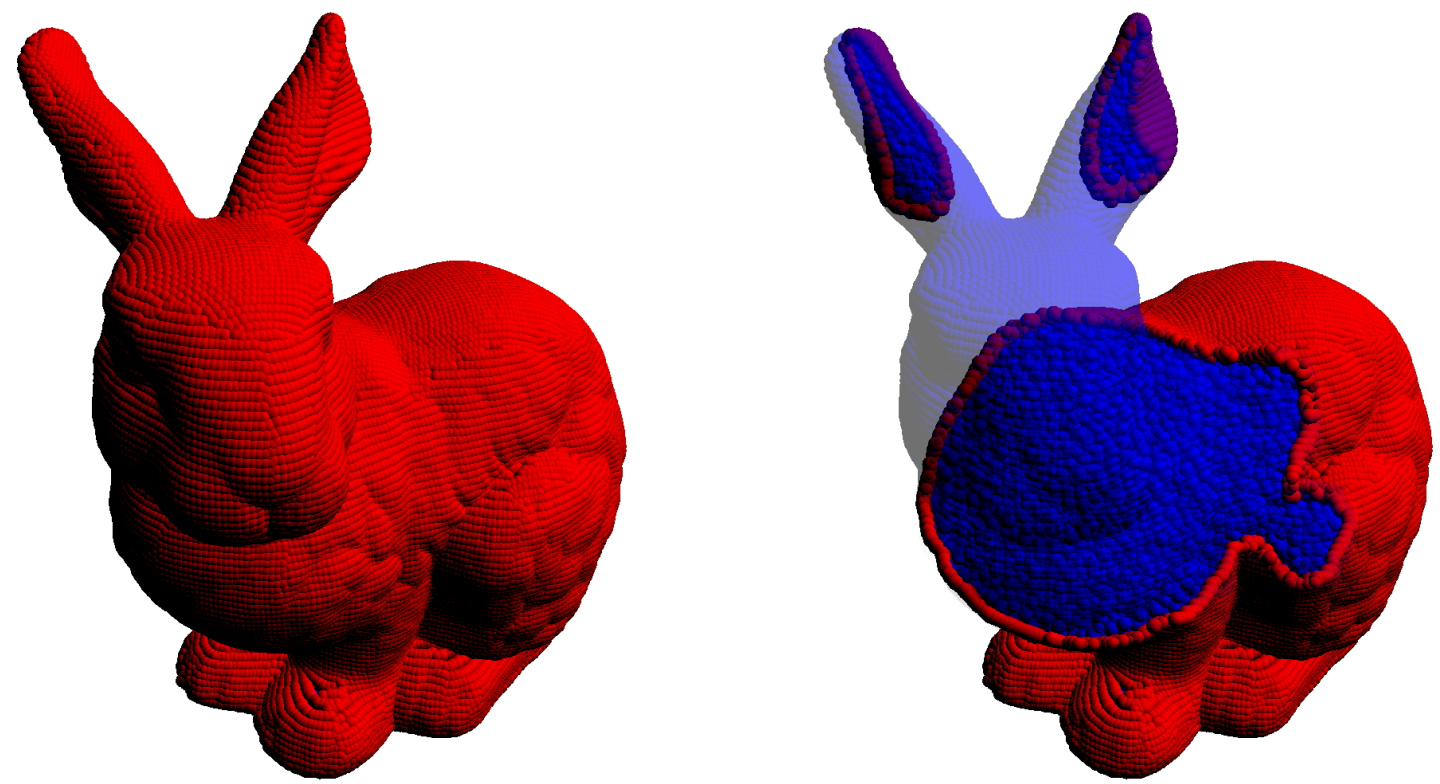

Figura 5.11: Conjunto de referência para o modelo Stanford Bunny, as partículas em vermelho representam a solução ideal para o problema de detecção de fronteira.
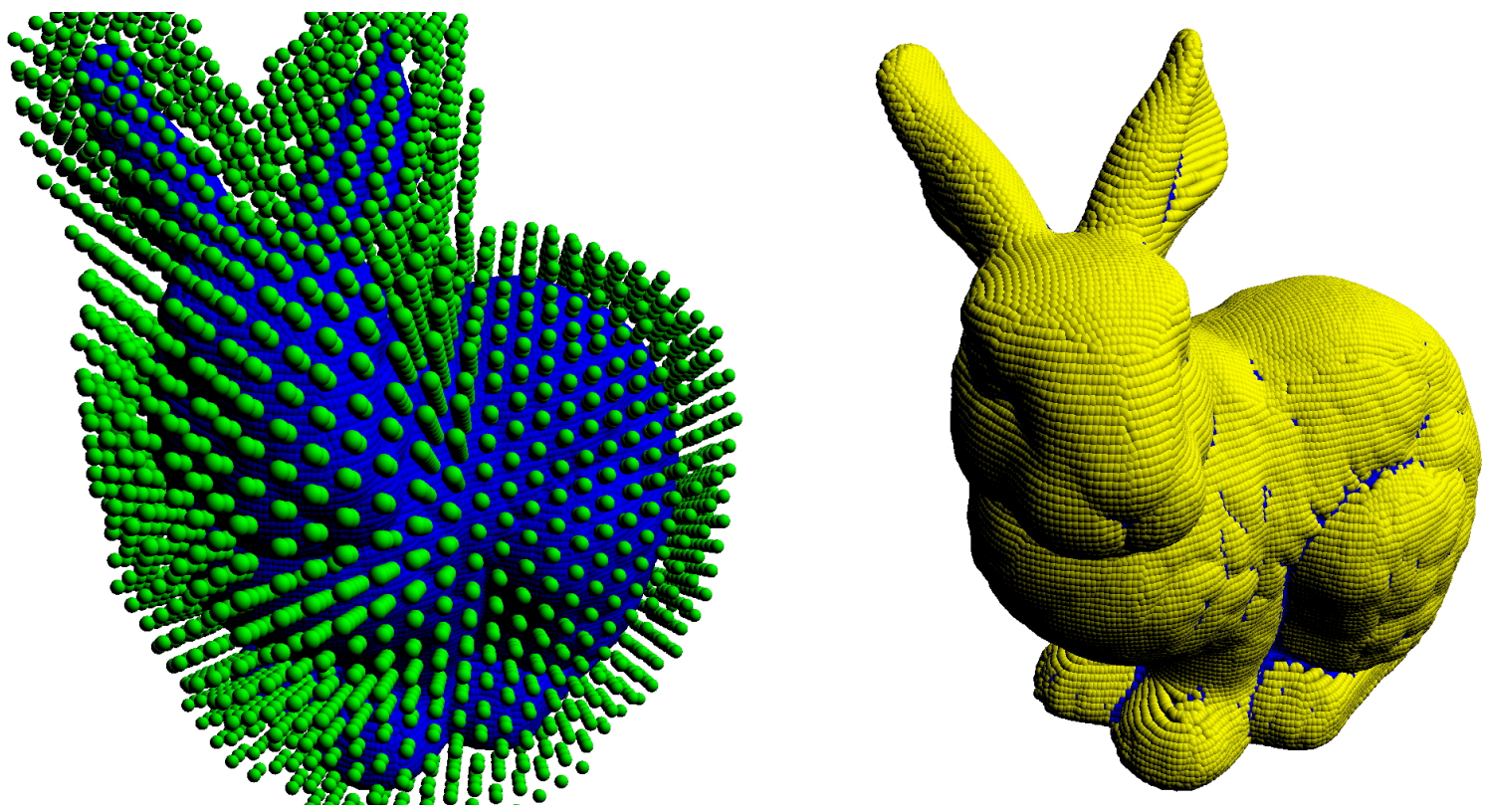

Figura 5.12: Resultados obtidos aplicando a técnica baseada em grade de busca ao modelo Stanford Bunny. O número de observadores (verdes) é relativamente baixo e a execução é rapida, mas há uma quantia considerável de falsos negativos em regiões de alta curvatura.

sos negativos quando usado o gradiente da função característica e 659 (1.85\%) falsos negativos quando usado PCA para cálculo das normais. As técnicas de Müller et al. e He et al. produzem um número elevado de falsos negativos e positivos para esses casos, tornando-os praticamente inaplicáveis. São produzidos 39157 falsos positivos utilizando a técnica de Müller et al., o que equivale a $109.72 \%$ do total de partículas do conjunto de referência, e 1206 (3.38\%) falsos negativos. A técnica de $\mathrm{He}$ et al. produz resultados grosseiros em termos de falsos negativos: 34741 

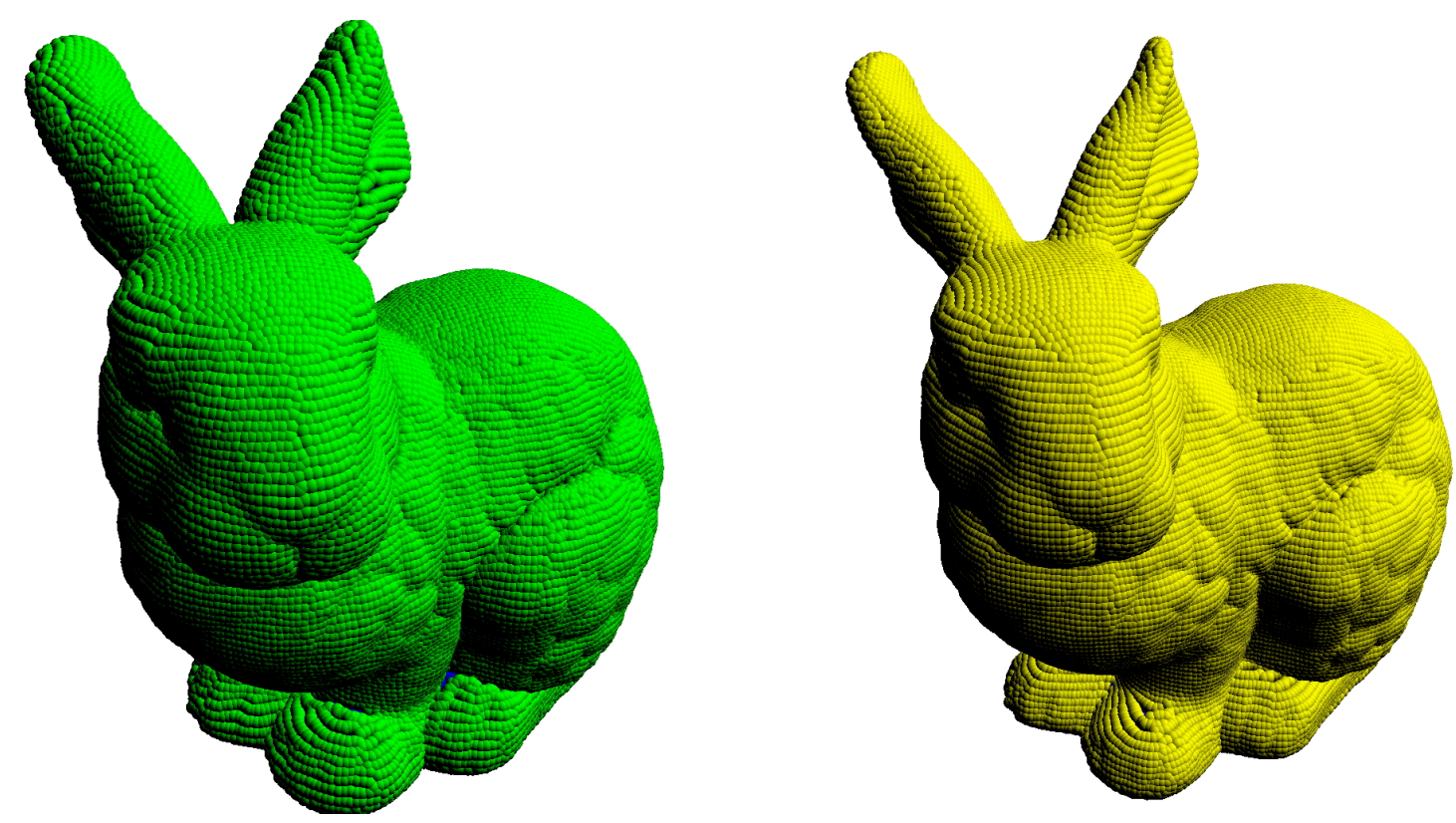

Figura 5.13: Resultados obtidos aplicando a técnica baseada deslocamento de centroide ao modelo Stanford Bunny. Os resultados obtidos possuem um número praticamente nulo de falsos negativos, porém o número de observadores gerados e o tempo de execução são muito maiores quando comparado à técnica baseada em grade de busca.

no total, o que equivale a uma falha de $97.34 \%$ na cobertura da fronteira, mas apenas $232(0.65 \%)$ falsos positivos.

Asian Dragon O modelo Asian Dragon foi simplificado e preenchido da forma descrita anteriormente, resultando em um conjunto de 77720 pontos com 45120 deles na fronteira. Esse é um modelo complexo com diversas regiões côncavas e com alta curvatura, que são críticas para o operador HPR, sendo assim esse é um teste crítico para o método desenvolvido. Nesse caso não foram produzidos falsos positivos para nenhum das versões da técnica desenvolvida. A versão baseada em grade resulta em um número consideravelmente alto de falsos negativos: 13909, o que representa $30.82 \%$ da fronteira de referência. Já a versão usando centroide produz 7100 falsos negativos ( $15.73 \%$ da fronteira). Essa é uma melhoria significativa mas longe do ideal, que é obtida ao custo do aumento no tempo de execução em mais de 13 vezes. Porém, a qualidade do resultado é visualmente aceitável e no caso da aplicação de uma técnica de reconstrução de superfície, resultaria em uma reconstrução com falhas em regiões pouco visíveis.

A aplicação das outras técnicas estudadas produziu resultados semelhantes àqueles observados para o modelo Stanford Bunny. A técnica de Müller et al. produz um elevado número de falsos positivos: 25493, o que equivale a $56.5 \%$ de erro em relação ao conjunto de referência. A técnica de He et al. e a de Marrone et al. utilizando o gradiente da função característica apresentaram os maiores números de falsos negativos: 35328 (44.8559\%) e 20239 (78.2979\%) respectivamente. A técnica de Marrone et al. utilizando PCA para as normais produziu um resultado pouco pior que o produzido pela técnica utilizando HPR e deslocamento de centroide: 9759 falsos negativos e 1 

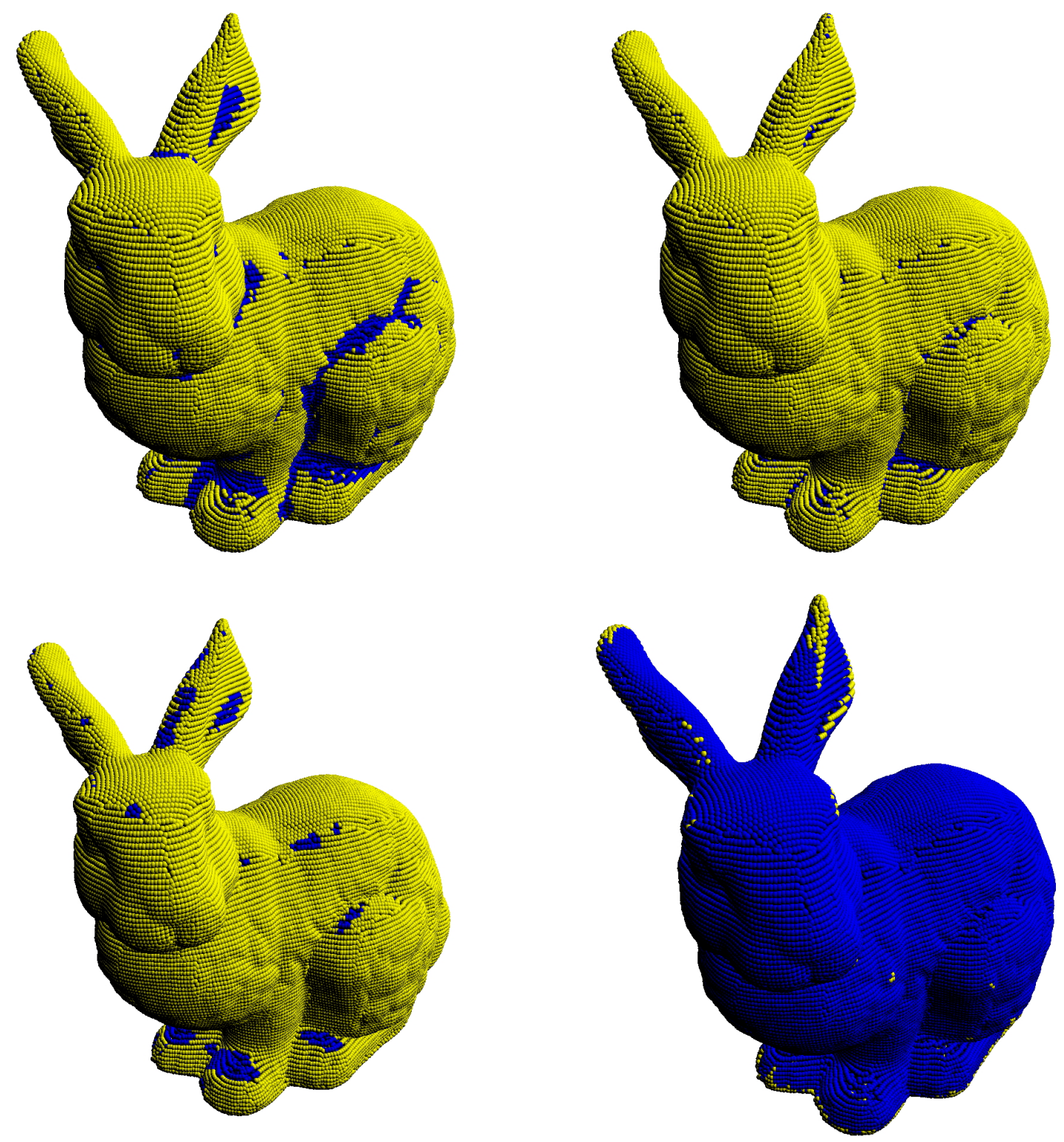

Figura 5.14: Resultados obtidos aplicando as técnicas de Marrone et al. usando o gradiente da função característica para cálculo das normais (superior esquerdo), Marrone et al. usando PCA para cálculo das normais (superior direito), Müller et al. (inferior esquerdo) e He et al. (inferior direito) ao modelo Stanford Bunny. As taxas de erro são consideravelmente maiores que o método proposto, exceto pelo método de Marrone et al. usando PCA para as normais.

falso positivo. O número de falsos negativos equivale a $21.63 \%$ do conjunto de referência, contra os $15.73 \%$ da técnica proposta. Esses resultados podem ser observados na Figura 5.19.

Armadillo O último exemplo estático usado foi criado com um número maior de partículas a partir do modelo Armadillo, contendo 797411 partículas com 172974 delas na fronteira. Este modelo possui diversas regiões côncavas mas com uma curvatura que em média é menor que as encontradas no Asian Dragon. As Figuras 5.20 e 5.21 mostram o conjunto de pontos usado e a fronteira de referência. 


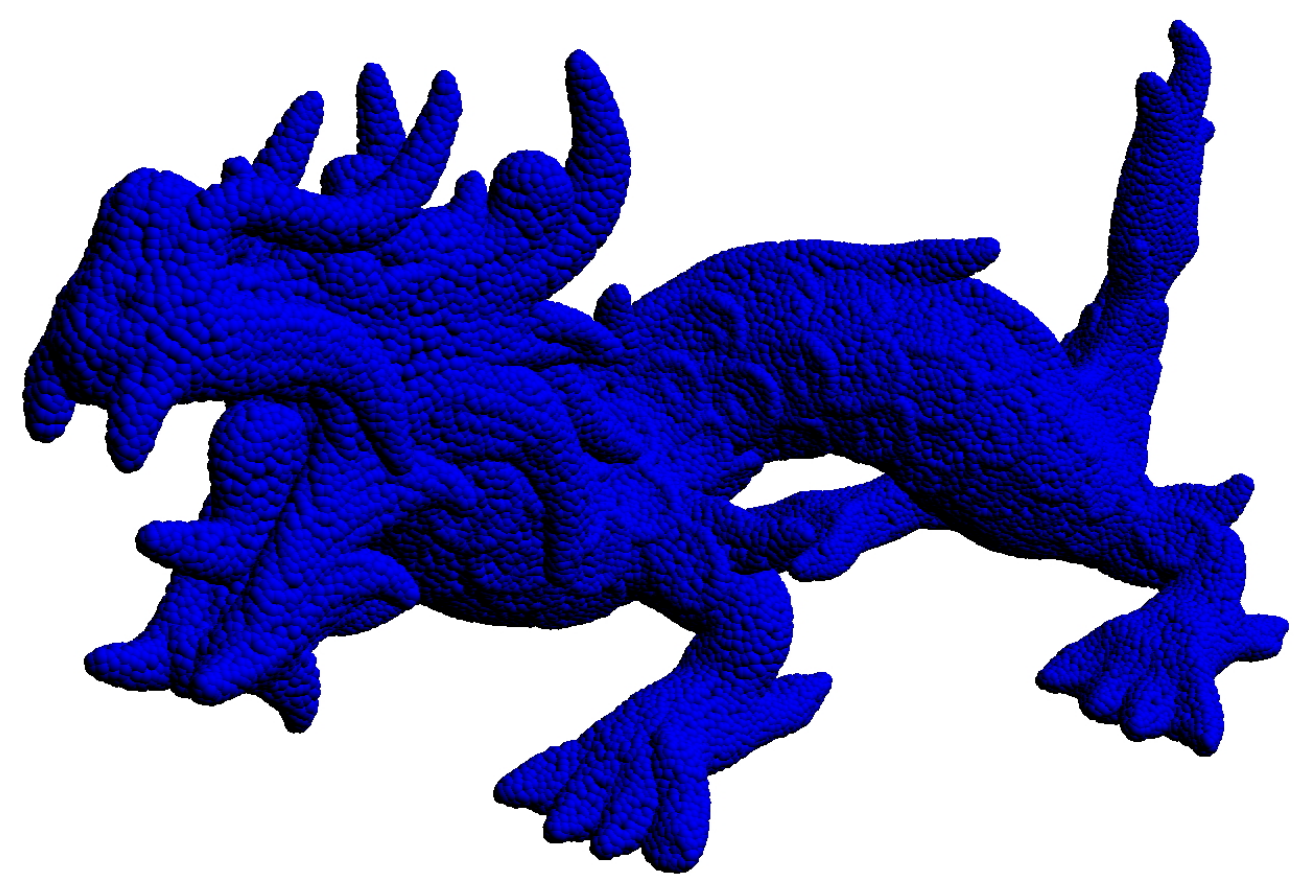

Figura 5.15: Conjunto de dados produzido a partir do modelo Asian Dragon.

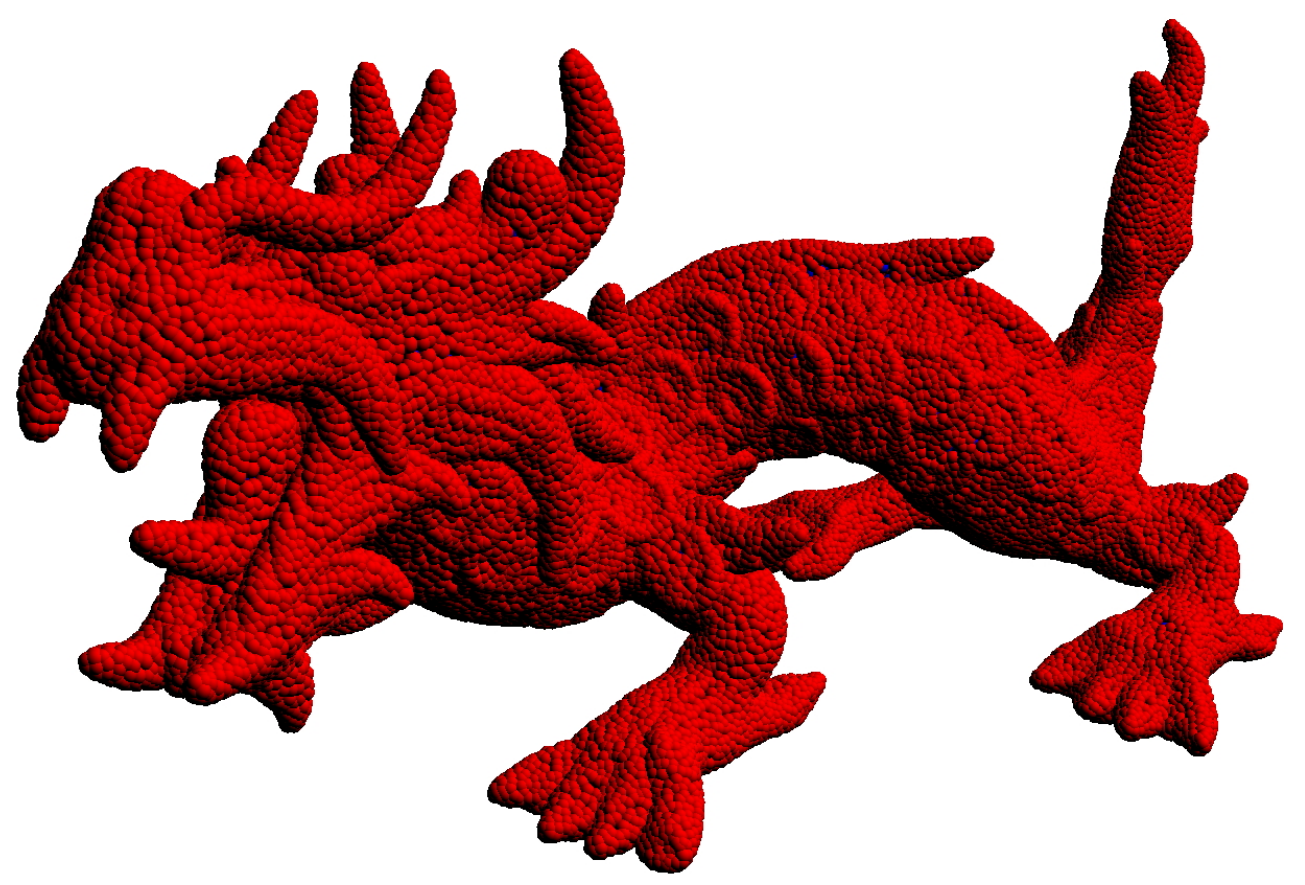

Figura 5.16: Conjunto de referência para o modelo Asian Dragon. As partículas em vermelho representam a solução ideal para o problema estudado. 

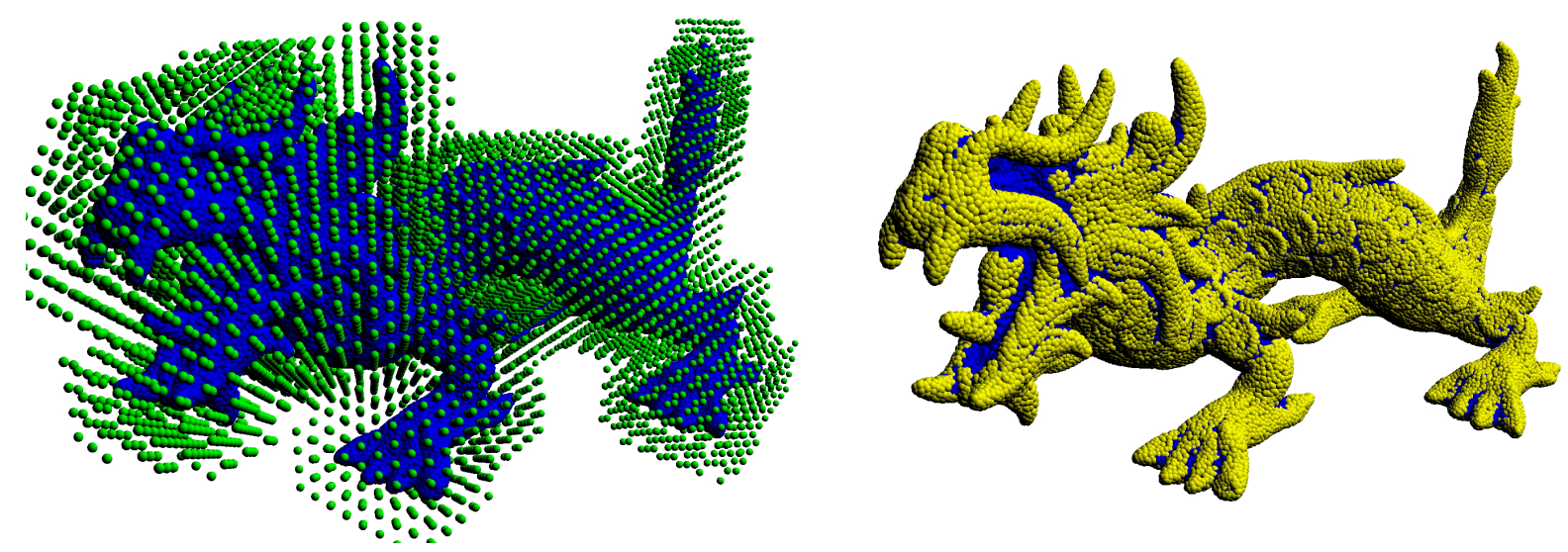

Figura 5.17: Resultados obtidos aplicando a técnica baseada em grade ao modelo Asian Dragon. Devido à alta curvatura e distribuição mais esparsa dos observadores, é produzido um número elevado de falsos negativos, em especial na região da cabeça do modelo.
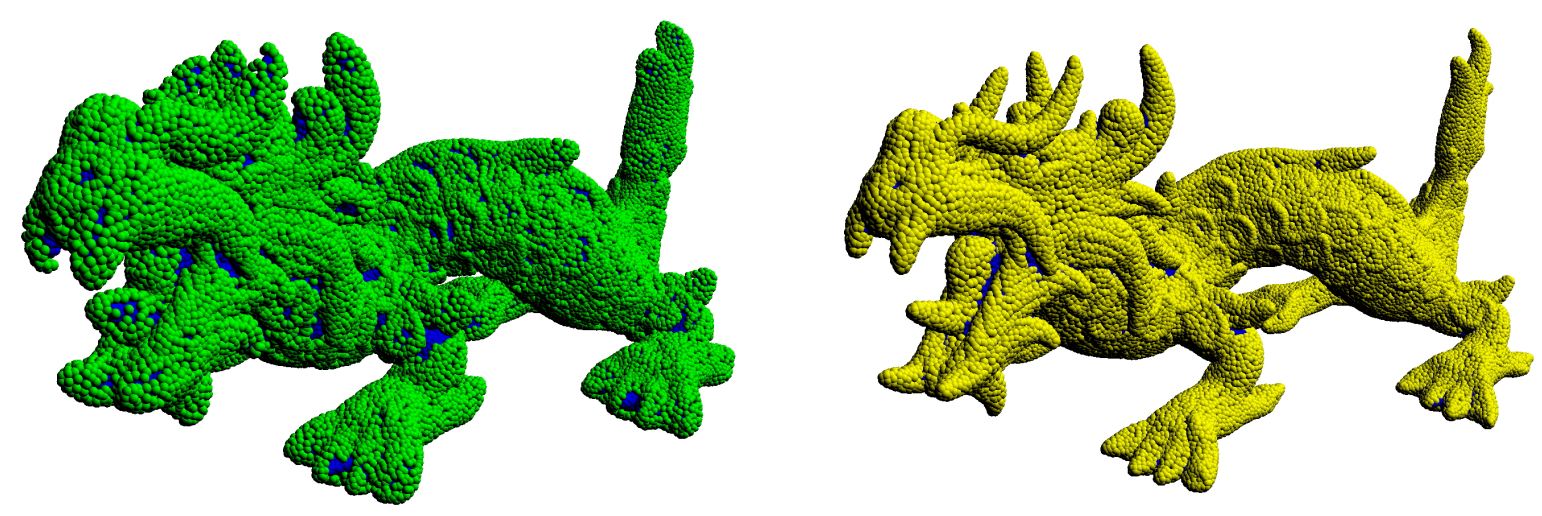

Figura 5.18: Resultados obtidos aplicando a técnica baseada em deslocamento de centroide ao modelo Asian Dragon. O maior número de observadores e sua melhor distribuição reduzem consideravelmente os problemas observados na Figura 5.17.

Nesse exemplo a diferença no tempo de execução das duas técnicas fica evidente uma vez que a técnica baseada em centroide leva quase 36 vezes mais tempo para realizar a mesma tarefa. Em compensação, a técnica baseada em grade produz $10.92 \%$ de falsos negativos, enquanto a baseada em centroide produz apenas $0.53 \%$. Na Figura 5.22 pode ser visto o resultado do método baseado em grade, com diversas falhas em regiões côncavas, e na Figura 5.23 o resultado do método baseado no centroide da vizinhança.

A técnica de He et al. apresenta uma deficiência notável para dados com distribuição regular e com densidade constante, como os utilizados nessa seção, produzindo sempre um número elevado de falsos negativos que vão além da margem de $90 \%$ de erro. A Figura 5.24 mostra isso novamente, além dos resultados das demais técnicas estudadas aplicadas ao modelo Armadillo. A técnica de Marrone et al. produziu resultados com boa qualidade quando adicionada a modificação no cálculo das normais, contendo apenas 1789 (1.03\%) de falsos negativos, um resultado pouco maior que os $0.53 \%$ obtidos através da versão baseada em deslocamento de centroide da técnica proposta. As 

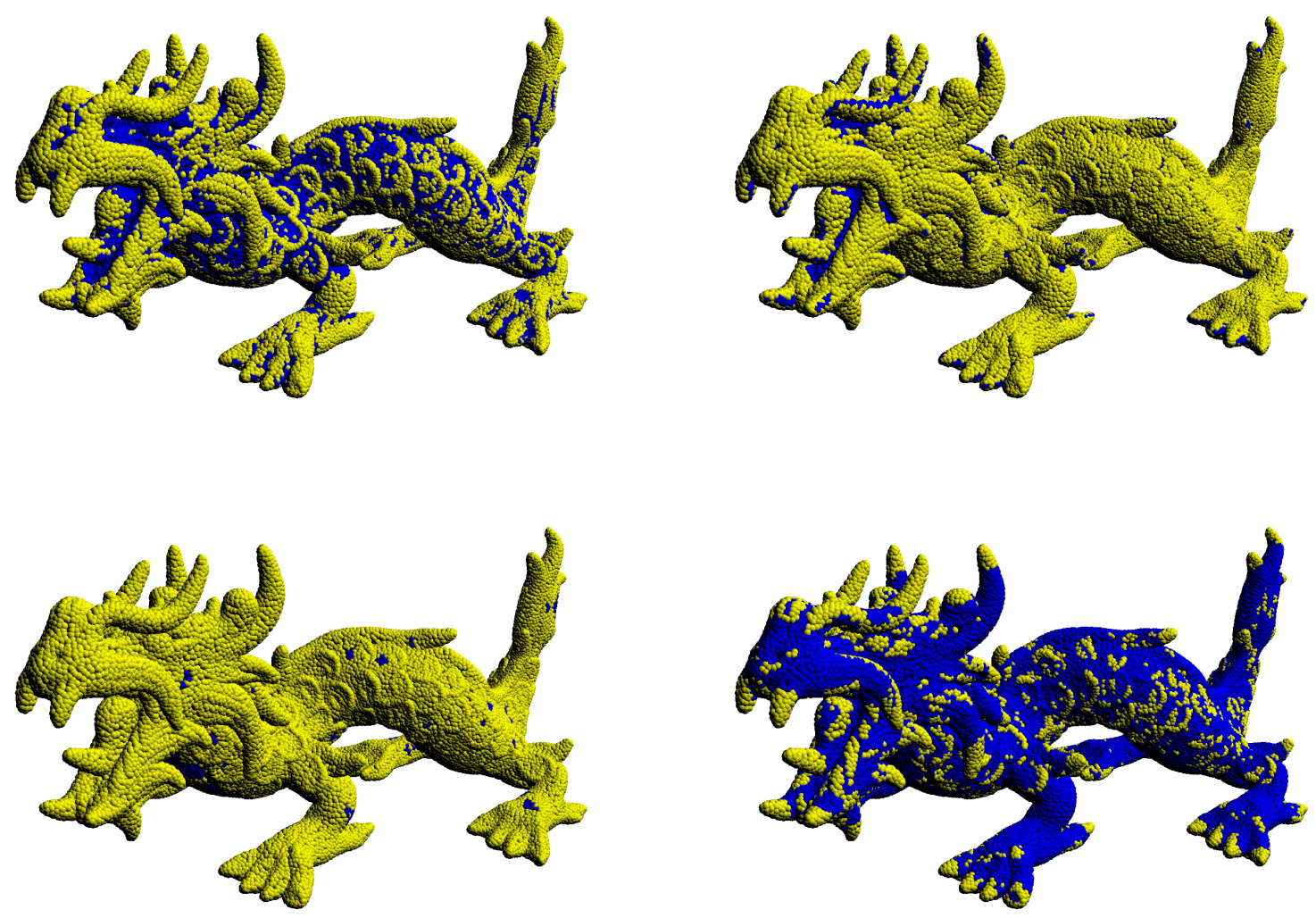

Figura 5.19: Resultados obtidos aplicando as técnicas de Marrone et al. usando o gradiente da função característica para cálculo das normais (superior esquerdo), Marrone et al. usando PCA para cálculo das normais (superior direito), Müller et al. (inferior esquerdo) e He et al. (inferior direito) ao modelo Asian Dragon. A melhor cobertura da fronteira foi obtida através dos métodos de Müller et al. e Marrone et al. utilizando PCA para as normais, os demais métodos produziram uma alta taxa de falsos negativos.

técnicas de He et al., Müller et al. e Marrone et al. utilizando gradiente da função característica produziram taxas de erro maiores. He et al.: $56(0.03 \%)$ falsos positivos e $159799(92.38 \%)$ falsos negativos, Müller et al.: 353552 (204.39\%) falsos positivos e 13937 (8.05\%) falsos negativos, e Marrone et al. utilizando gradiente da função característica: 0 falsos positivos e 11360 (6.57\%) falsos negativos.

A diferença no tempo de execução dos métodos propostos são consideráveis. Isso se deve ao número de observadores gerados, uma vez que isso implica em mais testes para gerar os observadores e em mais execuções do operador HPR. Para medir o tempo gasto pelas diferentes técnicas, foi utilizada uma máquina com processador Intel ${ }^{\circledR}$ Core $^{\mathrm{TM}}$ i5-3570 e 8GB de memória RAM. No caso do modelo Asian Dragon o método baseado em centroide leva aproximadamente 10 vezes mais tempo que o baseado em grade para executar todos os passos. Essa diferença sobe para $20 \mathrm{e}$ 35 vezes para os modelos Bunny e Armadillo, respectivamente, como mostrado na Tabela 5.1.

Uma comparação dos tempos de todas as técnicas discutidas nessa seção é mostrada na Tabela 5.2. Nela é possível notar que a técnica proposta, utilizando a grade de busca para definição dos observadores é consistentemente mais rápida que as demais, exceto para os casos das técnicas 


$$
\text { K }
$$



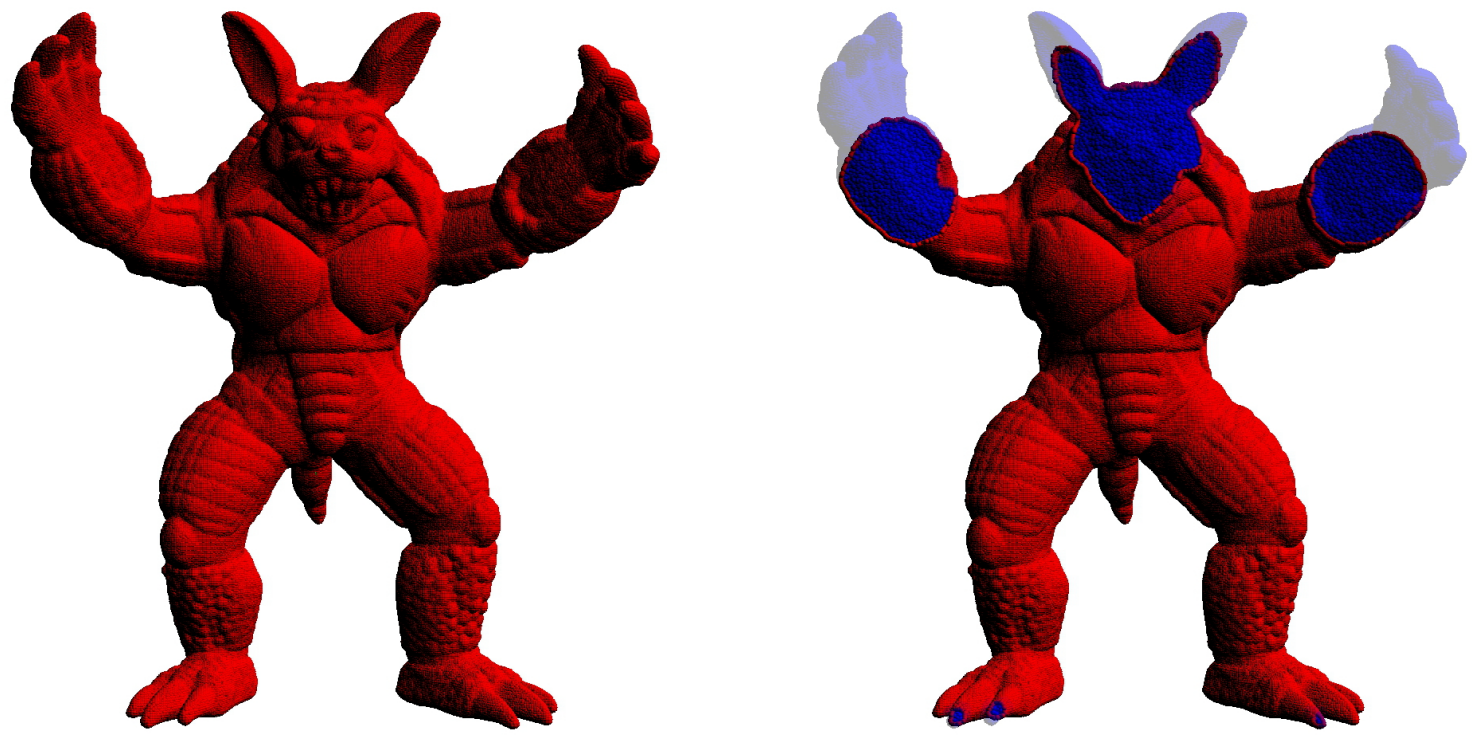

Figura 5.21: Conjunto de referência para o modelo Armadillo. As partículas de fronteira representam aproximadamente $21 \%$ do total de partículas do sistema.
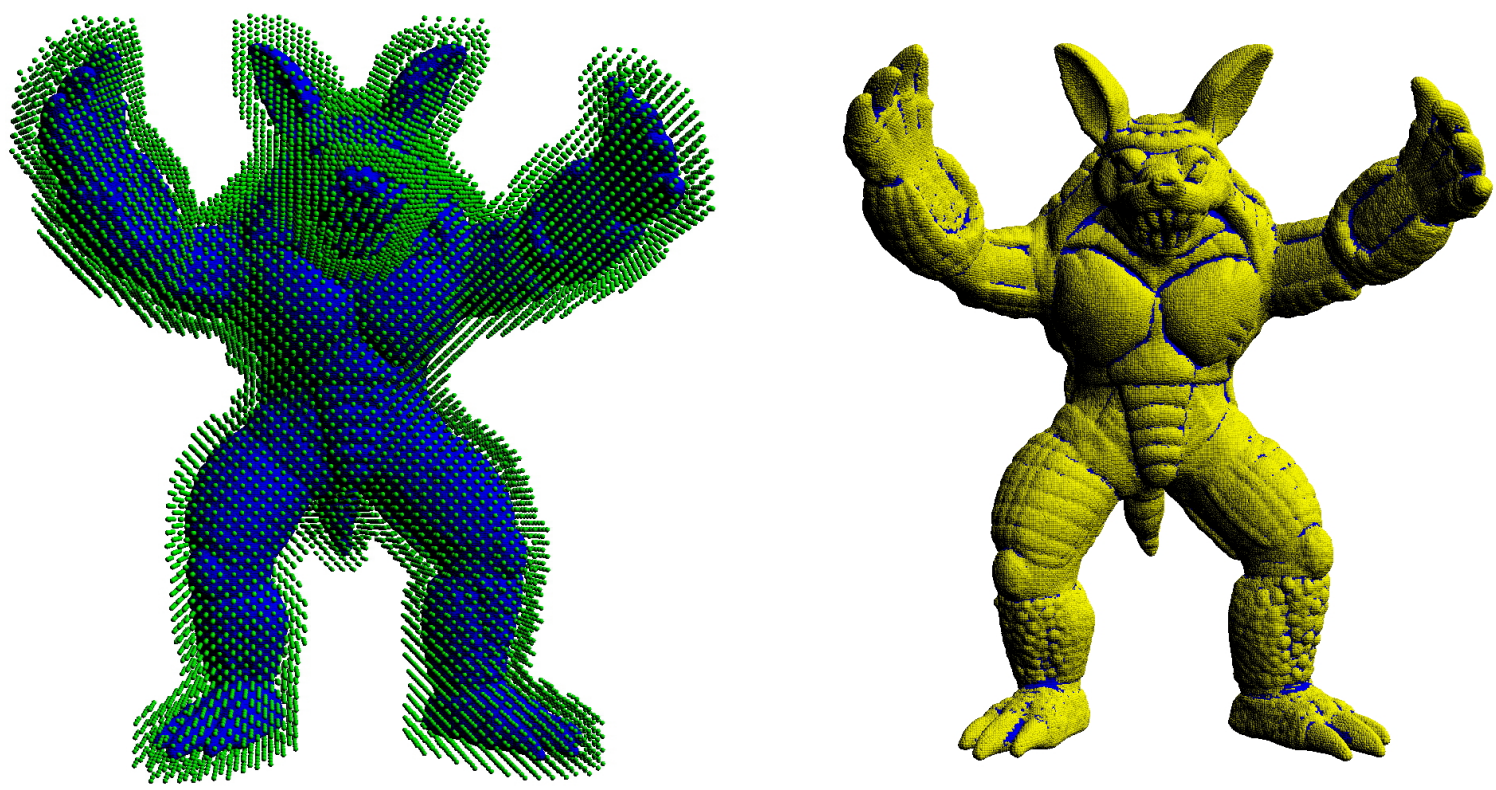

Figura 5.22: Resultados obtidos aplicando a técnica baseada em grade ao modelo Armadillo. Nesse caso há um número elevado de falsos negativos em diversas áreas que apresentam concavidades, principalmente no tórax e dedos do modelo. 

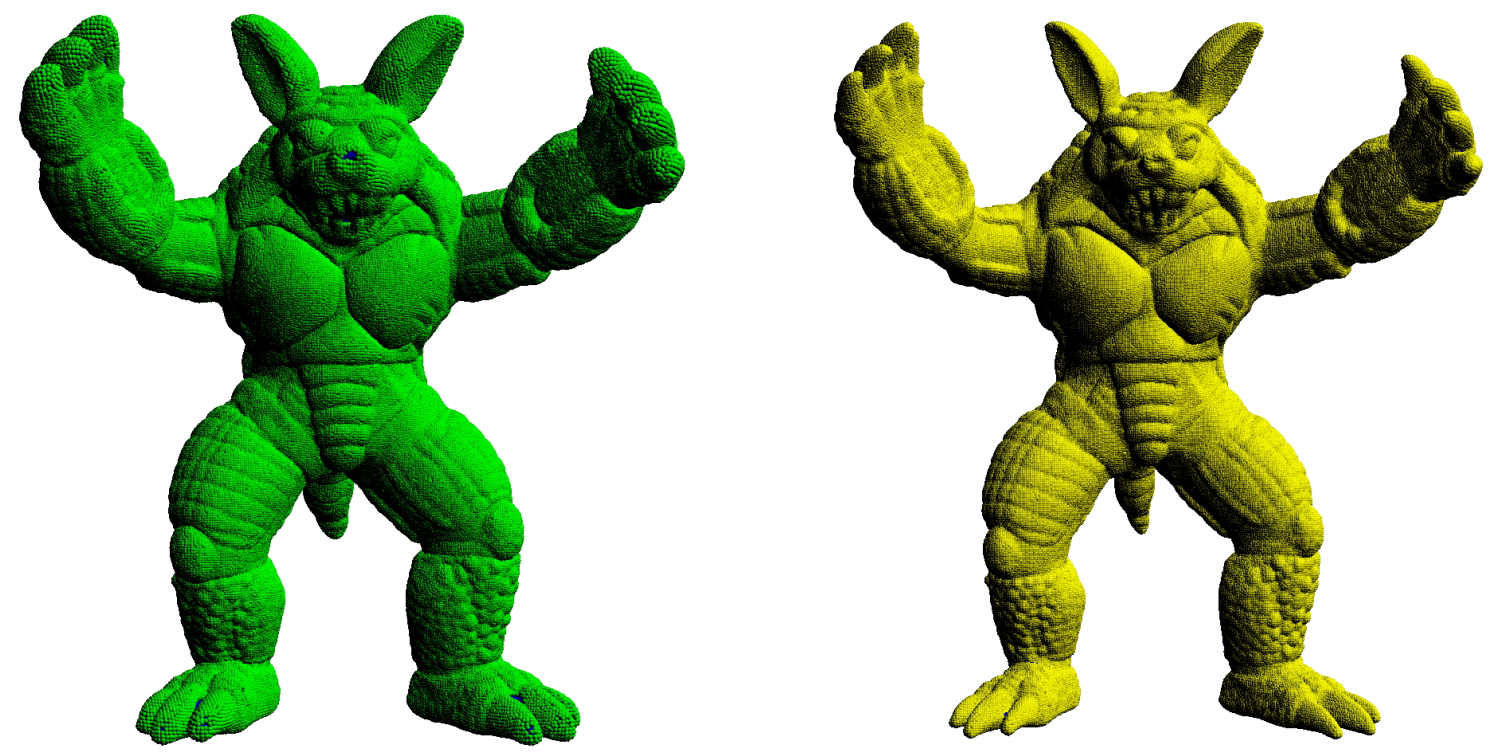

Figura 5.23: Resultados obtidos aplicando a técnica baseada em deslocamento de centroide ao modelo Armadillo. Os problemas observados na Figura 5.22 foram, em termos práticos, totalmente sanados, mas com o custo do aumento do tempo de processamento. 

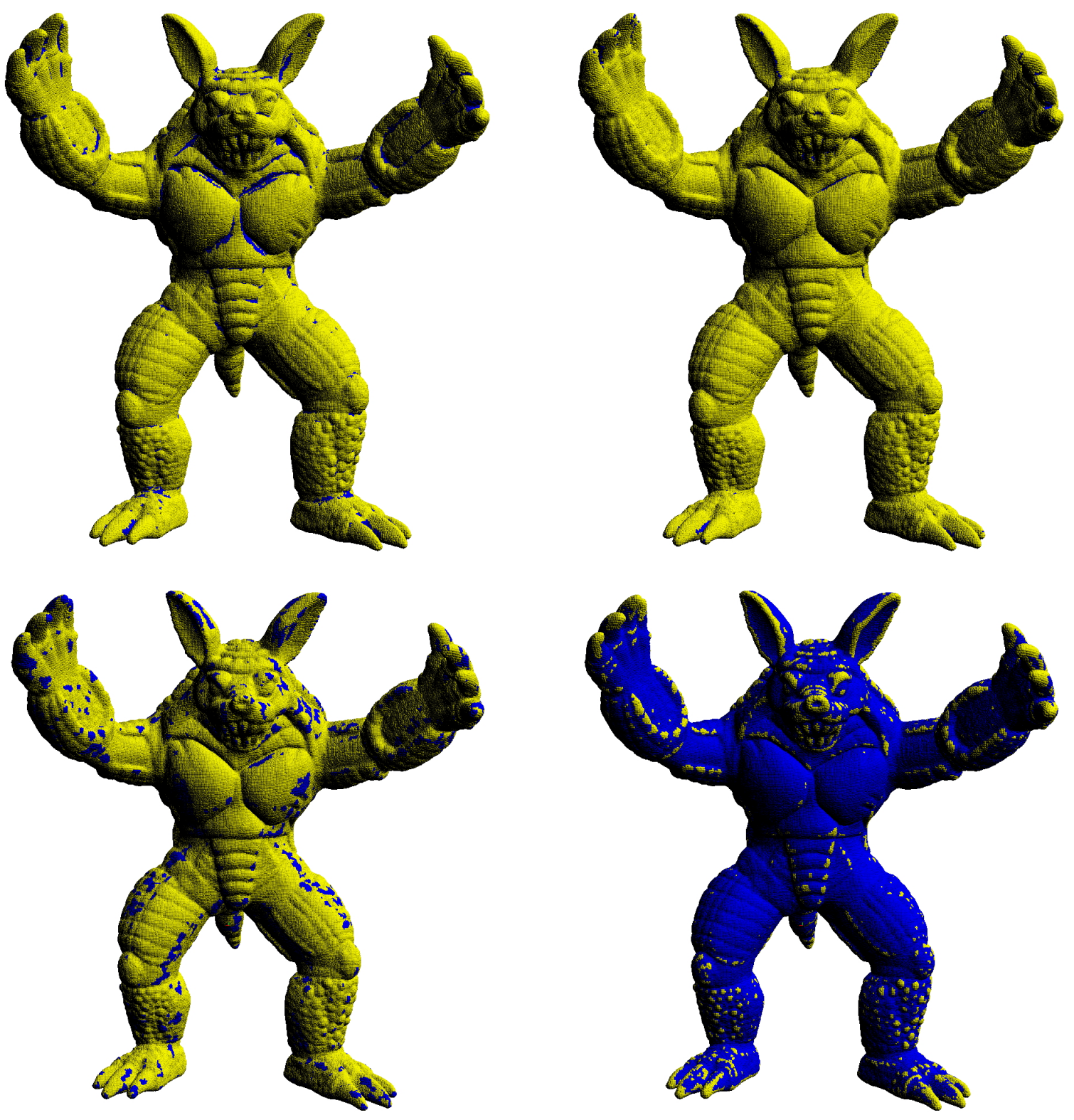

Figura 5.24: Resultados obtidos aplicando as técnicas de Marrone et al. usando o gradiente da função característica para cálculo das normais (superior esquerdo), Marrone et al. usando PCA para cálculo das normais (superior direito), Müller et al. (inferior esquerdo) e He et al. (inferior direito) ao modelo Armadillo. A técnica de Marrone et al. utilizando PCA para as normais apresentou um resultado com uma taxa de erros bastante baixa. A técnica de $\mathrm{He}$ et al. produziu novamente um elevado número de falsos negativos, enquanto as demais produziram resultados medianos. 
Tabela 5.1: Tempo de execução em milissegundos das técnicas desenvolvidas.

\begin{tabular}{|c|r|c|r|c|r|r|}
\hline \multirow{2}{*}{ Conjunto de dados } & \multicolumn{2}{|c|}{ Calculo de observadores } & Aplicação do operador HPR & \multicolumn{2}{|c|}{ Total } \\
\cline { 2 - 7 } & Grade & Centroide & Grade & Centroide & Grade & Centroide \\
\hline Stanford Bunny & 3 & 2051 & 2627 & 51066 & 2630 & 53117 \\
\hline Asian Dragon & 7 & 792 & 2127 & 26962 & 2134 & 27754 \\
\hline Armadillo & 28 & 48332 & 11606 & 370222 & 11634 & 418554 \\
\hline
\end{tabular}

Tabela 5.2: Tempo total de execução em milissegundos das técnicas estudadas. Onde Marrone (a) equivale à técnica de Marrone et al. utilizando PCA e Marrone (b) utilizando gradiente da função característica.

\begin{tabular}{|c|r|r|r|r|r|r|}
\hline Conjunto de dados & \multicolumn{1}{|c|}{ Grade } & Centroide & Marrone (a) & Marrone (b) & \multicolumn{1}{|c|}{ Muller } & \multicolumn{1}{|c|}{ He } \\
\hline Stanford Bunny & 2630 & 53117 & 4844 & 4452 & 2118 & 2206 \\
\hline Asian Dragon & 2134 & 27754 & 2439 & 2147 & 1014 & 1058 \\
\hline Armadillo & 11634 & 418554 & 91580 & 92676 & 44454 & 48011 \\
\hline
\end{tabular}

Tabela 5.3: Contagem de falsos positivos (FP) e falsos negativos (FN) para as técnicas estudadas. Onde Marrone (a) equivale à técnica de Marrone et al. utilizando PCA e Marrone (b) utilizando gradiente da função característica.

\begin{tabular}{|c|c|c|c|c|c|c|c|c|c|c|c|c|c|c|}
\hline \multirow{2}{*}{ Conjunto de dados } & \multicolumn{2}{|c|}{ \# de partículas } & \multicolumn{2}{|c|}{ Grade } & \multicolumn{2}{|c|}{ Centroide } & \multicolumn{2}{|c|}{ Marrone (a) } & \multicolumn{2}{|c|}{ Marrone (b) } & \multicolumn{2}{|c|}{ Müller } & \multicolumn{2}{|c|}{$\mathrm{He}$} \\
\hline & Total & Fronteira & FP & $\mathrm{FN}$ & FP & FN & FP & $\mathrm{FN}$ & FP & $\mathrm{FN}$ & FP & $\mathrm{FN}$ & FP & $\mathrm{FN}$ \\
\hline Stanford Bunny & 114137 & 35688 & 0 & 2534 & 1 & 247 & 0 & 659 & 0 & 3922 & 39157 & 1206 & 232 & 34741 \\
\hline Asian Dragon & 77720 & 45120 & 0 & 13909 & 0 & 7100 & 1 & 9759 & 1 & 20239 & 25493 & 857 & 3396 & 35328 \\
\hline Armadillo & 797411 & 172974 & 0 & 171504 & 0 & 921 & 0 & 1789 & 0 & 11360 & 353552 & 13937 & 56 & 159799 \\
\hline
\end{tabular}




\subsubsection{Exemplos dinâmicos}

Os testes dinâmicos usados incluem dados provenientes de simulações SPH e um teste muito conhecido na parte da literatura de física computacional que trata de superfícies de nível, proposto por LeVeque [LeV96] e modificado por Enright et al. [EFFM02].

Deformação de esfera O teste de deformação de uma esfera é semelhante ao vórtice em duas dimensões usado anteriormente. Este teste consiste em uma esfera de raio 0.15 inicialmente centrada em $(0.35,0.35,0.35)$ que é deformada pelo campo de velocidades dado pela Equação (5.2). No caso da discretização por partículas, o campo da Equação (5.2) é aplicado a cada uma das partículas. A discretização usada resulta em um conjunto com 1904660 partículas com espaçamento médio inicial em torno de 0.0019 .

$$
\mathbf{v}(x, y, z, t)=\left(\begin{array}{l}
2 \operatorname{sen}^{2}(\pi x) \operatorname{sen}(2 \pi y) \operatorname{sen}(2 \pi z) \\
-\operatorname{sen}(2 \pi x) \operatorname{sen}^{2}(\pi y) \operatorname{sen}(2 \pi z) \\
-\operatorname{sen}(2 \pi x) \operatorname{sen}(2 \pi y) \operatorname{sen}^{2}(\pi z)
\end{array}\right) \cos \left(\frac{\pi t}{T}\right)
$$

Como este é um conjunto de dados que não possui um conjunto de referência para contagem de falsos positivos e negativos, a avaliação dos resultados fica limitada à análise visual. Há uma diferença considerável entre os resultados produzidos pelas diferentes técnicas propostas, mas que estão limitados a regiões que podem ser consideradas ambíguas como as estrias formadas quando a deformação da esfera é maior. Essas diferenças podem ser observadas nos passos 60 e 80 da Figura 5.25. A Figura 5.26 mostra os mesmos resultados da Figura 5.25, mas com um plano de corte para facilitar a análise do resultado obtido. 

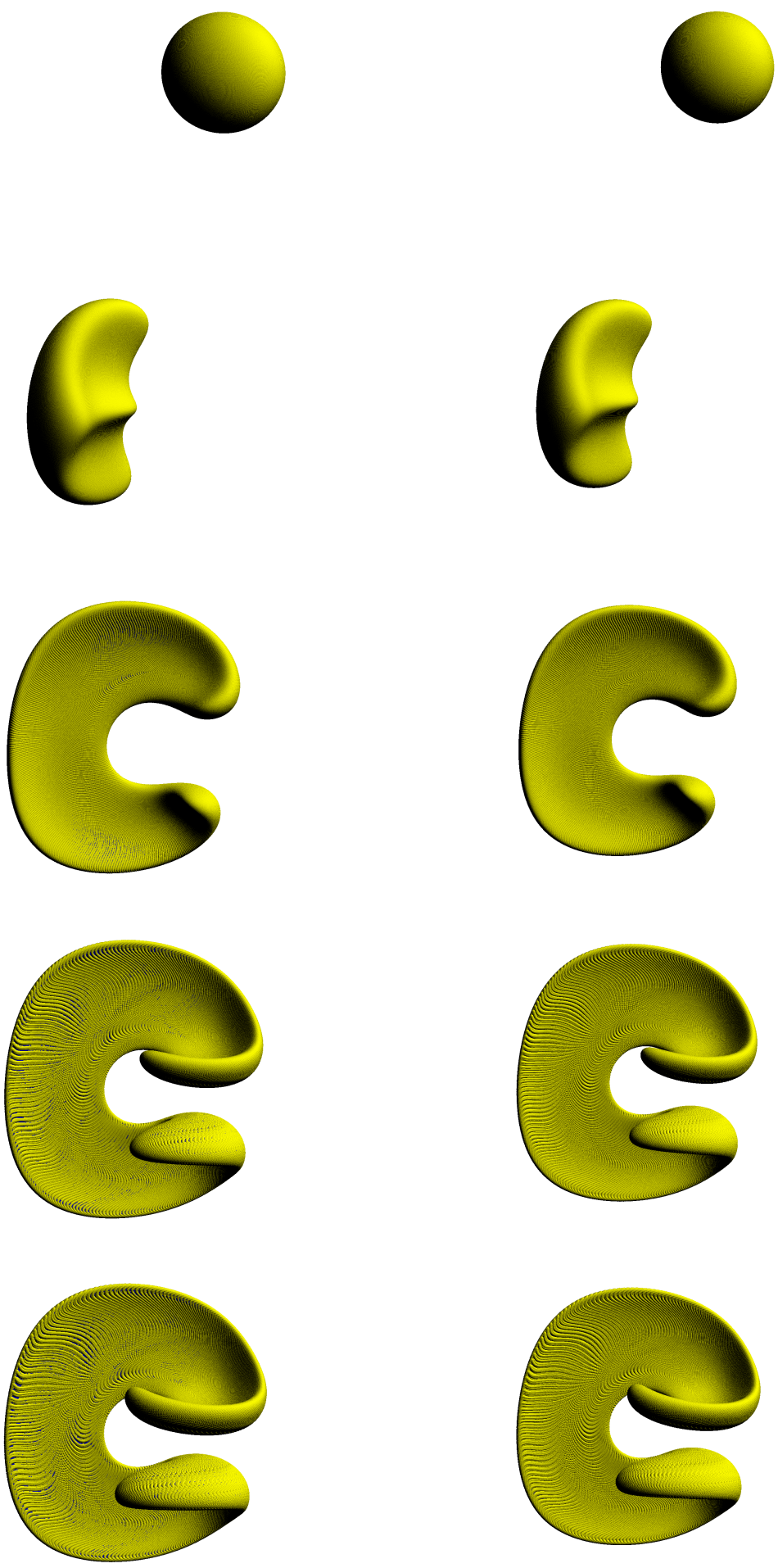

Figura 5.25: Fronteira obtida no teste de deformação de uma esfera para os instantes de tempo $t=0$, $t=20, t=40, t=60$ e $t=80$. O resultado obtido através do método baseado em grade (esquerda) possui falsos negativos nas estrias formadas pela deformação da esfera quando comparado com a técnica baseada no deslocamento do centroide (direita). 

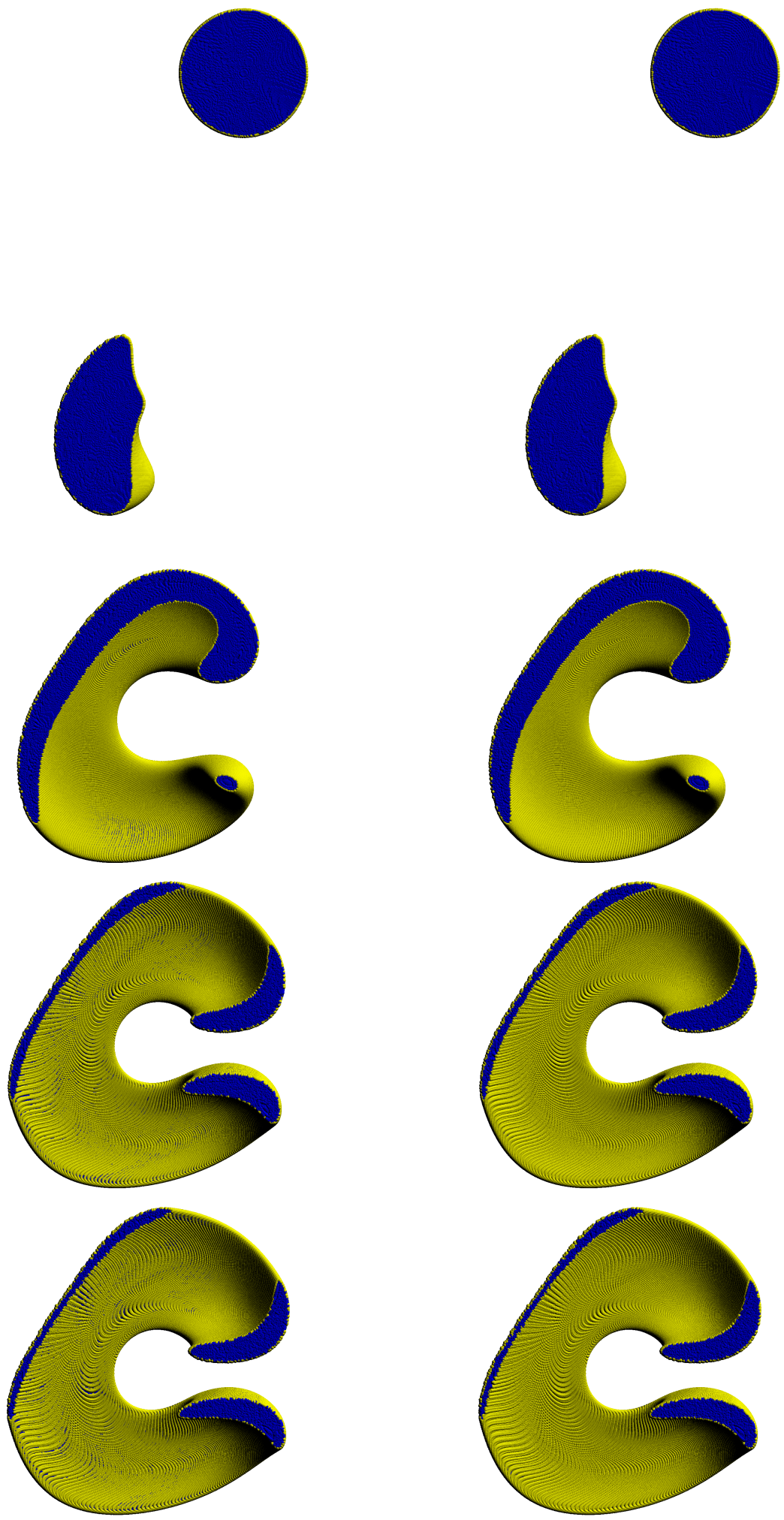

Figura 5.26: Fronteira obtida no teste de deformação de uma esfera (corte). Nessa imagem é adicionado um plano de corte para facilitar a visualização dos resultados. É possível notar que mesmo com variações entre os dois métodos propostos, os resultados são consistentes e de fato representam apenas uma camada na fronteira do sistema. 
SPHysics - Gota Usando dados provenientes de simulações SPH realizadas através do SPHysics, foi possível analisar o comportamento dessas técnicas em situações onde as partículas se distribuem de forma caótica. As cenas usadas possuem instantes de tempo onde são observadas folhas finas formadas pelas partículas, gotas dispersas e regiões de alta curvatura. Essas características fazem com que esses dados sirvam como teste de estresse para os métodos estudados. Por serem dados provenientes de simulação não há um conjunto de referência para análise dos resultados obtidos, a avaliação da qualidade deve ser feita de forma empírica.

A primeira cena consiste em uma esfera (gota) de raio 0.375 e centro $(1.5,1.5,2)$ em queda livre sobre um bloco de dimensões $(3,3,0.25)$, contidos em uma caixa fechada de dimensões $(3,3,4)$. Essa organização é mostrada na Figura 5.27. A esfera e o bloco são compostos de partículas distribuídas de forma regular com um espaçamento médio de 0.02 entre partículas, resultando em um cojunto com 297875 partículas. As Figuras 5.28 e 5.29 mostram os resultados obtidos através das técnicas propostas e, assim como no teste de deformação da esfera, há uma diferença visível entre o método baseado em grade e o baseado no deslocamento de centroide. A versão que utiliza grade para posicionamento de observadores resulta em uma fronteira mais espaçada em regiões onde há uma perturbação maior na distribuição da partícula, mas um resultado praticamente idêntico em regiões onde a perturbação é menor. Nesse caso é preciso levar em consideração o tempo gasto pela técnica baseada em deslocamento de centroide que, como dito anteriormente, chega a ser 35 vezes maior que o tempo gasto pela baseada na grade de busca.

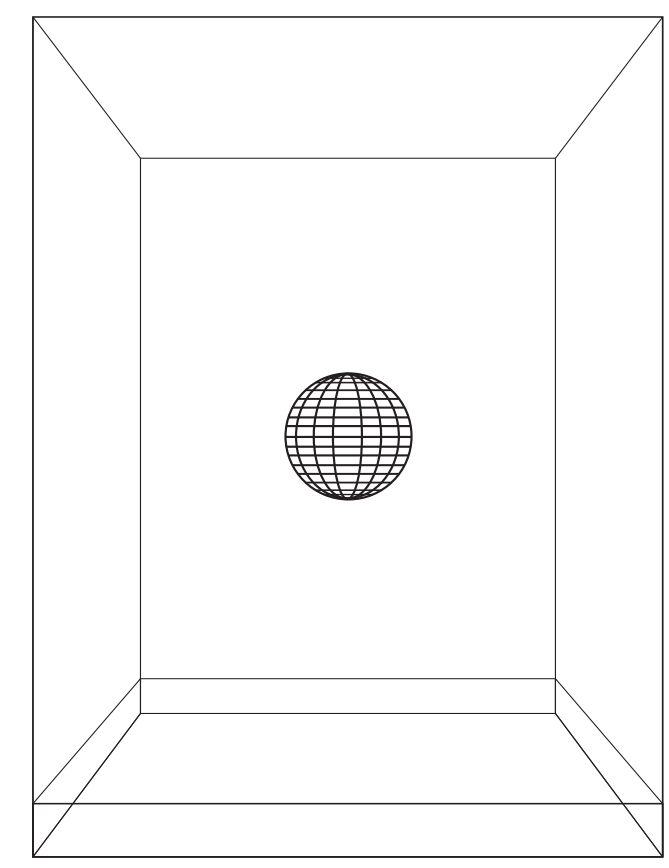

Figura 5.27: Geometria inicial da cena da queda de esfera (gota). A esfera ao centro e o bloco retangular logo abaixo representam regiões a serem preenchidas com o fluido a ser simulado, enquanto o bloco que envolve os demais objetos é o recipiente que contém a simulação. 

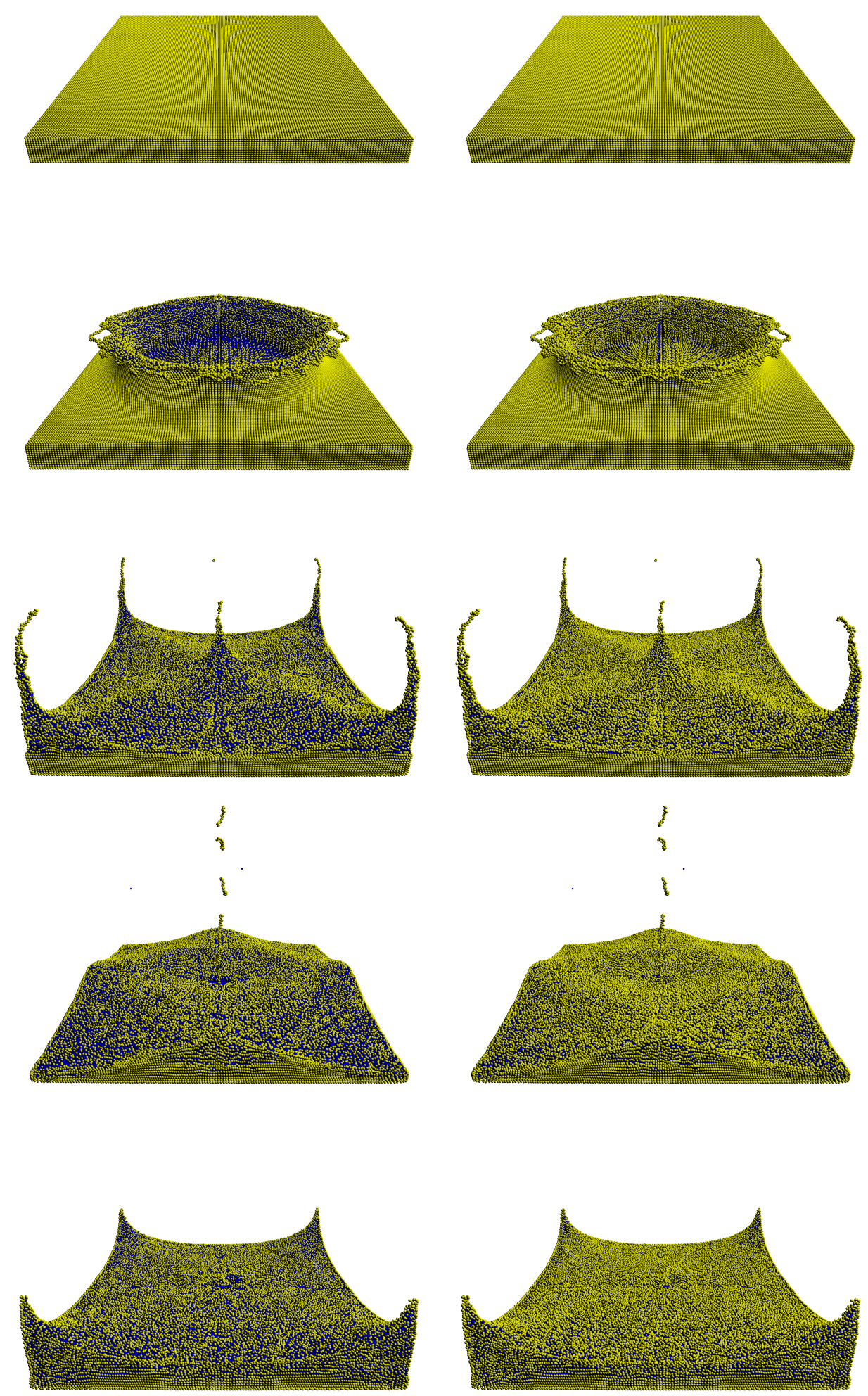

Figura 5.28: Resultado do teste de queda de esfera, instantes $t=0, t=20, t=40, t=60$ e $t=80$. Há uma diferença perceptível entre os dois métodos (grade à esquerda e deslocamento de centroide à direita) nos instantes onde a perturbação das partículas é maior e no instante $t=0$ onde ocorrem falsos negativos na esfera. 

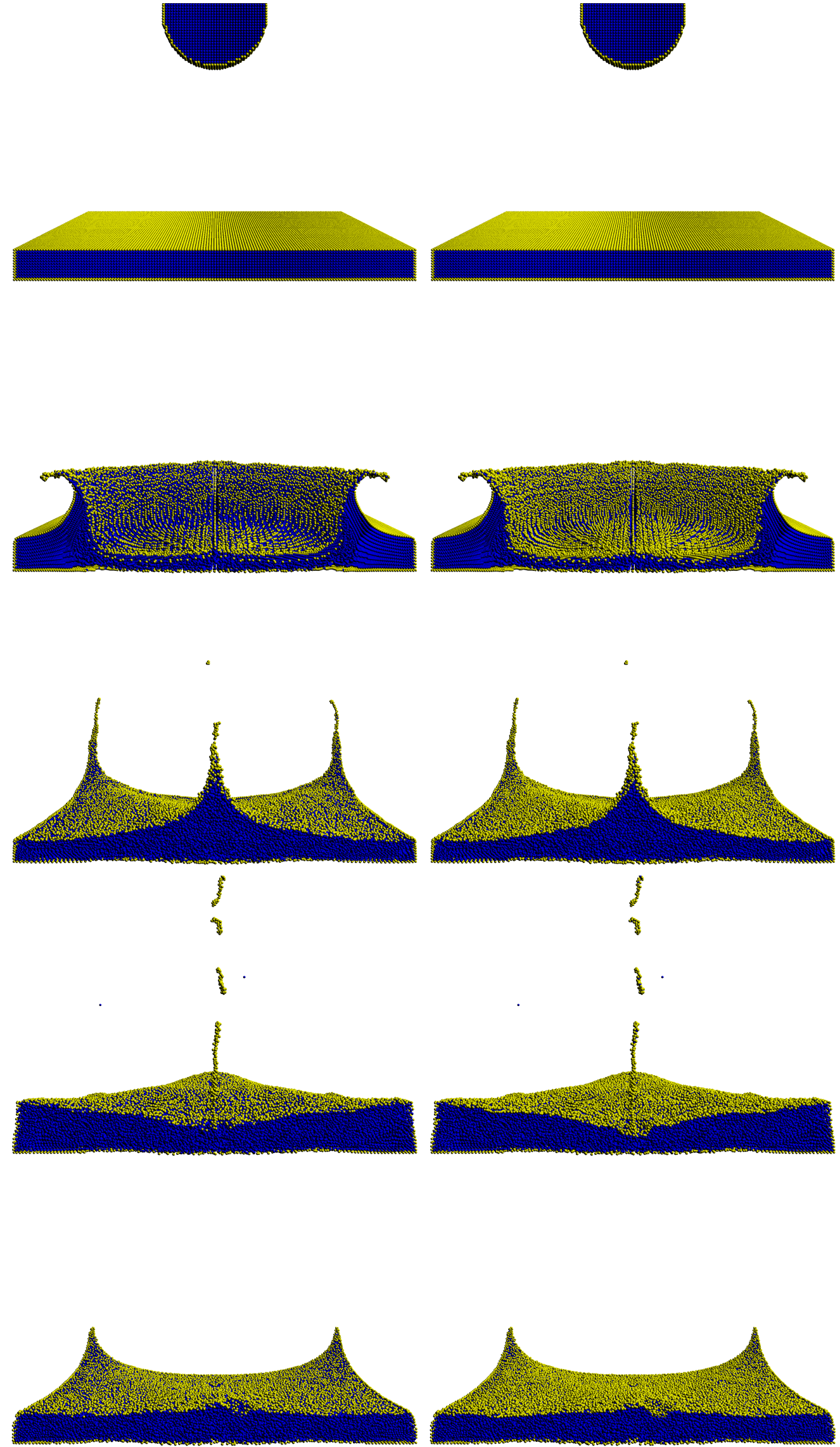

Figura 5.29: Corte do resultado do teste de queda de esfera, instantes $t=0, t=20, t=40, t=60 \mathrm{e}$ $t=80$. 
SPHysics - Colisão de blocos A segunda é uma variação da cena de quebra de barragem que é mostrada em diversos trabalhos na literatura sobre SPH. Essa cena consiste em uma caixa onde estão localizados, em cantos opostos, dois blocos de fluido que colidem no centro do recipiente que contém a simulação. A Figura 5.30 mostra a forma dessa cena, onde a caixa possui dimensões de $(2.5,2.5,3.5)$ e as dimensões dos blocos são $(1,1,1.5)$. O total de partículas do sistema é de 275350, distribuídas entre os blocos e com um espaçamento médio de 0.022 entre partículas. Os resultados obtidos possuem, assim como nos casos anteriores, diferenças mais aparentes em regiões côncavas. As Figuras 5.31 e 5.32 mostra estes resultados, e também alguns problemas relacionados a falsos negativos em filetes formados no passo 41 da simulação. Os falsos negativos em filetes e partículas dispersas é causado pela má distribuição dos observadores, que podem estar distantes das partículas no caso da técnica baseada em grade ou aglomerados em um dos lados do filete ou gota no caso da técnica baseada em deslocamento de centroide. Outra questão é o maior espaçamento das partículas de fronteira em regiões com distribuição irregular de partículas, que é ainda maior no caso do método baseado em grade. Esse espaçamento nas partículas de fronteira é causado por variações na curvatura local, o que faz com que o operador HPR marque um maior número de partículas como internas.

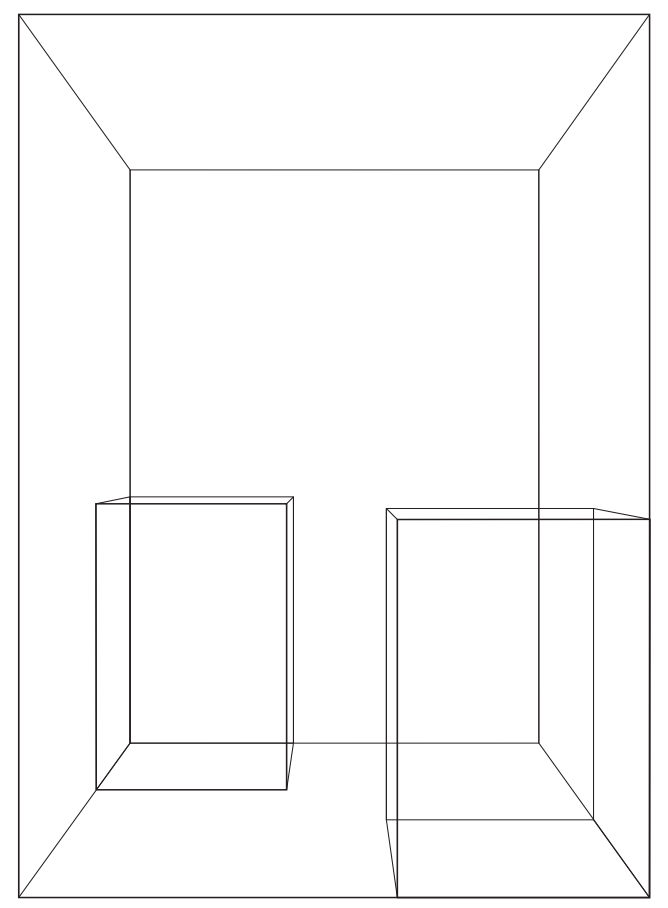

Figura 5.30: Geometria inicial da cena de colisão de blocos (quebra de barragens). Os dois blocos menores possuem as mesmas dimensões e estão localizados em cantos opostos do bloco retangular que contém a simulação. 

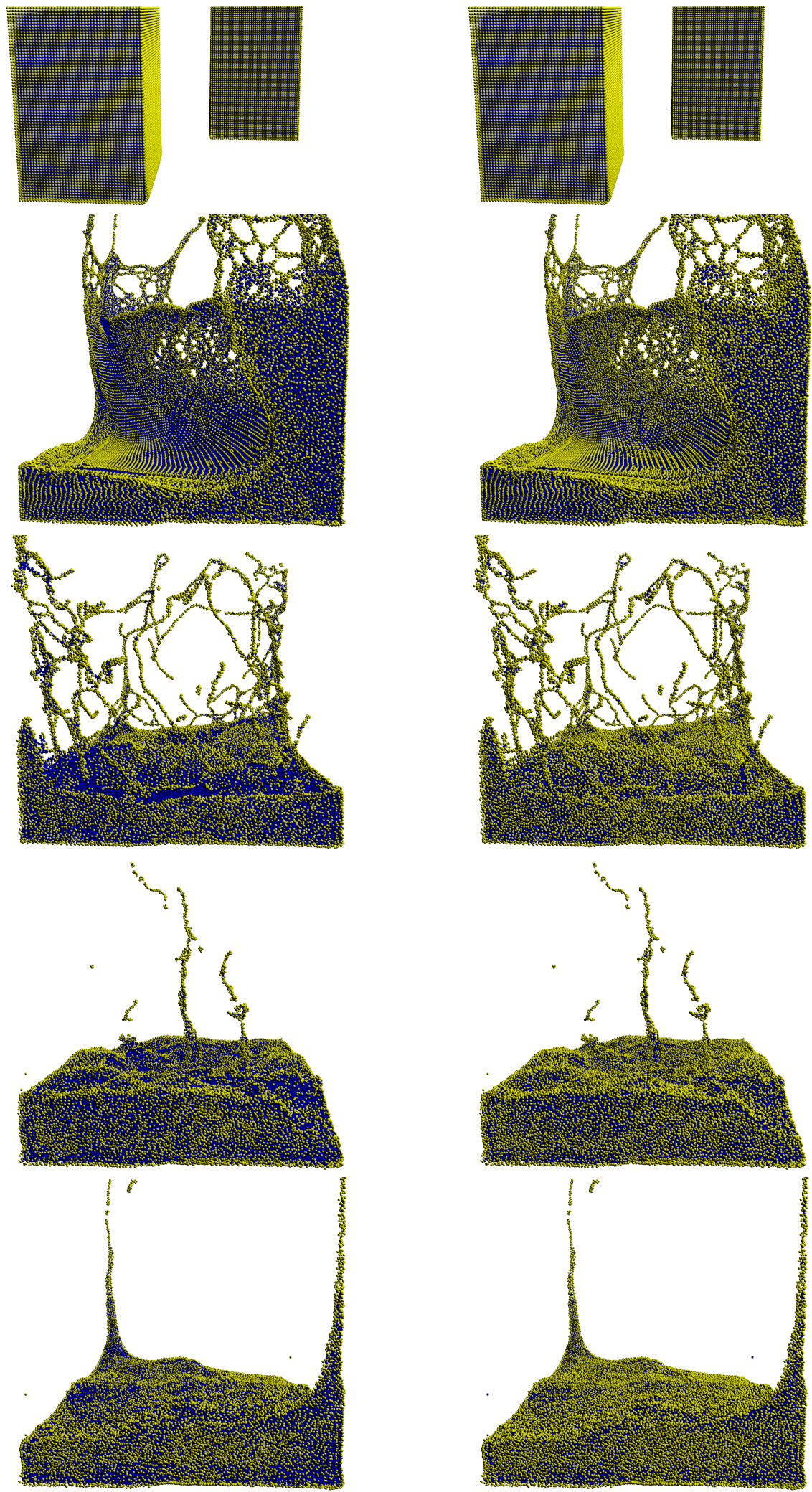

Figura 5.31: Resultados obtidos na cena de colisão de blocos. Instantes $t=1, t=21, t=41, t=61$ e $t=81$. Em diversos instantes é possível observar filetes e partículas dispersas onde ocorrem falsos negativos, causados pela má distribuição dos observadores. 

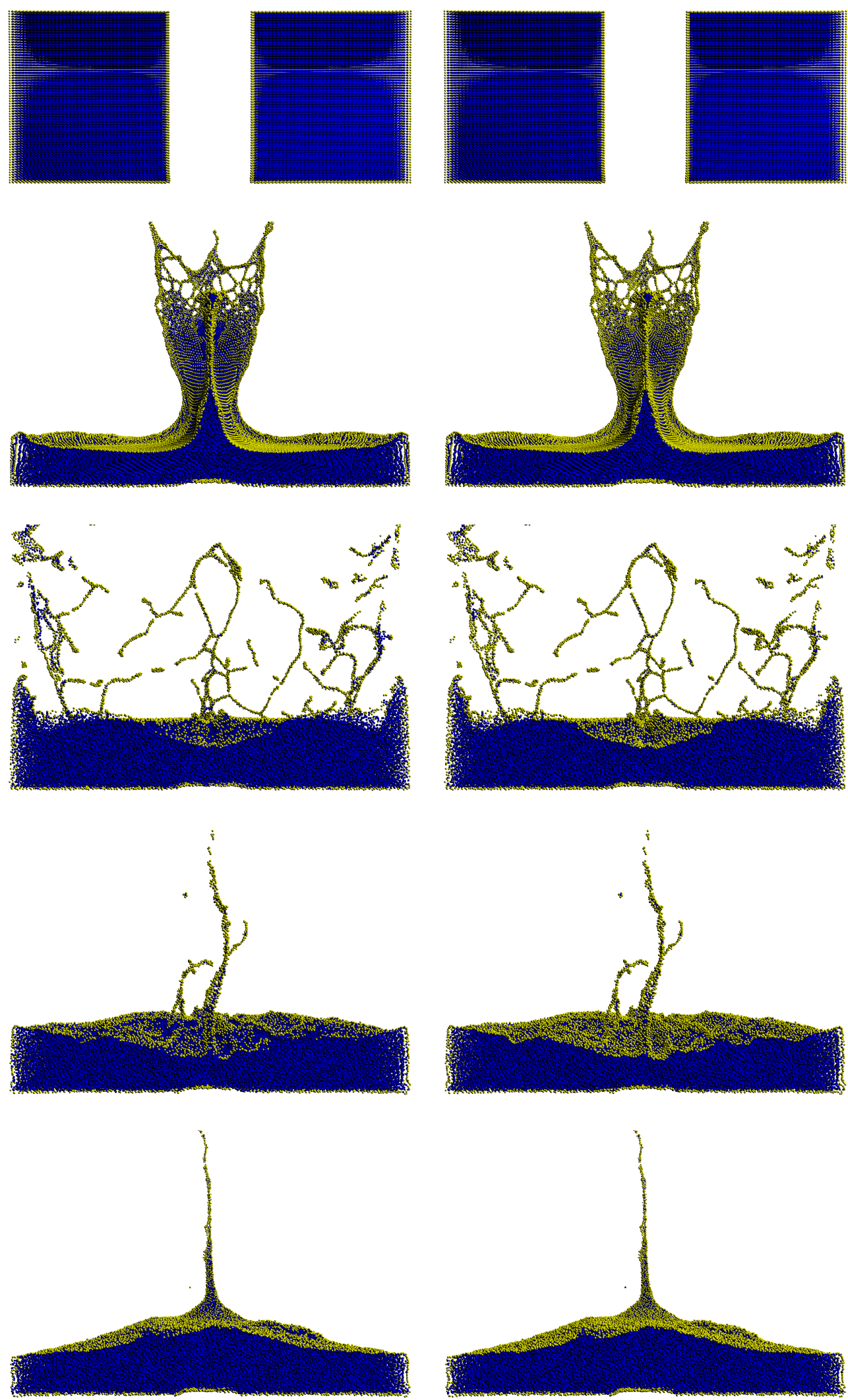

Figura 5.32: Corte do resultado mostrado na Figura 5.31, para os mesmos instantes de tempo. É possível observar a ausência de falsos positivos ou intrusões da superfície nas regiões internas. 

Com esse trabalho é possível concluir que a aplicação do operador HPR para detecção de fronteira em dados volumétricos representados por partículas é um caminho viável. A complexidade da aplicação desse operador depende apenas do algoritmo usado para o fecho convexo, uma vez que a aplicação da função de inversão possui complexidade linear. Existem diversos algoritmos para solução de fecho convexo com complexidade $O(n \log n)$ ou $O(n \log h)$ onde $n$ é o total de pontos do conjunto e $h$ é o número de pontos que pertencem ao fecho convexo, lembrando que existem casos em que $n=h$. Dessa forma, a complexidade do método proposto torna-se dependente apenas da escolha dos $K$ observadores a serem usados nas aplicações locais do operador HPR e da aplicação do operador em si. Com isso, a complexidade da aplicação do operador HPR para um sistema de partículas pode ser expressa como $O(K n \log n)$.

No modelo proposto, deve ser feita uma compensação em termos de tempo de processamento e qualidade dos resultados. A técnica baseada em grade possui uma boa performance mas falha em diversos casos, enquanto a baseada em deslocamento de centroide possui um desempenho consideravelmente pior, mas em compensação produz resultados claramente melhores. Mas quando comparados aos métodos existentes, a qualidade dos resultados é claramente mais consistente, não apresentando erros elevados (acima de $90 \%$ de falsos positivos ou negativos como em alguns casos mostrados), e pode ter um custo controlado através da forma escolhida para a escolha dos observadores. Outro ponto forte é a independência de outros fatores, como distribuição de partículas, propriedades específicas de fluidos ou vetores normais com boa qualidade.

Para maximizar a eficiência do método proposto é necessário reduzir o valor de $K$, mas ao mesmo tempo garantir que toda a extensão da fronteira do sistema possui observadores dentro do limite da sua vizinhança. Outra questão a ser considerada no futuro é o parâmetro $\gamma$ usado pela 
inversão exponencial, que nos testes realizados possui um valor fixo, mas pode ser modificado de forma adaptativa, levando em conta informações como curvatura local e distância entre observador e partículas.

Uma conclusão secundária é o fato de que o método de Marrone et al. [MCLTG10], apesar de relativamente rápido, produz erros em diversos casos mas a adição de normais computadas através de PCA pode melhorar os resultados obtidos. Sendo assim, esse método é passível de melhorias para obtenção dos conjuntos $\mathbb{E}, \mathbb{B}$ e $\mathbb{I}$ que pode ser problemática em diversos casos e para obtenção dos vetores normais a serem usados na aplicação da região de sondagem.

\subsection{Trabalhos futuros}

Para o futuro desse trabalho existem dois pontos principais que podem ser melhorados: o parâmetro $\gamma$ usado pela inversão exponencial e a escolha de observadores. A escolha do parâmetro $\gamma$, idealmente, deve ser baseada na distribuição do subconjunto de partículas no qual o operador é aplicado. Para isso pode ser levada em conta a curvatura local na região do subconjunto de partículas a ser processado ou a distribuição da direção das normais.

A escolha dos observadores é um passo importante e capaz de alterar totalmente os resultados obtidos e a eficiência do método. Uma possibilidade é criar uma técnica que combine a escolha de observadores baseada na grade de busca com a baseada em deslocamento de centroide, criando uma solução que produza observadores mais espaçados em regiões mais planas e melhor localizados em regiões com maior curvatura para uma melhor cobertura com um número menor de observadores. 
APÊNDICE

\section{$A$}

Prova do Lema 4.1

Seja $\hat{p}=f(p)=(\hat{x}, \hat{y})$ a imagem de $p$ e $\hat{\Lambda}$ a linha que passa através de $\hat{p}$ no fecho convexo. Sem perda de generalidade, pode ser definido um sistema de coordenadas da seguinte forma (Figura A.1): O observador $C$ está localizado na origem; o eixo $Y$ é paralelo a $\hat{\Lambda}$; o eixo $X$ é perpendicular ao eixo $Y ; p=(x, y)$ no espaço euclidiano e $(d, \theta)$ em coordenadas polares. Como $\theta=\tan ^{-1}(x / y)$, então $\theta=\beta-\pi / 2$. Logo,

$$
(x, y)=\left(\cos (\theta)\left(\frac{\hat{x}}{\cos (\theta)}\right)^{\frac{1}{\gamma}}, \operatorname{sen}(\theta)\left(\frac{\hat{x}}{\cos (\theta)}\right)^{\frac{1}{\gamma}}\right)
$$

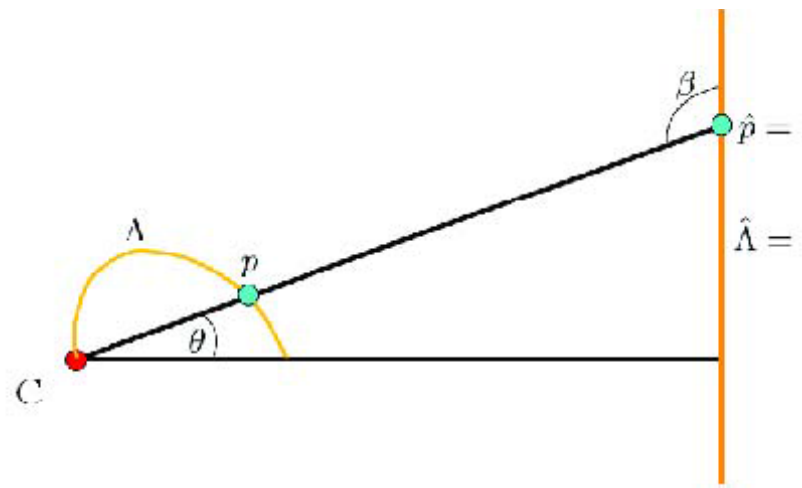

Figura A.1: Esboço usado na prova do Lema 4.1. A figura mostra a linha $\hat{\Lambda}$ paralela ao eixo $Y$ e sua fonte de inversão $\Lambda$ através de $p$. A curvatura $\kappa_{\Lambda}$ of $\Lambda$ em $p$ é a curvatura máxima a partir da qual $p$ é marcado como ocluso. 
O interesse está na curva $\Lambda$, que é a fonte de inversão de $\hat{\Lambda}$, e na sua curvatura $\kappa_{\Lambda} \cdot p$ será marcado como visível se a curvatura em $p$ é menor que $\kappa_{\Lambda}$ e marcado como ocluso caso contrário. Variando $x$ e $y$ ao longo de $\Lambda$ e obtendo suas derivadas com relação a $\theta$ obtém-se:

$$
\begin{aligned}
& \dot{x}=-\frac{(\gamma-1)}{\gamma} \operatorname{sen}(\theta)\left(\frac{\hat{x}}{\cos (\theta)}\right)^{\frac{1}{\gamma}}, \\
& \dot{y}=\left(\cos (\theta)-\frac{\cos ^{2}(\theta)-1}{\gamma \cos (\theta)}\right)\left(\frac{\hat{x}}{\cos (\theta)}\right)^{\frac{1}{\gamma}}, \\
& \ddot{x}=\frac{(1-\gamma)\left(\gamma \cos ^{2}(\theta)-\cos ^{2}(\theta)+1\right)}{\gamma^{2} \cos ^{2}(\theta)}\left(\frac{\hat{x}}{\cos (\theta)}\right)^{\frac{1}{\gamma}}, \\
& \ddot{y}=\frac{\operatorname{sen}(\theta)\left(\gamma+1-\gamma^{2} \cos ^{2}(\theta)+2 \gamma \cos ^{2}(\theta)-\cos ^{2}(\theta)\right.}{\gamma^{2} \cos ^{2}(\theta)}\left(\frac{\hat{x}}{\cos (\theta)}\right)^{\frac{1}{\gamma}} .
\end{aligned}
$$

Usando a definição de curvatura $\frac{\dot{x} \ddot{y}-\dot{y} \ddot{x}}{\left(\dot{x}^{2}+\dot{y}^{2}\right)^{3 / 2}}$,

$$
\kappa_{\Lambda}=\frac{\left(\frac{\hat{x}}{\cos (\theta)}\right)^{\frac{2}{\gamma}}(\gamma-1)\left(\cos (\theta)^{2}+\gamma \cos (\theta)^{2}-1\right)}{\gamma^{2} \cos (\theta)^{2}\left(\frac{\operatorname{sen}(\theta)^{2}\left(\frac{\hat{x}}{\cos (\theta)}\right)^{\frac{2}{\gamma}}(\gamma-1)^{2}}{\gamma^{2}}+\frac{\left(\frac{\hat{x}}{\cos (\theta)}\right)^{\frac{2}{\gamma}}\left(\gamma \cos (\theta)^{2}-\cos (\theta)^{2}+1\right)^{2}}{\gamma^{2} \cos (\theta)^{2}}\right)^{\frac{3}{2}}}
$$

Expressando $\kappa_{\gamma}$ em termos de $d$ e $\beta$, usando as identidades $\beta=\frac{\pi}{2}+\theta, x=d \cos \theta=d \operatorname{sen} \beta$, $y=d \operatorname{sen} \theta=-d \cos \beta$, e $\hat{x}=d^{\gamma} \operatorname{sen} \beta$, obtém-se

$$
\kappa_{\Lambda}=\frac{\gamma(1-\gamma) \operatorname{sen}(\beta)\left(\cos ^{2}(\beta)-\gamma \operatorname{sen}^{2}(\beta)\right)}{d\left(\gamma^{2} \operatorname{sen}^{2}(\beta)+\cos ^{2}(\beta)\right)^{\frac{3}{2}}} .
$$


[BCG89] John B. Bell, Phillip Colella, and Harland M. Glaz. A second-order projection method for the incompressible Navier-Stokes equations. Journal of Computational Physics, 85:257-283, 1989.

$\left[\mathrm{CDB}^{+} 11\right]$ Alejandro C. Crespo, Jose M. Dominguez, Anxo Barreiro, Moncho GómezGesteira, and Benedict D. Rogers. GPUs, a new tool of acceleration in CFD: Efficiency and reliability on smoothed particle hydrodynamics methods. PLoS ONE, 6, 2011.

[CL03] Andrea Colagrossi and Maurizio Landrini. Numerical simulation of interfacial flows by smoothed particle hydrodynamics. Journal of Computational Physics, 191(2):448 - 475, 2003.

[Di100] G.A. Dilts. Moving least-squares particle hydrodynamics II: conservation and boundaries. International Journal for Numerical Methods in Engineering, 48(10):1503-1524, 2000.

[EFFM02] Douglas Enright, Ronald Fedkiw, Joel Ferziger, and Ian Mitchell. A hybrid particle level set method for improved interface capturing. Journal of Computational Physics, 183(1):83 - 116, 2002.

[GGCR $\left.{ }^{+} 12\right]$ M. Gomez-Gesteira, A. J C Crespo, B. D. Rogers, R. A. Dalrymple, J. M. Dominguez, and A. Barreiro. SPHysics - development of a free-surface fluid solver - Part 2: Efficiency and test cases. Computers and Geosciences, 48:300-307, 2012.

[GGRC $\left.^{+} 12\right]$ M. Gomez-Gesteira, B.D. Rogers, A.J.C. Crespo, R.A. Dalrymple, M. Narayanaswamy, and J.M. Dominguez. SPHysics - development of a free-surface fluid solver - Part 1: Theory and formulations. Computers \& Geosciences, 48:289-299, November 2012. 
[GM77] R. A. Gingold and J. J. Monaghan. Smoothed particle hydrodynamics: theory and application to non-spherical stars. Monthly Notices of the Royal Astronomical Society, 181:375-389, 1977.

[GR09] Christophe Geuzaine and Jean François Remacle. Gmsh: A 3-D finite element mesh generator with built-in pre- and post-processing facilities. International Journal for Numerical Methods in Engineering, 79:1309-1331, 2009.

[HD07] Aamer Haque and Gary A. Dilts. Three-dimensional boundary detection for particle methods. Journal of Computational Physics, 226(2):1710 - 1730, 2007.

[HE55] Francis H Harlow and MW Evans. A machine calculation method for hydrodynamic problems. LAMS-1956, 1955.

$\left[\mathrm{HLW}^{+}\right.$12] Xiaowei He, Ning Liu, Guoping Wang, Fengjun Zhang, Sheng Li, Songdong Shao, and Hongan Wang. Staggered meshless solid-fluid coupling. ACM Trans. Graph., 31(6):149:1-149:12, November 2012.

[KO96] S. Koshizuka and Y. Oka. Moving-particle semi-implicit method for fragmentation of incompressible fluid. Nuclear Science Engineering, 123:421-434, July 1996.

[KT13] Sagi Katz and Ayellet Tal. Improving the visual comprehension of point sets. In Proceedings of the 2013 IEEE Conference on Computer Vision and Pattern Recognition, CVPR '13, pages 121-128, Washington, DC, USA, 2013. IEEE Computer Society.

[KTB07] Sagi Katz, Ayellet Tal, and Ronen Basri. Direct visibility of point sets. ACM Trans. Graph., 26(3), July 2007.

[LeV96] R. J. LeVeque. High-resolution conservative algorithms for advection in incompressible flow. SIAM J. Numer. Anal., 33:627-665, 1996.

[MCG03] Matthias Müller, David Charypar, and Markus Gross. Particle-based fluid simulation for interactive applications. In Proceedings of the 2003 ACM SIGGRAPH/Eurographics symposium on Computer animation, SCA '03, pages 154-159, Aire-laVille, Switzerland, Switzerland, 2003. Eurographics Association.

[MCLTG10] S. Marrone, A. Colagrossi, D. Le Touzé, and G. Graziani. Fast free-surface detection and level-set function definition in sph solvers. Journal of Computational Physics, 229(10):3652-3663, May 2010.

[MeSEMO14] R. Machado e Silva, C. Esperança, R. Marroquim, and A. A. F. Oliveira. Image space rendering of point clouds using the hpr operator. Computer Graphics Forum, 33(1):178-189, 2014. 
[MeSEO12] R. Machado e Silva, C. Esperanca, and A. Oliveira. Efficient hpr-based rendering of point clouds. In Graphics, Patterns and Images (SIBGRAPI), 2012 25th SIBGRAPI Conference on, pages 126-133, Aug 2012.

[MTSM10] Ravish Mehra, Pushkar Tripathi, Alla Sheffer, and Niloy J. Mitra. Visibility of noisy point cloud data. Computers \& Graphics, 34(3):219-230, June 2010.

[Par62] E. Parzen. On the estimation of a probability density function and mode. Annals of Mathematical Statistics, 33:1065-1076, 1962. 